7 Corresponding author:

\section{ABSTRACT}

\section{INTRODUCTION}

\title{
CONTRIBUTION OF EXTERNALLY BONDED FRP SHEAR REINFORCEMENT TO THE
} SHEAR STRENGTH OF RC BEAMS

\author{
Eva Oller*, Mireia Pujol* and Antonio Marí*
}

*Universitat Politècnica de Catalunya, Barcelona, Spain

Eva Oller, e-mail: eva.oller@upc.edu, Phone (+34) 934016512

An experimental program of T-beams strengthened in shear by CFRP sheets has been developed with two longitudinal reinforcement ratios and different externally bonded CFRP shear strengthening amounts in a discontinuous or continuous U-shaped configuration with and without mechanical anchorages. The effectiveness of the external reinforcement without anchorages was low regardless the CFRP reinforcement ratio. There is an evidence of the interaction of the different shear strength components, concrete $V_{c}$, transverse steel $V_{s}$, CFRP sheets $V_{f}$ that have been obtained from the registered data of the instrumentation. This interaction might explain that the ultimate shear force of some CFRPstrengthened beams was lower than the one of the control beam. There is a significant difference between the sum of the $V_{c}, V_{s}$, and $V_{f}$ components and the total shear force. This difference is assumed to be carried out by the flange (including its internal transverse reinforcement), which represents a significant percentage of the total shear strength (with a mean value of $38 \%$ ). Finally, the contribution of the CFRP has been obtained by different existing guidelines and has been compared to the experimental values.

Keywords: Strengthening, shear, externally bonded FRP, sheets, shear strength, shear components

Due to their low stiffness-to-weight and strength-to-weight ratios, as well as due to its low corrosion susceptibility, externally bonded (EB) fibre reinforced polymer (FRP) have become an alternative to other traditional strengthening techniques. In the last years, real applications of this technique have increased, becoming consolidated in the market. 

engineering domain, and in particular when FRP materials are used as shear strengthening [1]. There is not still a consensus on the evaluation of the shear strength contribution of the EB FRP reinforcement to the total shear strength. This is mainly due to the complexity of the shear phenomenon, and due to the definition of the FRP level of stresses. This definition is not clear, on one hand because FRP does not yield due to its linear elastic-brittle behaviour and on the other hand, due to the uncertainties in the prediction of the premature debonding of the external reinforcement for some configurations (U-shaped and side-bonded) once the critical shear crack opens and widens. For the fully wrapped configuration, a fibre rupture often occurs at the bottom corner of the section. The evaluation of this type of failure is generally based on tests of FRP-confined rectangular columns.

According to [2-8], the ultimate shear strength of beams externally strengthened in shear by FRP laminates can be obtained as the sum of the contribution of the different components: concrete, transverse steel and FRP external reinforcement. However, the interaction between all aforementioned components in not clear enough. The presence of the FRP could influence the effective stress in the internal steel reinforcement due to possible changes in the strut orientation or additional cracking that may change the relative contribution of each individual contribution to the resulting shear strength. Bousselham and Chaallal in [9] concluded that the contribution of concrete remains more or less unchanged after the formation of diagonal cracking for small and medium size beams and FRP has a significant influence on the actual contribution of the transverse steel. In the case of beams with transverse stirrups, the transverse steel contribution is higher than that of FRP, due to better bonding at the stirrup-concrete interface. According to Pellegrino and Modena [10], Deniaud and Cheng [11], Monti and Liotta [7], and Ali et al. [12], the interaction between transverse steel and FRP is important, since the system is not always ductile enough to allow that the maximum contribution of each material, FRP $\left(V_{f}\right)$ and transverse steel $\left(V_{s}\right)$, occurs at the same instant.

In the existing literature, there are several existing experimental programs on shear strengthened beams $[7,8,13-16]$, and in particular with T-beams strengthened with U-shaped or wrapped configurations, with or without transverse reinforcement [17-22]. Recently, shear tests have been performed with textile reinforced mortar as shear external reinforcement [23-25]. Despite results are analysed in detail in all of them, the contributions of each component to the shear strength are not clearly identified. 

CFRP sheets in a U-shaped configuration without and with anchorage devices. The contribution of the different components to the shear strength $\left(V_{c}, V_{s}, V_{f}\right)$ has been quantified through the data registered by the instrumentation. The contribution of the flange to the shear strength has also been quantified as the difference between the total shear force and the sum of the previous mentioned components. The quantification of the different contributions is the basis for the future development of a realistic formulation to evaluate the shear strength, accounting for the interaction between all them.

\section{EXPERIMENTAL PROGRAM}

An experimental program was developed in the Laboratory of Technology of Structures and Materials of the Universitat Politècnica de Catalunya (UPC) with the aim to study the performance of beams strengthened in shear with CFRP sheets with different configurations, and to quantify the contribution of each material (concrete, internal steel and CFRP sheets) to the shear strength of EB FRP reinforced beams [26]. The tested beams have a T-shaped cross-section to simulate a real slab. Two different amounts of longitudinal internal reinforcement as well as different CFRP reinforcement ratios were employed to study the influence of both parameters.

\subsection{Geometry of specimens}

The experimental program consisted of 10 full-scale RC beams with a T-shaped cross-section. Beams were 5,800 mm long with flange and web cross sections of $600 \times 150 \mathrm{~mm}$ and $200 \times 400 \mathrm{~mm}$, respectively. This program comprised two sets of beams ( $\mathrm{M}$ and $\mathrm{H}$ ), with different bottom longitudinal internal steel reinforcement, consisting of two layers of $4 \phi 16$ for beams $M$ and two layers of $2 \phi 16$ and $2 \phi 20$ for beams H (See Fig. 1). The top longitudinal internal steel reinforcement was $4 \phi 12$. The web shear stirrups were $6 \mathrm{~mm}$ diameter spaced at $240 \mathrm{~mm}$ along the shear span of 1,480 $\mathrm{mm}$ from both supports to the centre of the beam, and $140 \mathrm{~mm}$ along the rest of the beam. The same spacing was used for the flange stirrups of $8 \mathrm{~mm}$ diameter. Concrete cover was $20 \mathrm{~mm}$. The external CFRP shear reinforcement was made by one unidirectional sheet of $0.17 \mathrm{~mm}$ thickness in a U-shaped configuration with the fibers at $90^{\circ}$ with the beam axis. Different shear strengthening amounts were applied in each set of beams (see Fig. 2):

a) (0) without external reinforcement;

b) (1) with laminates of $50 \mathrm{~mm}$ width at $240 \mathrm{~mm}\left(A_{f}=466.6 \mathrm{~mm}^{2} / \mathrm{m}\right)$;

c) (2) with laminates $100 \mathrm{~mm}$ width at $240 \mathrm{~mm}\left(A_{f}=933.3 \mathrm{~mm}^{2} / \mathrm{m}\right)$; 
d) (3) continuous laminates $\left(A_{f}=2240 \mathrm{~mm}^{2} / \mathrm{m}\right)$. In order to delay a premature debonding failure of the external reinforcement, an anchorage device system was employed in some of the tests. Two types of anchorages were tested:
a) Anchorage device type A consisted of bolts of $10 \mathrm{~mm}$ diameter glued at the end of each strip and a multidirectional CFRP laminate, $3 \mathrm{~mm}$ thick, glued under these bolts to avoid any possible damage in the externally bonded shear reinforcement (Fig. 3). In order to reduce the accumulation of stresses, some steel plates $4 \mathrm{~mm}$ thick were placed on top of the multidirectional laminate.

b) Anchorage device type B consisted on extending the FRP reinforcement, anchoring it around a steel plate $4 \mathrm{~mm}$ thick. This plate was bonded parallel to the beam axis under the flange. Additionally, $10 \mathrm{~mm}$ diameter bolts were placed in between the CFRP reinforcement (see Fig. 3). The notation of the beams included information about: a) the amount of longitudinal reinforcement (M or H); b) the amount of FRP shear strengthening (0) (1) (2) or (3); c) the type of anchorage (-, A or B); d) the number of test (a or b) in case two tests were performed with the same configuration. For instance, M1-a is a M beam with two layers of $4 \phi 16$, with an amount (1) of FRP reinforcement (sheets of $50 \mathrm{~mm}$ width at $240 \mathrm{~mm}$ ), without anchorage (-) and test number "a".

Fig. 1. Geometry of tested beams.

Fig. 2. CFRP externally bonded reinforcement (EBR) amounts for types 1, 2 and 3 respectively.

Fig. 3. Anchorage system type A and type B for the CFRP reinforcement.

\subsection{Materials characterization}

Tests were carried out on the concrete, the steel and the CFRP reinforcement in order to quantify their mechanical properties. Concrete strength class was $\mathrm{C} 25 / 30$. For all specimens, Table 1 summarizes the values of relevant mechanical properties, such as, the concrete compressive strength at 28 days $\left(f_{c m, 28 d}\right)$, the compressive strength $\left(f_{c m, t e s t}\right)$, the tensile strength $\left(f_{c t m, t e s t}\right)$ and the modulus of elasticity at the day of the failure test $\left(E_{c m, t e s t}\right)$.

Table 1. Concrete properties of the specimens. 
123 performed for the different bar diameters employed. Results are summarized in Table 2.

Table 2. Mechanical properties of the longitudinal and transverse steel reinforcement. epoxy resin (Mbrace fibre saturant) supplied by BASF. According to the manufacturer, the sheet has a nominal thickness of $0.17 \mathrm{~mm}$, a nominal elastic modulus of $230 \mathrm{GPa}$, a nominal ultimate strength of $3400 \mathrm{~N} / \mathrm{mm}^{2}$, and a ultimate strain of $1.478 \%$. Tensile tests performed in sheet coupons showed a mean modulus of elasticity of $263 \mathrm{GPa}$ and a mean value of the ultimate tensile strength of $2739 \mathrm{~N} / \mathrm{mm}^{2}$.

\subsection{Test set-up and instrumentation}

Two tests were carried out in each beam with the same span of 3,300 mm, and under a shear span of 1,480 mm, which corresponds to three times the effective depth. Once the beam failed by one end, the supports were moved to the other end of the beam using a symmetrical configuration for the next test, which was performed in the undamaged part of the beam after the first test.

Fig. 4. Test set-up. as the strain of the external CFRP and internal transverse steel at different heights (see Fig. 5). Strain

143 gauges in the longitudinal reinforcement were named DLi, and ELi, being $\mathrm{i}=1$ or 2,1 if it is in between

144 the instrumented stirrups 1 and 2, and 2 if it is in between stirrups 2 and 3. Strain gauges in the each

145 stirrup were named DSAi, DSBi, ESAi, ESBi, being $i=1,3$ the number of stirrup. Finally three strain

146 gauges were placed at different heights of the FRP sheets.

147 Displacement transducers were used to measure the displacement at the load application point

148 and at the supports. In addition, one rosette has been placed in each side of the beam to obtain the strut 149 orientation. 
151 Fig. 5. Instrumentation. Displacement transducers and strain gauges.

\section{EXPERIMENTAL RESULTS}

\subsection{Ultimate shear force and failure mode}

Table 3 shows the concrete properties for each specimen (mean compressive strength at 28 days $f_{c m, 28}$ and the day of the test, $\left.f_{c m, t e s s}\right)$, the initiation of the first CFRP sheet debonding $\left(V_{\text {debonding }}\right)$, the shear

157 force at yielding of the first internal stirrup $\left(V_{\text {yield,Ast }}\right)$, the ultimate shear force obtained for each test

$158\left(V_{u, \text { exp }}\right)$ together with a fictitious ultimate shear force of the corresponding unstrengthened beam

$159\left(V_{u, u n s t r e n g t h e n e d}\right)$, and the percentage of increase of the ultimate shear force of the strengthened beam $(\Delta V)$

160 The fictitious ultimate shear force of the corresponding unstrengthened beam has been calculated from

161 the ultimate shear force of the control beam, by multiplying the concrete strength contribution of the

162 control beam by the ratio between the cubic root of the concrete compressive strengths of the control and

163 strengthened beams. This fictitious shear force was calculated because all beams were cast in different

164 batches with mean values of the concrete compressive strength ranging from 38.5 to $49.7 \mathrm{~N} / \mathrm{mm}^{2}$ (see

165 Table 1).

As observed for the set of beams with lower longitudinal reinforcement ratio, the percentage of

167 increase of ultimate shear force in relation to the control beam decreases as the CFRP reinforcement ratio increases. In addition, the ultimate shear force for beams strengthened with $100 \mathrm{~mm}$ width laminates at

$169240 \mathrm{~mm}$ is lower than that of the control beam. The negative strengthening ratio potentially shows that

170 there is an interaction between the transversal CFRP reinforcement, the transversal steel reinforcement

171 and the concrete. The existence of the FRP may modify the contribution of the remaining components

172 (concrete and transversal steel) to the shear strength.

173 For the set of beams with higher longitudinal reinforcement ratio, the percentage of increase of

174 the ultimate shear force in relation to the control beam is similar for the different FRP shear strengthening 175 ratios without anchorages.

176 The employment of an anchorage device helped to increase the ultimate shear force, especially

177 for those cases with higher amount of CFRP strengthening ratio. For set of beams M1 with CFRP

178 laminates of $50 \mathrm{~mm}$ width at $240 \mathrm{~mm}$, the mean value of the shear force increment increases from $8.2 \%$ to

$17910 \%$ at maximum with the employment of an anchorage. For set of beams M2 with CFRP sheets $100 \mathrm{~mm}$

180 width with the same spacing, the shear force increment increases from a mean value of $-12.1 \%$ to $13.1 \%$ 
at maximum with the anchorage device. For set of beams $\mathrm{H} 2$ with the same amount of FRP reinforcement than set M2, the shear force increment increases from a mean value of $2.8 \%$ to a maximum value of $18.8 \%$ due to the effect of the anchorage.

Table 3. Concrete properties, initiation of debonding, ultimate shear force of the fictitious control and tested beams, and percentage of reinforcement. identical manner, with a critical crack involving two branches. The first branch is an inclined shear crack in the web and the second branch, less inclined, develops in the flange. Failure occurs with the formation of the second branch (see Figure 6). The failure shear force indicates a high contribution of the flange to the shear resistance.

Fig. 6. Failure of the control beam: (a) M0 and (b) H0.

For the strengthened beams, the strips located in the shear span debonded progressively while the crack in the web increases its width (Fig 7.a). However, after the debonding of the laminates, the load was increased up to failure which took place after the formation of an inclined crack in the flange. When an anchorage system was applied, the strip debonding was delayed. Once debonding is initiated, the anchorage system held the CFRP and failure was observed when the second branch of the critical shear crack (with an inclination lower than in the web) propagated through the flange as in the remaining beams (Fig. 7b).

Fig. 7. Failure of strengthened beams without (a) and with anchorage (b).

\subsection{Shear force vs load point displacement.}

Figures 8 and 9 show the shear force at the support closed to the load application point vs. displacement at the load application point for beam set $\mathrm{M}$ and $\mathrm{H}$ with different CFRP strengthening ratios.

209 As previously explained, for beam set M, the ultimate shear force of the beam with lower shear strengthening ratio (50 mm width @240 mm) is higher than the ultimate shear force of the control beam. 
211 However, the beam with higher shear strengthening ratio (100 mm width @240 mm) showed a ultimate

212 shear force lower than that of the control beam due to the laminate debonding that leads to a shear failure.

213 The influence of the anchorage system is more significant in the case of higher longitudinal

214 reinforcement ratio in terms of ultimate shear force and displacement. Due to the premature laminate

215 debonding, the strengthening system is not effective for the $\mathrm{H}$ set if the U-shaped laminates are not

216 anchored (see Figure 9b).

217

218 Fig. 8. Shear force vs. displacement for beam set M (lower longitudinal reinforcement ratio) without (a)

219 and with anchorage (b).

220

221 Fig. 9. Shear force vs. displacement for beam set H (higher longitudinal reinforcement ratio) without (a)

222 and with anchorage (b).

223

224

3.3. Crack pattern

225

226

Figure 10 shows the crack pattern of some beams included in set $\mathrm{H}$ (control beam $\mathrm{H} 0-\mathrm{b}, \mathrm{H} 1-\mathrm{b}$, H2-b, H2A). As observed the critical shear crack has been remarked for all beams. The inclination angle of the critical shear crack in the web $\left(\theta_{\text {web }}\right)$ and in the flange $\left(\theta_{\text {flange }}\right)$ as well as the mean value $\left(\theta_{\text {mean }}\right)$ is reported in Table 3. In general, for beams with anchorages an increment of the shear strengthening ratio implies a more inclined critical shear crack along the web. Beams with an anchored FRP system also show a more vertical shear crack along the web. Except for beam M1-a, the angle of the shear crack along

231 the flange ranges between 7.0 and 15.5. Table 3 also shows the inclination angle of the total critical shear crack, measured between the bottom of the web and the top of the flange. As observed, this value is more

233 or less similar to the control beams for the strengthened beams without anchorages. However, it increases

234 when anchorage devices are employed. The effect of the longitudinal reinforcement ratio in the critical

235 shear crack inclination is not clear enough as shown by the tests results.

236

237 Fig. 10 Crack pattern in the shear span for some beams of set $\mathrm{H}$

238

239 3.4. Strains in the transverse internal reinforcement and the CFRP shear strengthening system 
reinforcement and in the CFRP sheets as a function of the shear force acting on the support for beams H2-

$\mathrm{b}$ and H2B with the same ratios of steel and CFRP reinforcements, without and with anchorage devices, respectively. As observed, the anchorage allows to reach higher shear forces and therefore, slightly higher strains in the stirrups and a better performance of the CFRP sheets shown by their higher strains. These strain distributions will be the basis for the calculation of the shear strength components of section 3 .

Fig. 11 Strains in the transverse reinforcement for beams H2-b and H2B.

\section{ANALYSIS OF THE EXPERIMENTAL RESULTS}

\subsection{Concrete, transverse steel and CFRP contributions to the shear strength}

From the strains obtained in the transverse steel reinforcement and in the CFRP system, the mean level of stresses of the stirrups and strips crossed by the shear critical crack can be obtained by considering a simplified bilinear constitutive law for internal steel and a linear-elastic stress-strain relationship for CFRP. The shear force resisted by each type of transverse reinforcement $\left(V_{s}\right.$ and $\left.V_{f}\right)$ can be obtained by multiplying the mean level of stresses at each stirrup or CFRP strip by the area of transverse steel reinforcement or the area of CFRP strip, respectively. Concrete contribution $\left(V_{c}\right)$ to the shear strength was defined as the mean value of shear force acting on the beam when the strains at the steel stirrups and CFRP are activated. Finally, the remaining component of the shear strength, that is the difference between the total shear force and the sum of $V_{c}, V_{s}$ and $V_{f}$, is assumed to be resisted by the concrete flange and the internal stirrups in the flange crossed by the critical shear crack $\left(V_{\text {flange }}\right)$. Table 4 shows the different contributions to the shear strength for each specimen at failure. As observed, in beams M1A, H2-a and $\mathrm{H} 2 \mathrm{~A}, V_{c}$ and $V_{s}$ are much lower in comparison to other tests: this can be explained by a possible error in

263 the strain gauge registration of the transverse stirrups. For all tests, the transverse steel component at failure

264 is higher than the FRP component, on one hand due to the higher steel reinforcement ratio and on the other

265 hand, due to the premature FRP debonding which took place before reaching failure in the case of unanchored specimens. shear strength components $\left(V_{c}, V_{s}\right.$, and $\left.V_{\text {flange }}\right)$ for beam M0-b for different shear force levels and Figure 
reinforcement yielded for a shear force of $177.5 \mathrm{kN}$ for beam M0-a and $172.1 \mathrm{kN}$ for beams M0-b. The longitudinal reinforcement yielded for a shear force of $290.1 \mathrm{kN}$ just before failure. However, the

272 percentage of $V_{s}$ remains almost constant just after the transverse reinforcement yields. As observed, the contribution of the flange at failure represented almost $50 \%$ of the ultimate shear strength.

Table 4. Contribution of the concrete web, flange, transverse steel and FRP to the ultimate shear force of the tested beams.

Fig. 12 Shear strength components for beam M0-b.

Figures $13 \mathrm{a}$ and $\mathrm{c}$ show the contribution of $V_{s}$ and $V_{f}$ during all test for beam M1-a (w/o anchorages) and M1B (with anchorages) with the same amount of external CFRP reinforcement (sheets of $50 \mathrm{~mm}$ width at $240 \mathrm{~mm}$ ). As observed the contribution of the transverse steel is quite similar in both cases, but it is quite different for the FRP system. Drops on the FRP shear contribution show the

284 progressive debonding of the sheets. In addition, a redistribution As observed for beam M1-a, the shear force resisted by the FRP increases even after the initiation of debonding, this is because the shear stresses are increasing in the remaining bonded sheets. This is in accordance with the redistribution of stresses during different load stages observed by [27]. Figure $13 \mathrm{~b}$ and $\mathrm{d}$ show the shear resisted by the concrete web and flange, the shear resisted by the concrete and the transverse steel and the total shear force. As observed, the CFRP component is higher for the case with anchorages. Figure 14 shows the shear strength components for beams M1-a and M1B at different load levels and the percentage of each component in relation to the total shear strength. As observed the CFRP shear strength component increases significantly for beam M1B with anchorages, in comparison with beam M1-a without anchorage. However, the transverse stirrup component remains similar after yielding. For beam M1B, the

294 maximum FRP contribution is obtained at failure, since the CFRP sheets does not debond due to the effect of the anchorages. For beam M1A, the maximum contribution of the CFRP was before failure at

$296280 \mathrm{kN}$, since the sheets debonded locally despite the anchorages. In general, the concrete contribution is lower for the cases with anchorages.

Fig. 13 Shear strength components for beams M1-a and M1B. 
301 Fig. 14 Shear strength components for beams M1-a and M1B.

302

303

304

305

306

307

308

309

310

311

312

313

314

315

316

317

318

319

320

321

322

323

324

325

326

327

328

329

The shear strength components $V_{s}$ and $V_{f}$ are given in Figure $15 \mathrm{a}$ and $\mathrm{c}$ for beams M2-b and M2B, both strengthened with sheets of $100 \mathrm{~mm}$ width at $240 \mathrm{~mm}$, without and with anchorages, respectively. As observed, for beam M2-b, the $V_{s}$ component increases in a similar manner than for beams M1-a. However, the $V_{f}$ component is higher than for beam M1-a due to the larger amount of CFRP reinforcement. A significant increase in the $V_{f}$ component was observed in beam M2B with anchorage devices. In particular, anchorage type B improved the efficiency of the FRP in a higher percentage (around $20 \%$ of the total shear force) in comparison to anchorage type A (9\%). As observed during the tests, for beam M2A, the debonding of the CFRP sheets is delayed by the anchorage system but not completely avoided. Figure $15 \mathrm{~b}$ and d show the concrete contribution of the web and flange, the sum of concrete and transverse steel contribution, and the total shear strength. As in the previous case the, the concrete contribution is slightly lower for the case with anchorages.

Figure 16 shows the shear strength component in absolute value and percentage of the total shear strength at different load levels, for beams M2-b and M2B. For beam M2-b, the $V_{f}$ component shows a maximum value of $15 \%$ (higher than the maximum $8 \%$ of M1-a). For beam M2B, the percentage of FRP shear strength component remains almost constant from an acting shear force of $250 \mathrm{kN}$ up to failure, with a maximum value of $24 \%$, showing the efficiency of the anchorage system.

Fig. 15 Shear strength components for beams M2-b and M2B.

Fig. 16 Shear strength components for beams M2-b and M2-B. For control beams H0-a H0-b with a higher longitudinal reinforcement ratio, the shear failure occurred before yielding of the longitudinal reinforcement. For a shear force of $177 \mathrm{kN}$ and $193.6 \mathrm{kN}$, first yielding of the transverse reinforcement occurred in beams $\mathrm{H} 0-\mathrm{a}$ and $\mathrm{H} 0-\mathrm{b}$, respectively. As for beams M0-a and M0-b, the shear strength resisted by the transverse steel increases faster before yielding of stirrups. Afterwards, the percentage of increase is kept constant or slightly decreases (Figure 17 for beam $\mathrm{H} 0-\mathrm{a})$. 
331 Fig. 17 Shear strength components for control beams H0-a.

Figure 18 a), c) and e) show the different shear strength components for beams H1-a, H2-b and

334 H2B. The first one with the lowest CFRP ratio, the second and third with $100 \mathrm{~mm}$ width CFRP sheets,

335 without and with anchorage type B. As observed, the $V_{s}$ component is quite similar for beam H1-a and

336 H2-b. Before CFRP debonding, the $V_{f}$ component of beam H2-b was almost double than for beams H1,

337 since the CFRP reinforcement ratio was twice the ratio of beam H1. In this case, the maximum

338 contribution of the CFRP was just before the debonding of the first sheet, then the $V_{s}$ component

339 increased significantly since the stirrups were not still yielded. In beam H2B with anchorage devices, the

$340 V_{s}$ component is lower than for beams H1-a and H2-b when comparing the same total shear force. The

341 shear strength resisted by the FRP was similar for beams H2-b and H2B, up to the sheet debonding for

342 beam H2-b without anchorages. Figure 18 b), d) and f) shows the concrete shear strength considering the

343 flange strength, the concrete and transverse steel strength together with the total shear force. As observed,

344 the main resisting component was the concrete strength including the shear resisted by the flange, which

345 is not considered in the main design formulations.

346

347 Fig. 18 Shear strength components for beams H1-a, H2-b and H2B.

The FRP shear strength component is significantly higher for beams H3A and H3B where an anchored continuous reinforcement was employed (see Figure 19). The percentage of $V_{f}$ in relation to the total shear force increases up to $43 \%$ in this case, being this component higher than the transverse steel reinforcement shear strength component, $V_{s}$, which was similar to previous cases. When comparing the performance of both anchorages types, it is not clear enough which shows better behavior A or B. In general, the $V_{f}$ component is higher for anchorage type B. However, for the continuous CFRP sheets, $V_{f}$ is higher in absolute value and percentage for anchorage type A.

Fig. 19 Shear strength components for beams H3A and H3B for different load levels. 

predictions given by the existing guidelines (ACI440.2R-17 [5], CNR-DT-200/2004 [4], Concrete Society

362 TR-55 [28], fib Bulletin 14 [2], DAfStb Heft 595 [3]). Column 2 and 3 of Table 5 show the FRP shear strength contribution at failure and the maximum FRP contribution, respectively. Both values have been

364 calculated from the strain gauges registration. As observed for all beams with anchorages, except for beams

365 M2A and H2B, the maximum FRP contribution was equal or almost equal to the FRP contribution at failure.

366 Column 4 shows the FRP contribution to the shear strength calculated as the difference between the ultimate

367 shear force and the ultimate shear force of the control beam, without considering a possible interaction

368 between FRP and transverse steel. This is the only way to calculate the FRP contribution for an existing experimental program when each component is unknown. As observed, this last value is quite different to the values obtained in columns 2 and 3. Columns 5 to 9 give the FRP shear strength contribution according different existing guidelines and, in brackets, the ratio between the maximum experimental FRP contribution and the analytical predictions. The prediction for beams with anchorages were obtained assuming a wrapping configuration, since the sheets do not debond as in the U-shaped configuration. In

374 addition, the experimental value of the angle of the struts inclination was assumed in the theoretical calculations when this value is not directly assumed by the guidelines (ACI-440.2R-17 [5] and the TR-55

$376[28]$ assume a 45 degree angle for the inclination of struts). The analytical FRP shear strength contribution according to fib Bulletin 14 [2] is very unconservative fot these tests. The ACI-440.2R-17 [5] and the TR55 [28] gave the same analytical predictions. In general, analytical predictions of $V_{f}$ are unconservative and with a huge dispersion for specimens without anchorages for all guidelines, and are very conservative for specimens with anchorages when analyzing ACI-440.2R-17[5], TR-55 [28] and DafStB [3].

382 Table 5. Comparison of the experimental to the analytical predictions

\section{CONCLUSIONS}

This paper presents an experimental program of T-beams externally strengthened in shear by

386 CFRP sheets in a discontinuous or continuous U-shaped configuration with different ratios of CFRP with 387 and without anchorages, and with two longitudinal reinforcement ratios. The following conclusions can be 388 drawn from this experimental work: 
1) In beams with $T$-shaped section, the contribution of the flange to the shear strength, which is not considered for design purposes, is quite relevant, since it represents in some cases $45 \%$ of the total shear strength.

2) The FRP sheets are not effective if they are not anchored, since a premature debonding takes place, as observed in all such cases. The existence of anchorages at the end of the FRP sheets delays or avoids debonding, showing a better performance.

3) In particular, the ultimate shear force of Beams M2-a and M2-b (strengthened in shear by 100 $\mathrm{mm}$ width FRP sheets at $240 \mathrm{~mm}$ ), was lower than that of the corresponding control beam, showing the interaction of the shear resisting mechanisms. In addition, $V_{s}$ do not follow the same trend for beams M1-a and M1-b.

4) The FRP strengthening system modifies the strut orientation affecting the contribution of the transverse steel reinforcement. In the case of beams without anchorages, where a premature sheet debonding was observed, the modification of strut orientation might be the reason of a lower ultimate shear force for some strengthened beams in comparison to the control beam.

5) Once the FRP sheets debond, if the transverse steel has not yielded, the beam can increase its shear strength capacity, because the further increment of shear force is carried out by the internal stirrups. But if the stirrups are already yielded, a shear failure occurs just after the FRP debonding.

6) The different shear strength components have been obtained for all beams. As observed, the $V_{f}$ component is much higher for beams with anchorages. The $V_{s}$ component is quite similar for beams $\mathrm{M}$ and $\mathrm{H}$.

7) A huge dispersion is observed when applying the different existing formulations to predict the

\section{ACKNOWLEDGEMENTS}

415 This paper has been developed under the framework of the Research Project "BIA2015-64672-

416 C4-1-R", funded by the Spanish Ministry of Economy and Competitiveness (MINECO) and cofunded by 417 the European Regional Development Funds (ERDF). 
420 [1] Sas G, Täljsten B, Barros J, Lima J, Carolin A. Are available models reliable for predicting the FRP contribution to the shear resistance of RC beams? J Compos Constr 2009;13:514-34. doi:10.1061/(ASCE)CC.1943-5614.0000045.

[2] fib Task Group 9.3 FRP Reinforcement for Concrete Structures. Externally bonded FRP reinforcement for RC structures (2001). Technical report on the design and use of externally

[3] German Committee for Reinforced Concrete. DAfStb Heft 595 Erläuterungen und Beispiele zur DAfStb-Richtlinie Verstärken von Betonbauteilen mit geklebter Bewehrung. Berlin, Germany: 2013.

[4] CNR (National Research Council) Advisory Committee on technical recommendations for construction. Guide for the Design and Construction of Externally Bonded FRP Systems for Strengthening Existing Structures (CNR-DT200/2004). Rome, Italy: 2004.

[5] ACI Committee 440. ACI 440.2R-17, Guide for the Design and Construction of Externally Bonded FRP Systems for Strengthening Concrete Structures. Farmington Hills, Michigan, USA: 2017.

441 [8] Bocciarelli M, Gambarelli S, Nisticò N, Pisani MA, Poggi C. Shear failure of RC elements strengthened with steel profiles and CFRP wraps. Compos Part B Eng 2014;67:9-21. doi:10.1016/j.compositesb.2014.06.009. Elzanaty AH, Nilson AH, Slate FO. Shear Capacity of Prestressed Concrete Beams Using HighFRP-strengthened reinforced concrete beams. Mech Compos Mater 2008;44:231-44. doi:10.1007/s11029-008-9016-y. 
[11] Deniaud C, Cheng JJR. Review of shear design methods for reinforced concrete beams strengthened with fibre reinforced polymer sheets. Can J Civ Eng 2001;28:271-81. doi:10.1139/cjce-28-2-271.

[12] Mohamed Ali MS, Oehlers DJ, Seracino R. Vertical shear interaction model between external FRP transverse plates and internal steel stirrups. Eng Struct 2006;28:381-9.

[13] Pellegrino C, Modena C. Fiber Reinforced Polymer Shear Strengthening of Reinforced Concrete Beams with Transverse Steel Reinforcement. J Compos Constr 2002;6:104-11. doi:10.1061/(ASCE)1090-0268(2002)6:2(104).

[14] Khalifa A, Nanni A. Improving the shear capacity of existing RC T-section beams using CFRP composites. Cem Concr Compos 2000;22:165-74.

[15] Grande E, Imbimbo M, Rasulo A. Effect of transverse steel on the response of RC beams

[16] Alzate A, Arteaga A, De Diego A, Cisneros D, Perera R. Shear strengthening of reinforced

[17] Bousselham A, Chaallal O. Shear Strengthening Reinforced Concrete Beams with FiberReinforced Polymer: Assessment of Influencing Parameters and Required Research. ACI Struct J

[18] Bousselham A, Chaallal O. Behaviour of RC T beams strengthened in shear with CFRP: An

[19] Bousselham A, Chaallal O. Effect of transverse steel and shear span on the performance of RC beams strengthened in shear with CFRP. Compos Part B Eng 2006;37:37-46.

473 [20] Bousselham A, Chaallal O. Mechanisms of Shear Resistance of Concrete Beams Strengthened in Shear with Externally Bonded FRP. J Compos Constr 2008;12:499-512. doi:10.1061/(ASCE)1090-0268(2008)12:5(499). distributions in the FRP reinforcement. Constr Build Mater 2009;23:1544-54. 
concrete T-beams with fully or partially bonded fibre-reinforced polymer composites. Struct Concr 2014;15:229-39. doi:10.1002/suco.201300031.

481 [23] Tetta ZC, Koutas LN, Bournas DA. Textile-reinforced mortar (TRM) versus fiber-reinforced polymers (FRP) in shear strengthening of concrete beams. Compos Part B Eng 2015;77:338-48. doi:https://doi.org/10.1016/j.compositesb.2015.03.055.

[24] Tetta ZC, Koutas LN, Bournas DA. Shear strengthening of concrete members with TRM jackets: Effect of shear span-to-depth ratio, material and amount of external reinforcement. Compos Part B Eng 2018;137:184-201. doi:https://doi.org/10.1016/j.compositesb.2017.10.041.

[25] Tetta ZC, Triantafillou TC, Bournas DA. On the design of shear-strengthened RC members through the use of textile reinforced mortar overlays. Compos Part B Eng 2018;147:178-96. doi:https://doi.org/10.1016/j.compositesb.2018.04.008.

[26] Pujol M. Refuerzo a cortante de estructuras de hormigón armado con laminados de polímeros reforzados con fibras (FRP). Verificación experimental. Universitat Politècnica de Catalunya, 2018.

[27] Nisticò N, Ožbolt J, Polimanti G. Modeling of reinforced concrete beams strengthened in shear with CFRP: Microplane-based approach. Compos Part B Eng 2016;90:351-64. doi:10.1016/j.compositesb.2016.01.009. 
502 Fig. 1. Geometry of tested beams.

503 Fig. 2. FRP externally bonded reinforcement (EBR) amounts for type 1, 2 and 3 respectively.

504 Fig. 3. Anchorage system type A and type B for the CFRP reinforcement.

505 Fig. 4. Test set-up.

506 Fig. 5. Instrumentation. Displacement transducers and strain gauges.

507 Fig. 6. Failure of the control beam: (a) M0 and (b) H0.

508 Fig. 7. Failure of strengthened beams without (a) and with anchorage (b).

509 Fig. 8. Shear force vs. displacement for beam set M (lower longitudinal reinforcement ratio) without (a)

510 and with anchorage (b).

511 Fig. 9. Shear force vs. displacement for beam set H (higher longitudinal reinforcement ratio) without (a)

512 and with anchorage (b).

513 Fig. 10 Crack pattern in the shear span for some beams of set $\mathrm{H}$

514 Fig. 11 Strains in the transverse reinforcement for beams H2-b and H2B.

515 Fig. 12 Shear strength components for beam M0-b.

516 Fig. 13 Shear strength components for beams M1-a and M1B.

517 Fig. 14 Shear strength components for beams M1-a and M1B.

518 Fig. 15 Shear strength components for beams M2-b and M2B.

519 Fig. 16 Shear strength components for beams M2-b and M2-B.

520 Fig. 17 Shear strength components for control beams H0-a.

521 Fig. 18 Shear strength components for beams H1-a, H2-b and H2B.

522 Fig. 19 Shear strength components for beams H3A and H3B.

523

524

525

526

527

528

529 
$530 \quad$ List of Tables

531 Table 1. Concrete properties of the specimens.

532 Table 2. Mechanical properties of the longitudinal and transverse steel reinforcement.

533 Table 3. Concrete properties, initiation of debonding, ultimate shear force of the fictitious control and

534 tested beams, and percentage of reinforcement.

535 Table 4. Contribution of the concrete web, flange, transverse steel and FRP to the ultimate shear force of 536 the tested beams.

537 Table 5. Comparison of the experimental to the analytical predictions. 

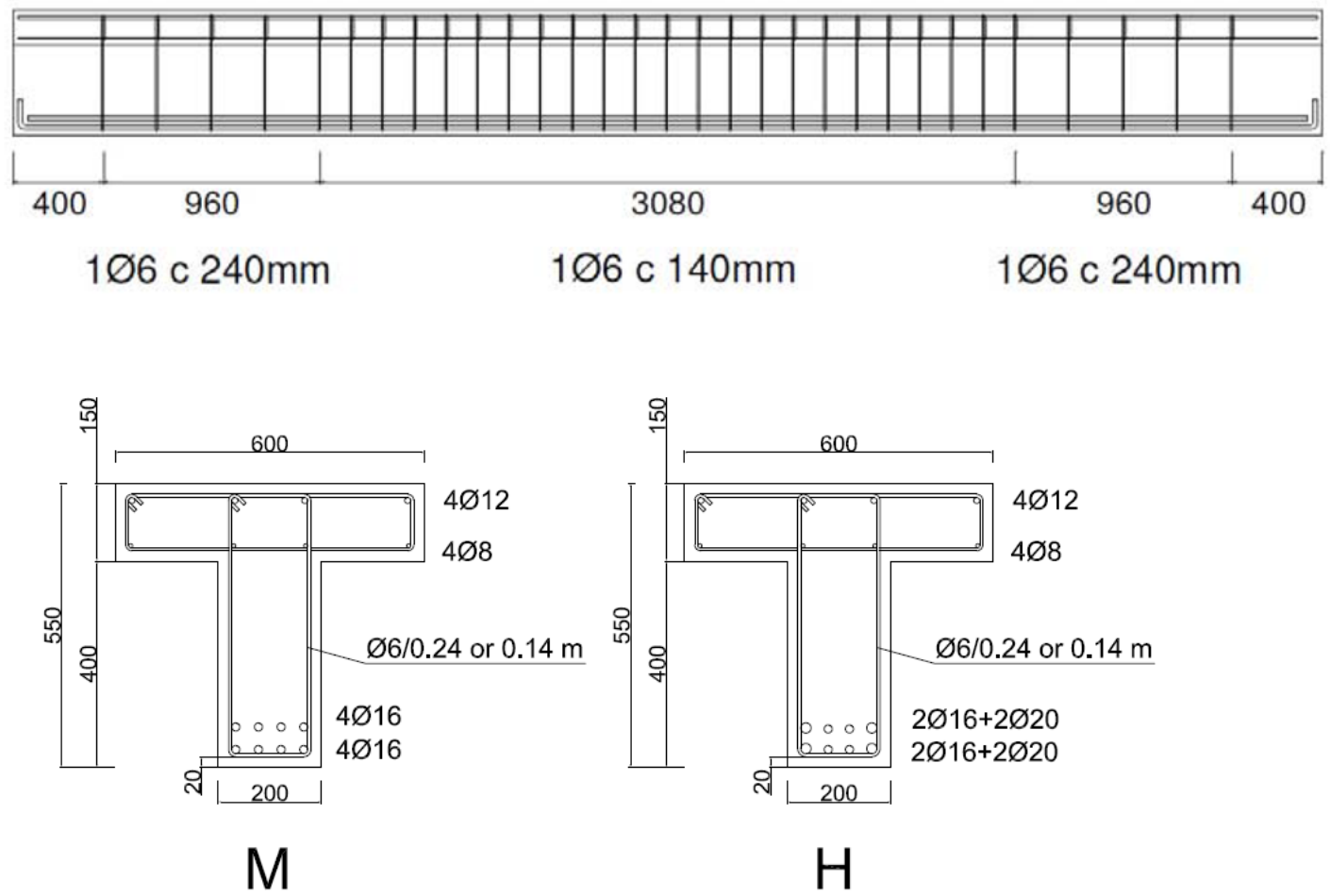

Fig. 1. Geometry of tested beams. 


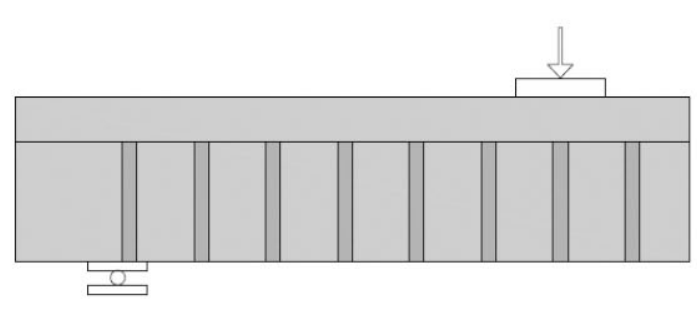

Type 1: 50 mm width@240mm

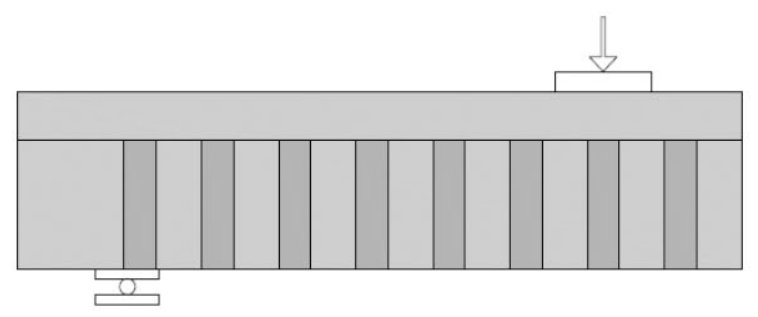

Type 2: 100 mm width@240 mm

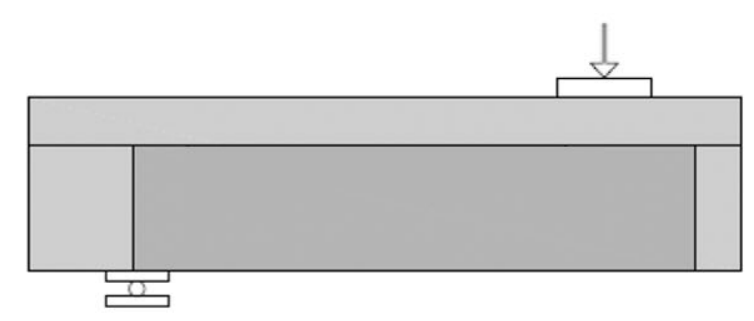

Type 3: Continuous

541 Fig. 2. CFRP externally bonded reinforcement (EBR) amounts for types 1, 2 and 3 respectively. 
Anchorage Type A

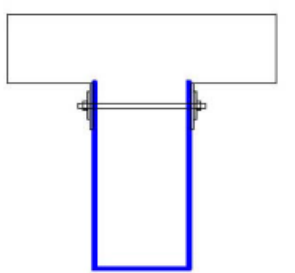

544

Anchorage Type B

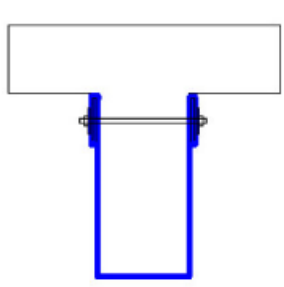

545

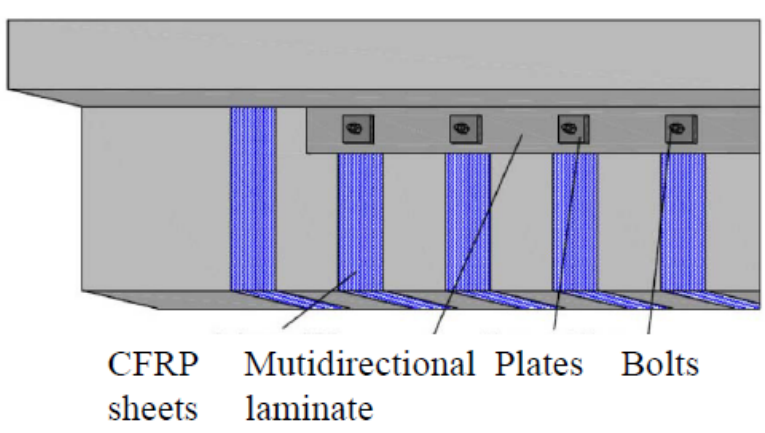

CFRP Mutidirectional Plates Bolts

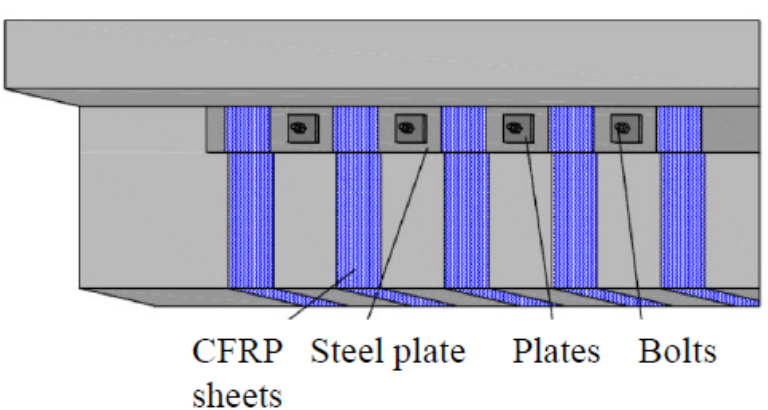

Fig. 3. Anchorage system type A and type B for the CFRP reinforcement. 

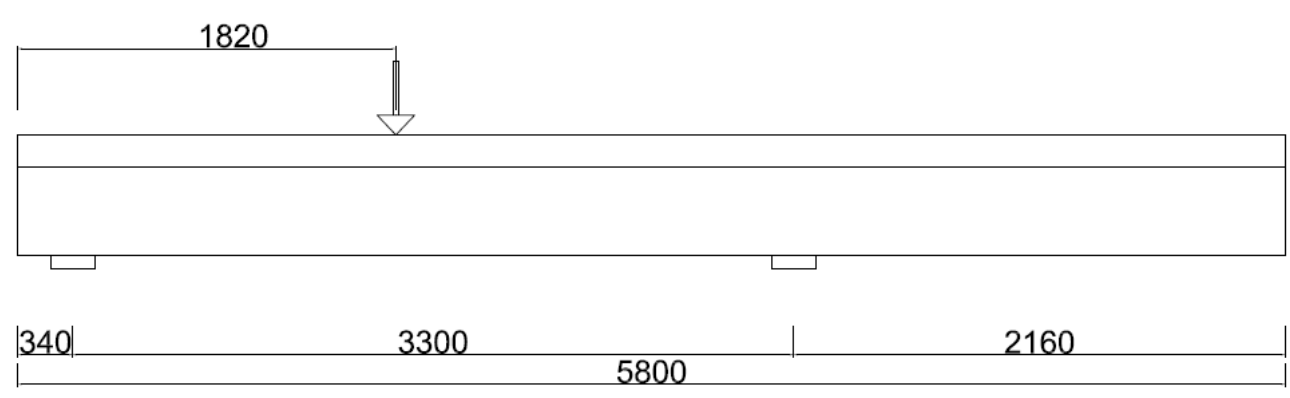

Test 1

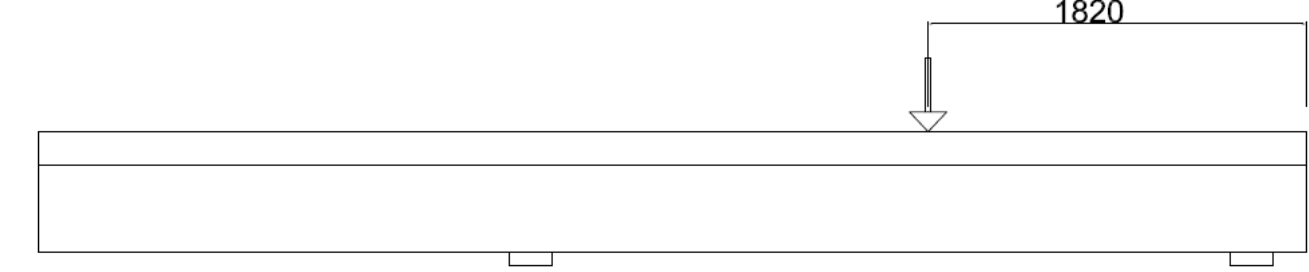

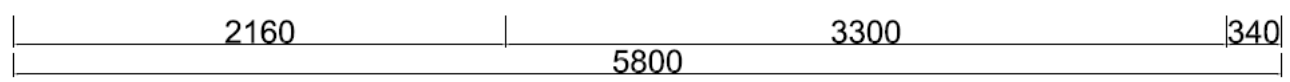

$548 \quad$ Fig. 4. Test set-up. 


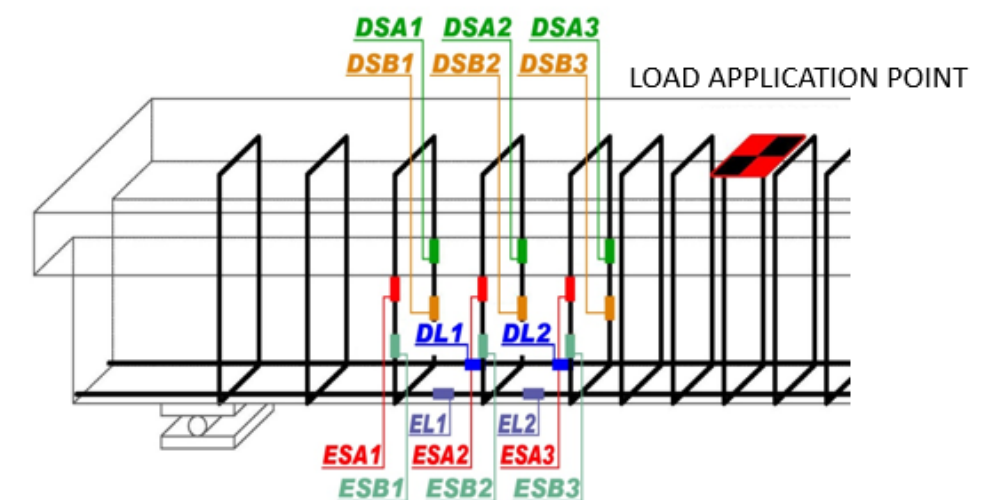

549

550

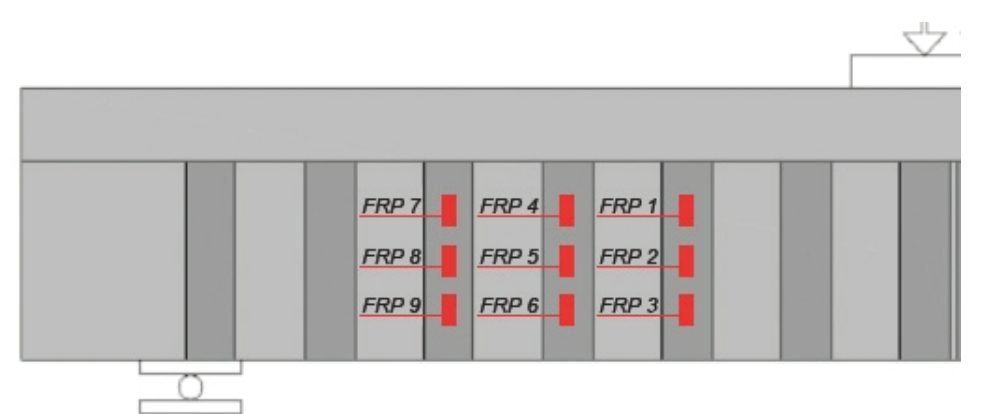

551 Fig. 5. Instrumentation. Displacement transducers and strain gauges.

552 


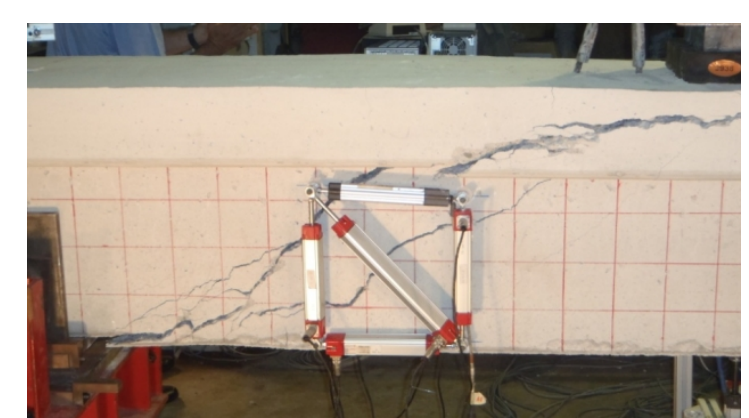

(a)

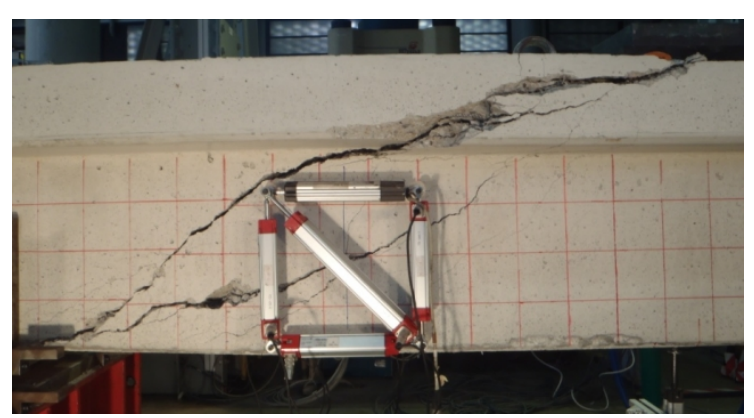

(b)

553

Fig. 6. Failure of the control beam: (a) M0 and (b) H0.

554

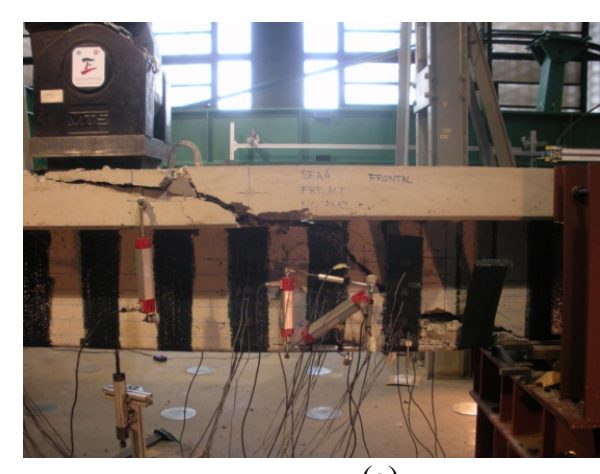

(a)

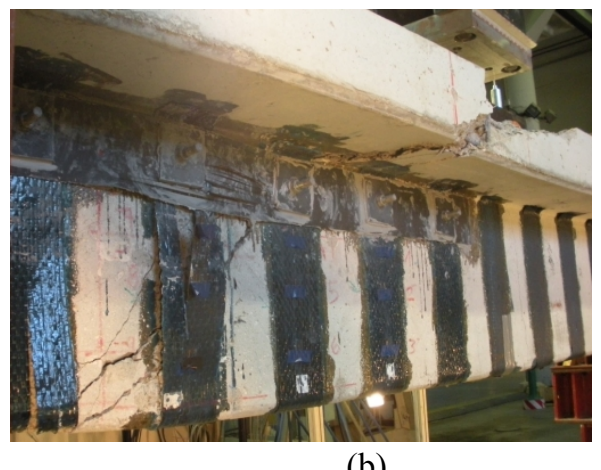

(b)

555 Fig. 7. Failure of strengthened beams without (a) and with anchorage (b). 


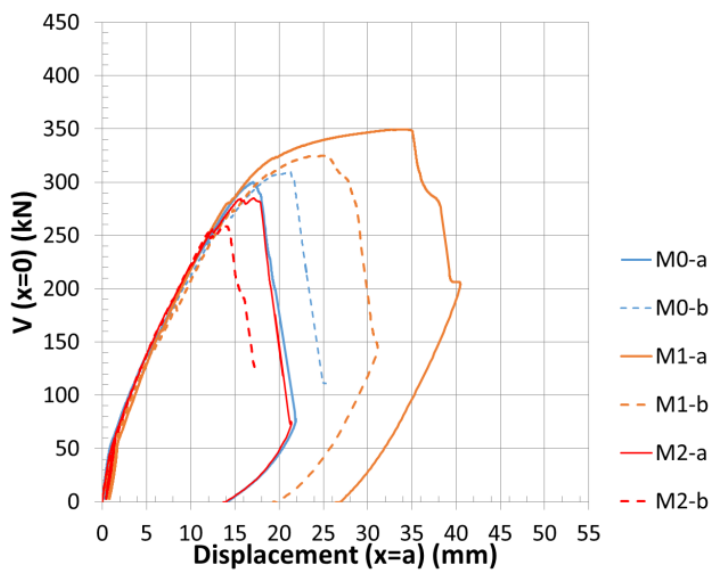

a)

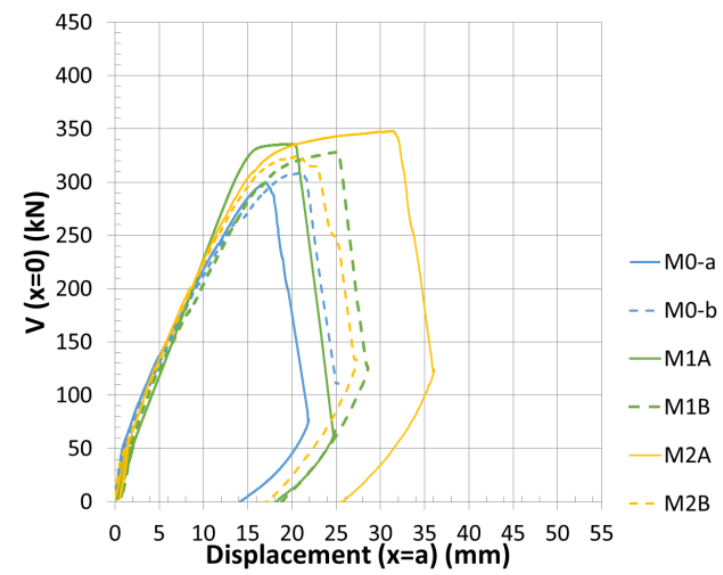

b)

556 Fig. 8. Shear force vs. displacement for beam set M (lower longitudinal reinforcement ratio) without (a) and with anchorage (b).

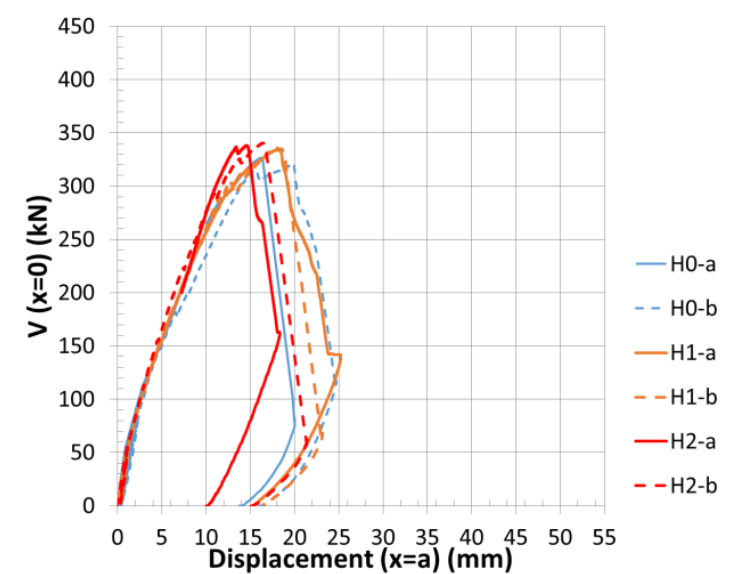

557 Fig. 9. Shear force vs. displacement for beam set H (higher longitudinal reinforcement ratio) without (a) and with anchorage (b).

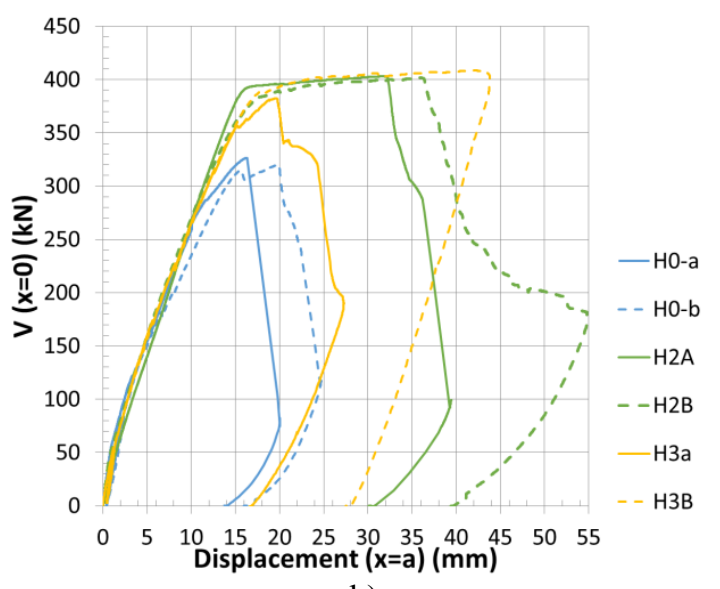


558

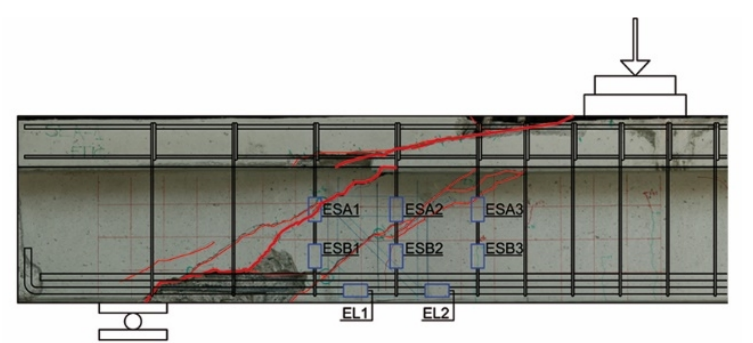

a) $\mathrm{H} 0$-a
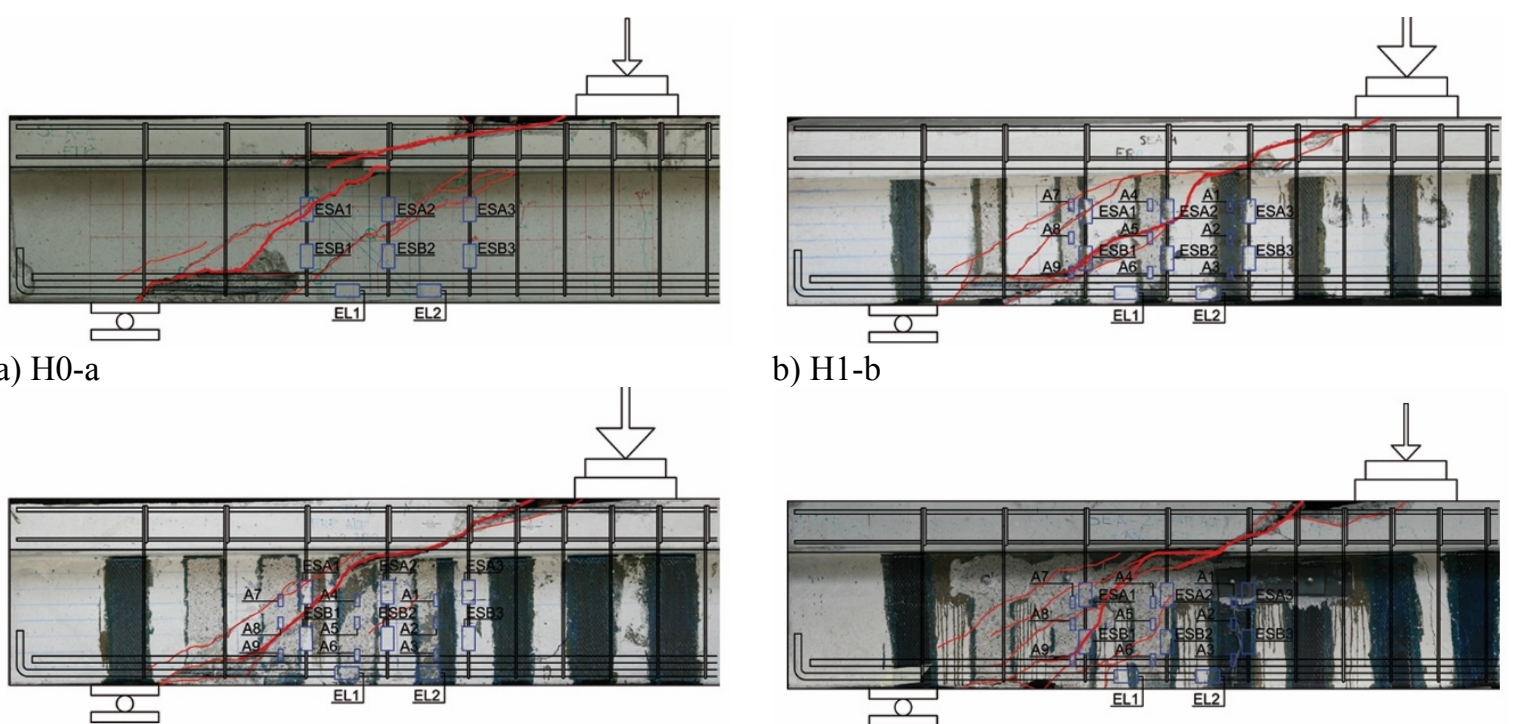

b) $\mathrm{H} 1-\mathrm{b}$

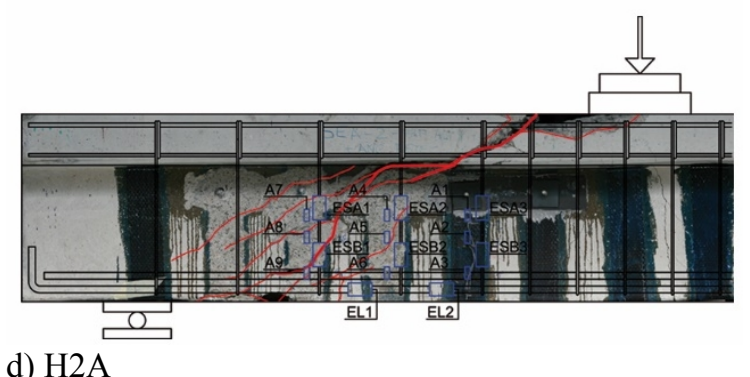

559 Fig. 10 Crack pattern in the shear span for some beams of set $\mathrm{H}$. 


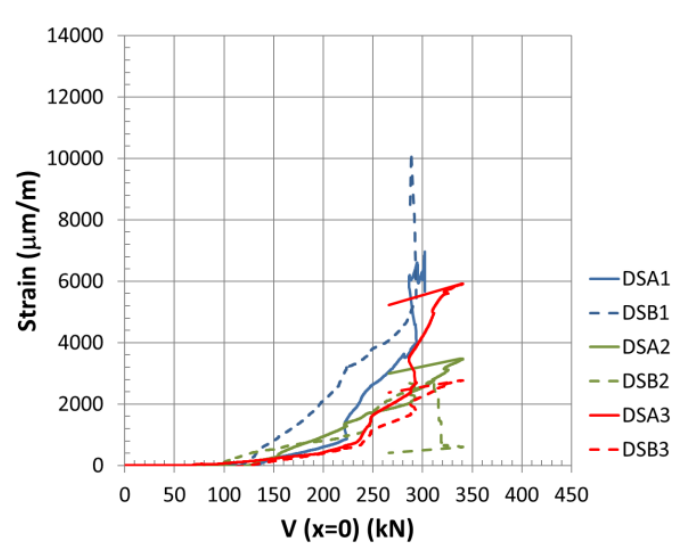

$\mathrm{V}(\mathrm{x}=0)(\mathrm{kN})$

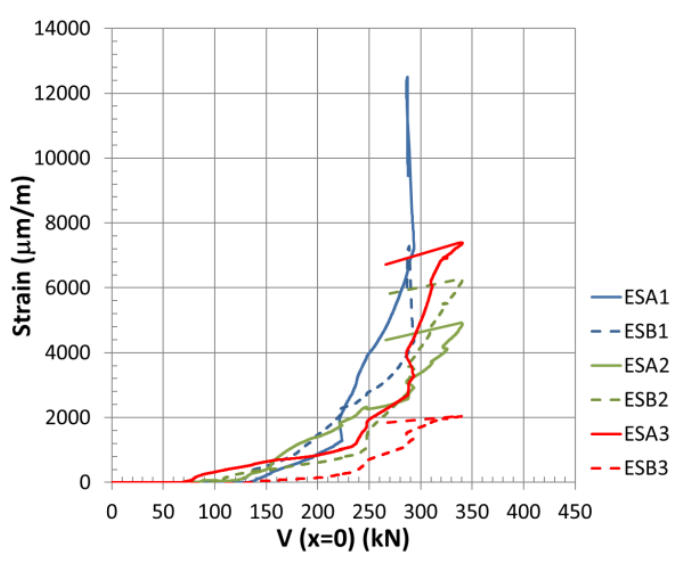

a) H2-b. Internal transverse reinforcement
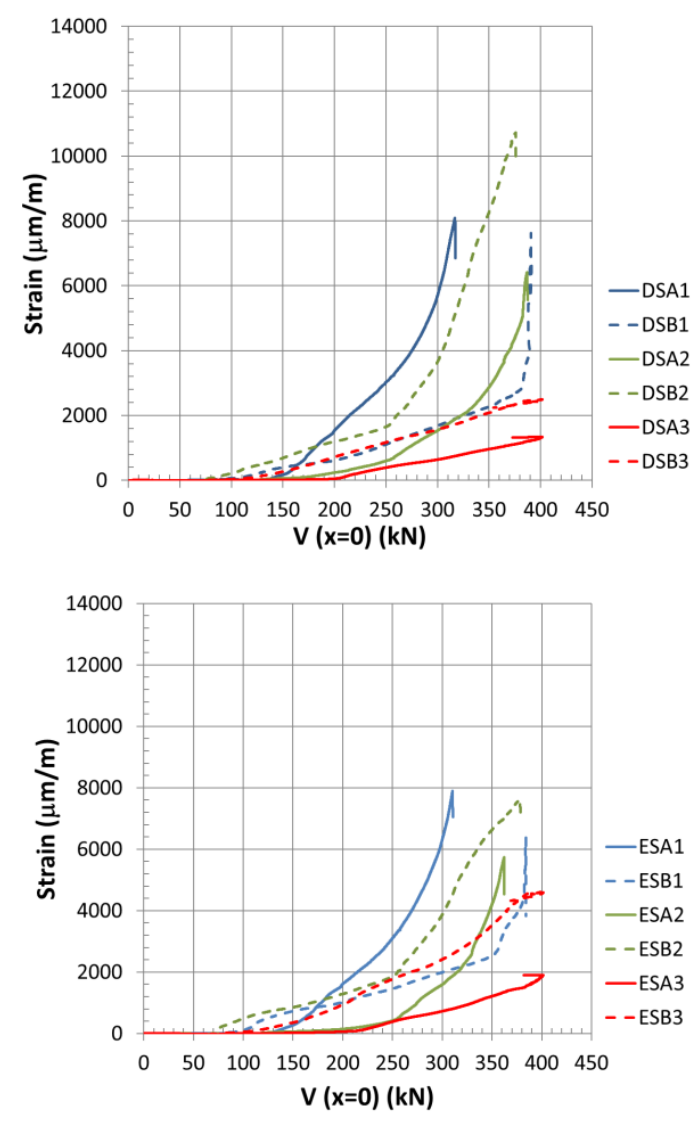

b) H2B. Internal transverse reinforcement 

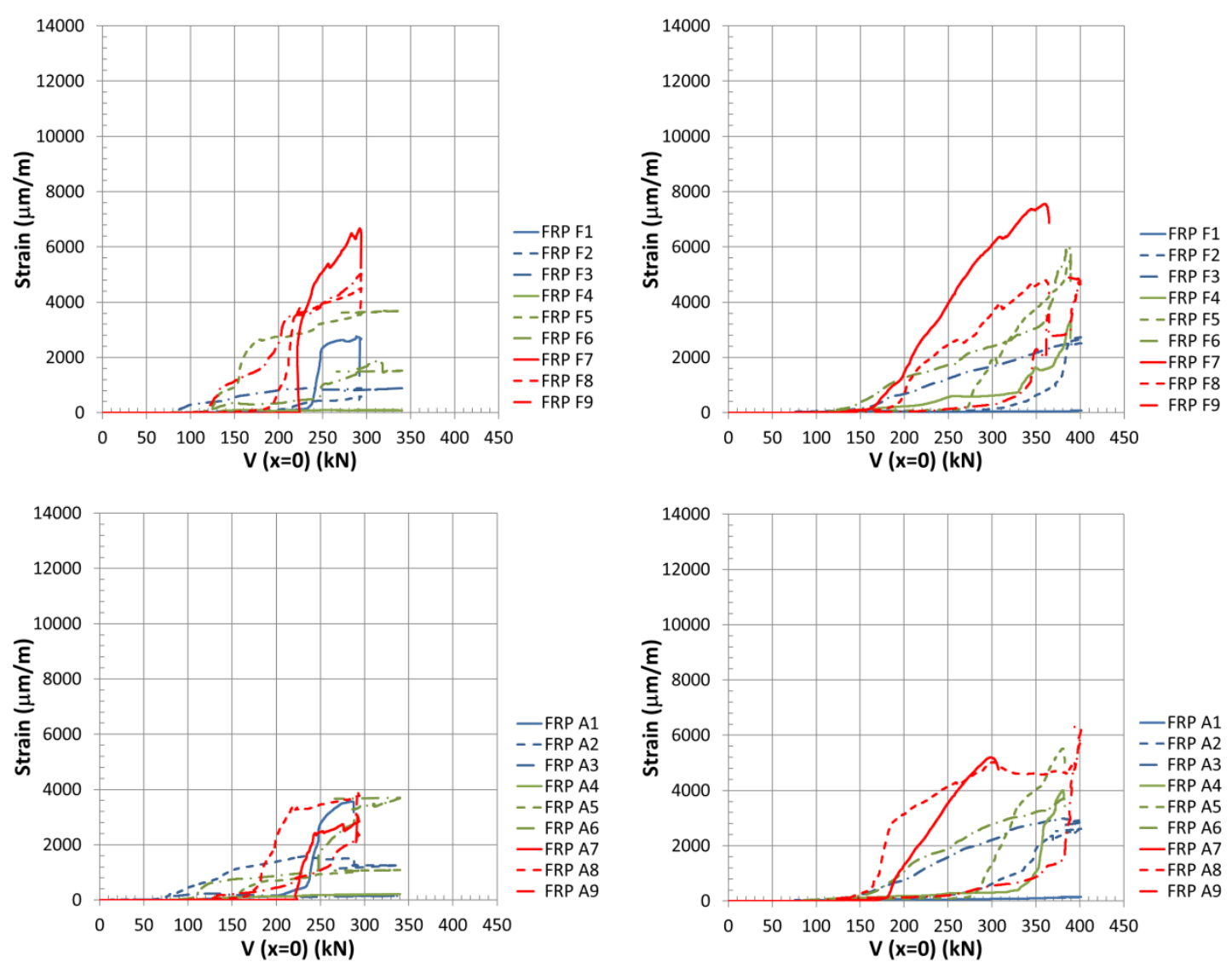

c) H2-b. CFRP shear reinforcement

d) H2B. CFRP shear reinforcement

561 Fig. 11 Strains in the transverse reinforcement for beams H2-b and H2B. 


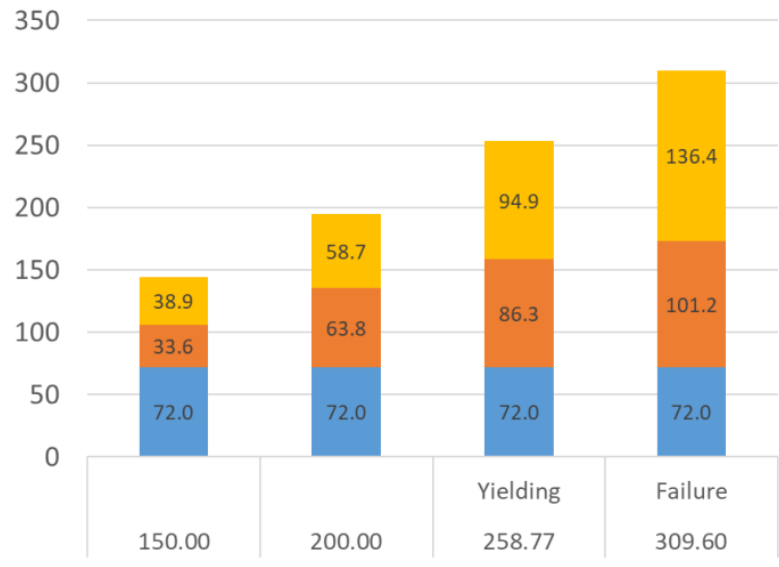

a)

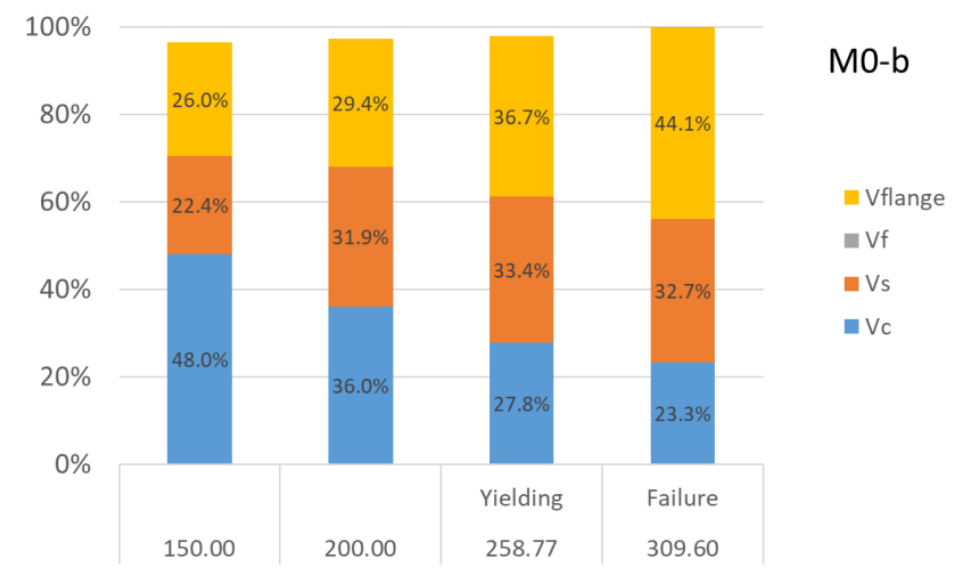

563 Fig. 12 Shear strength components for beam M0-b. 

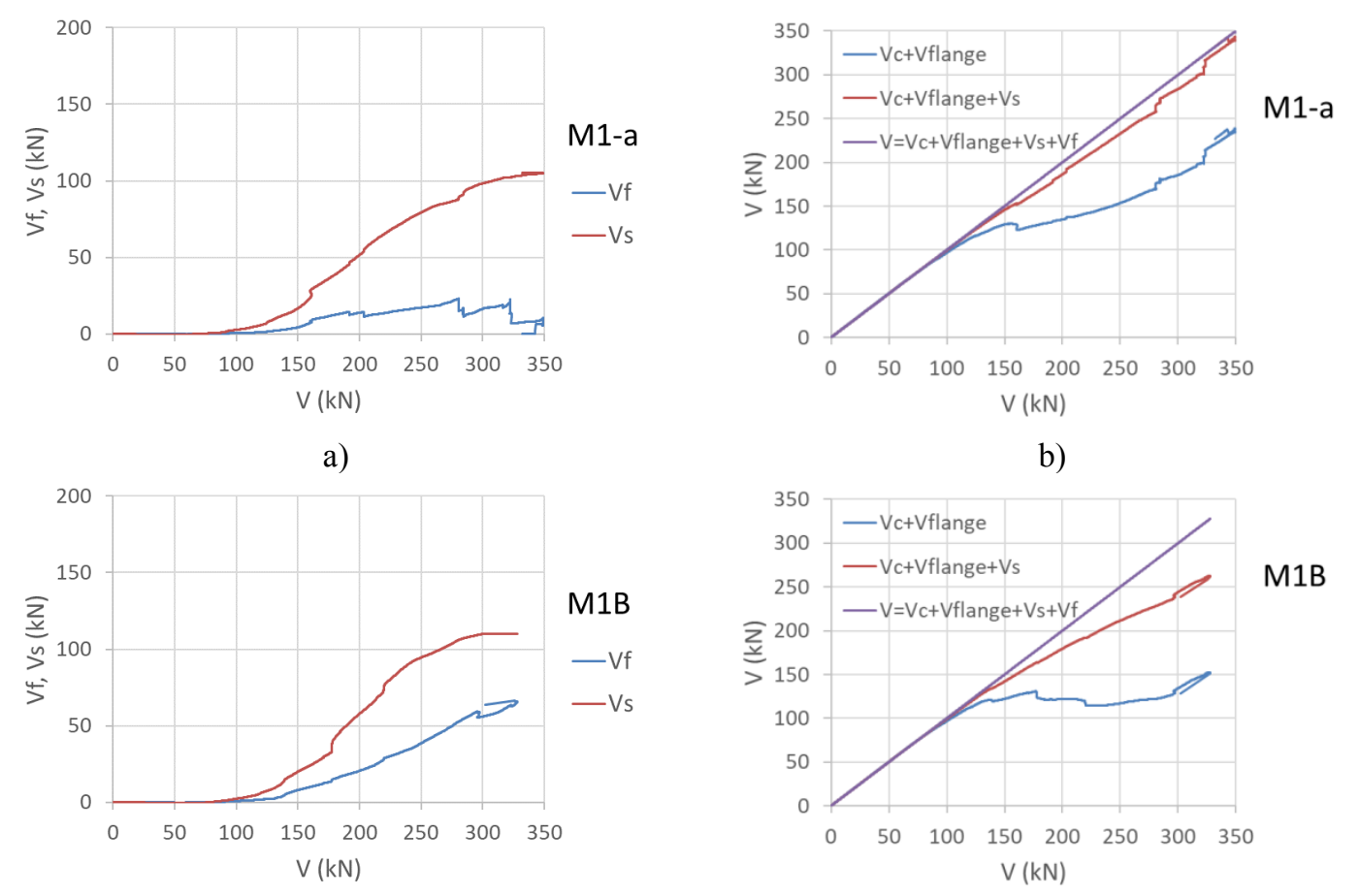

567

c)

d)

568

569

570 

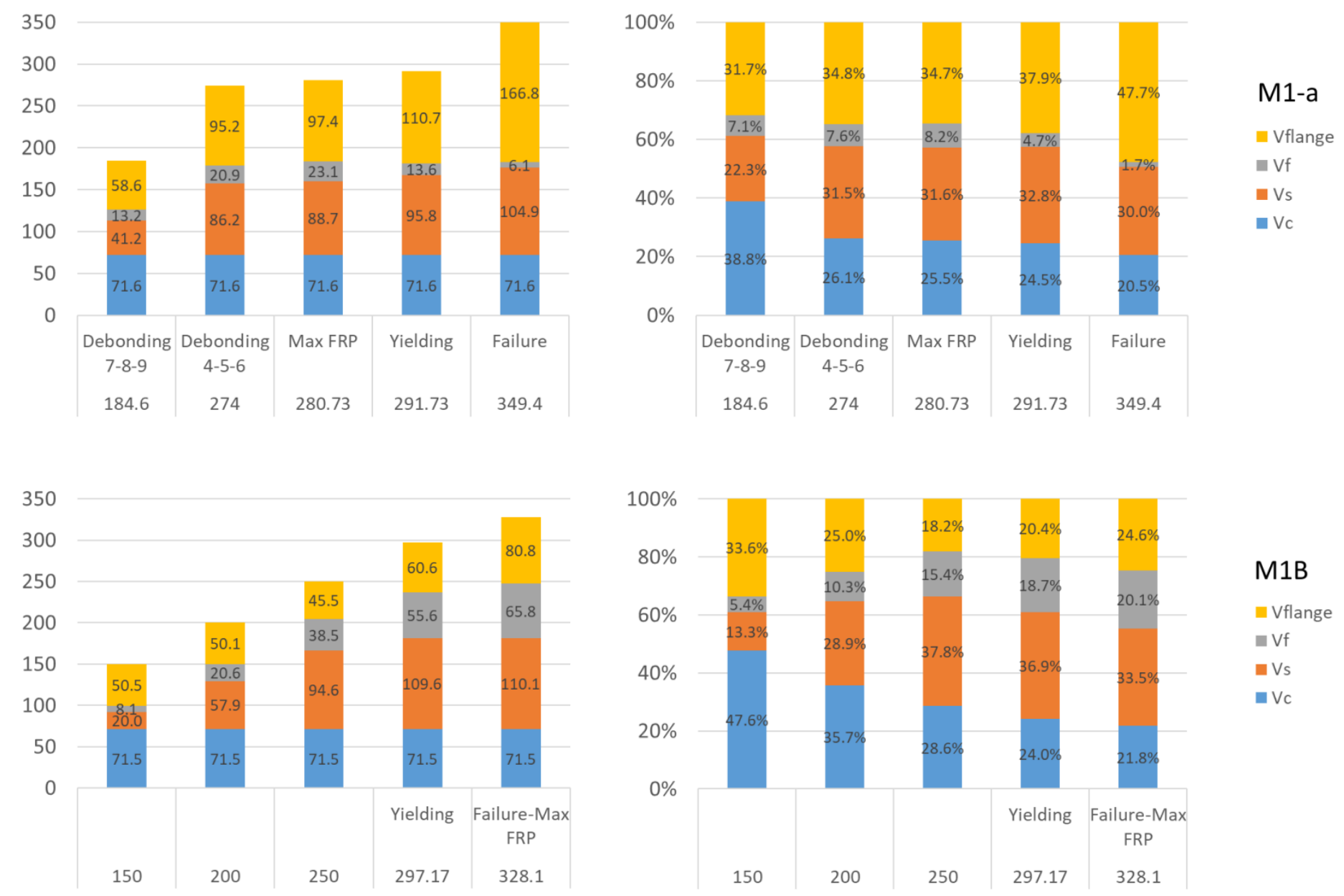

Fig. 14 Shear strength components for beams M1-a and M1B. 


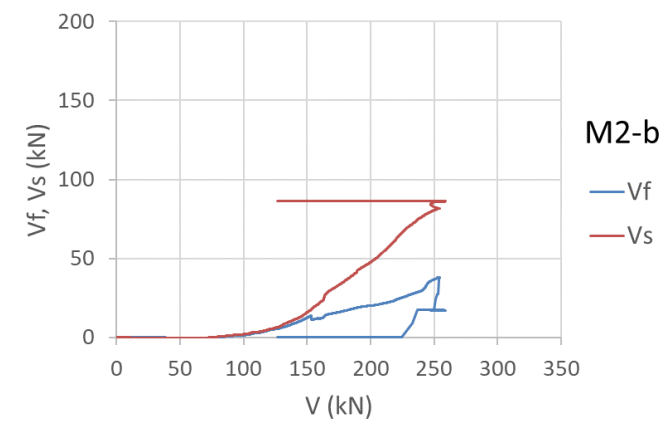

a)

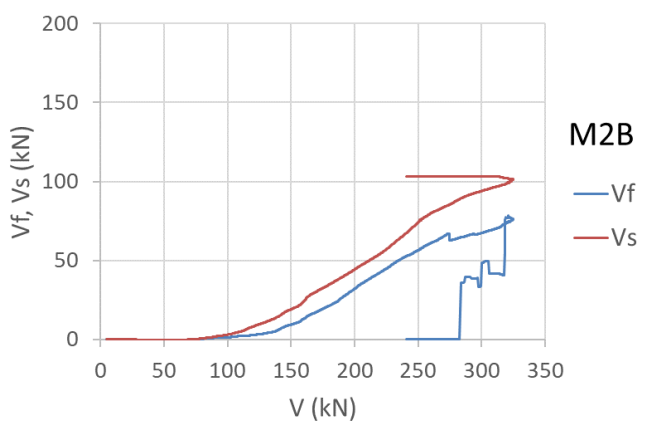

c)

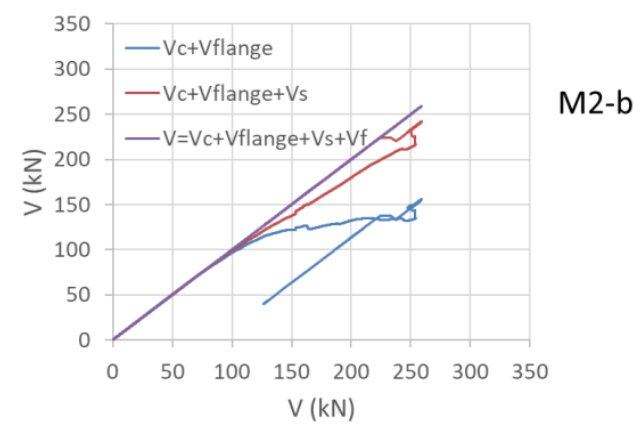

b)

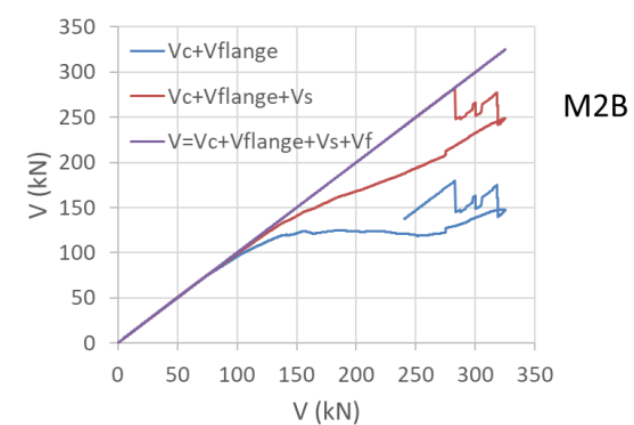

d)

Fig. 15 Shear strength components for beams M2-b and M2B. 

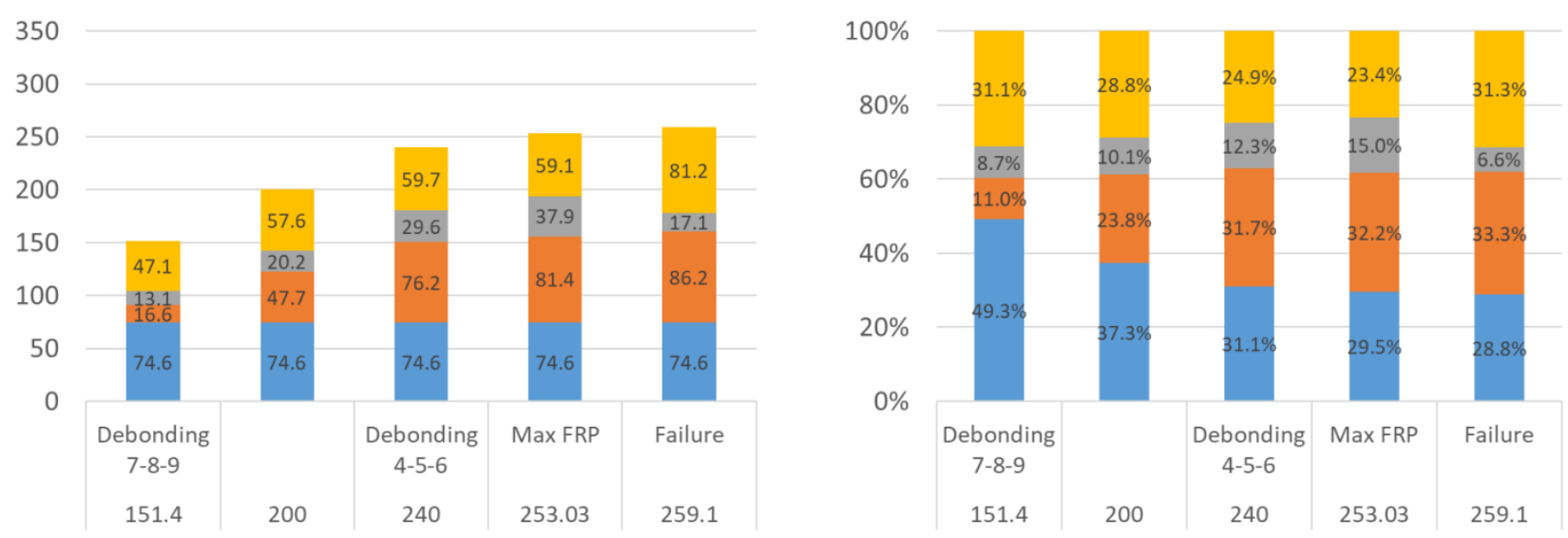

M2-b

Vala

vf

Vs

- Vo
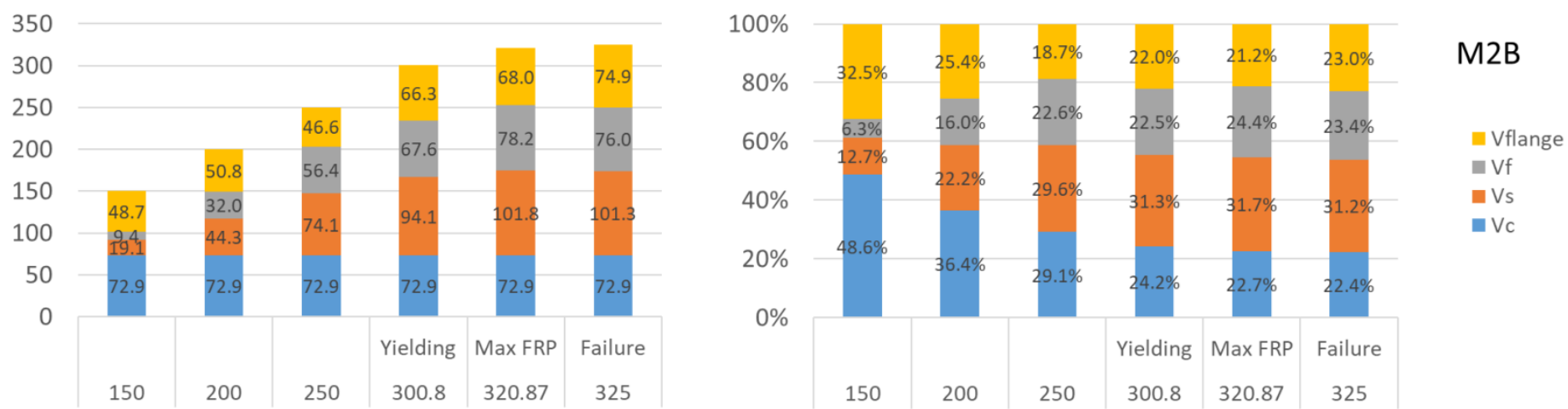

Fig. 16 Shear strength components for beams M2-b and M2-B. 

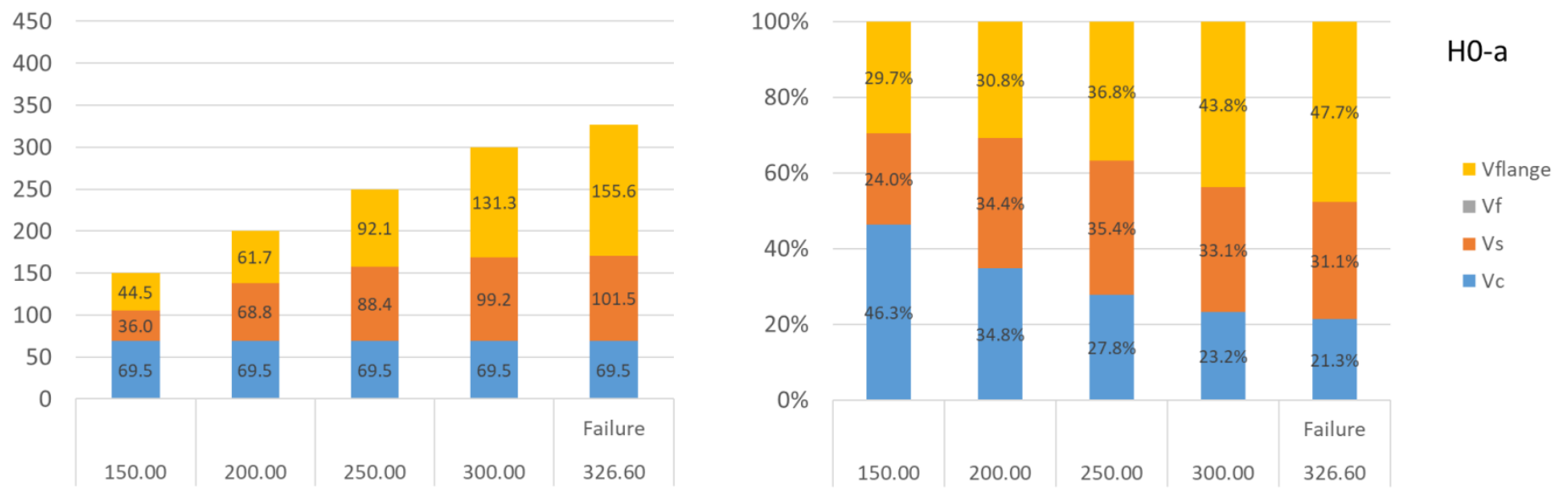

579 Fig. 17 Shear strength components for control beams H0-a. 


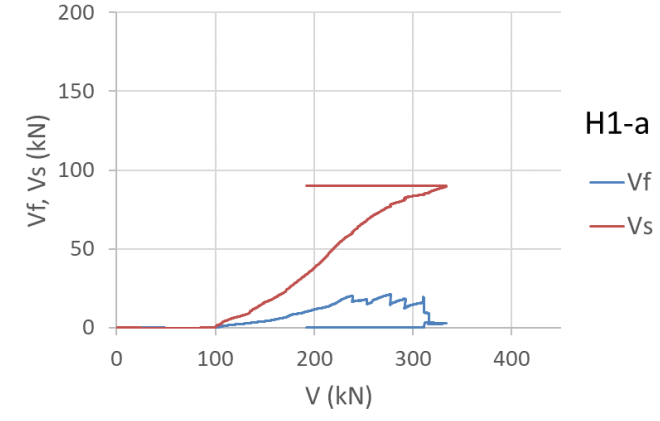

a)

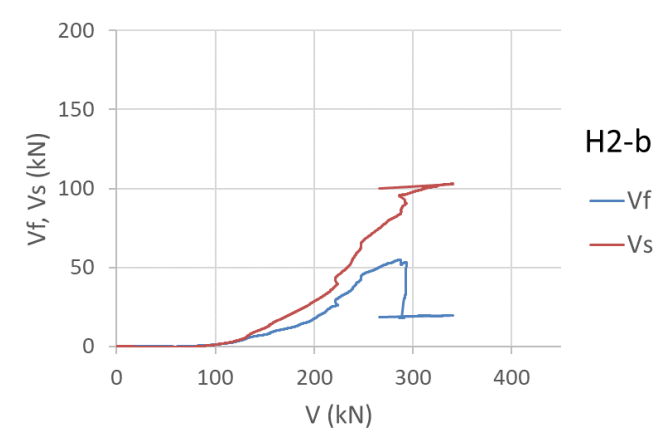

c)

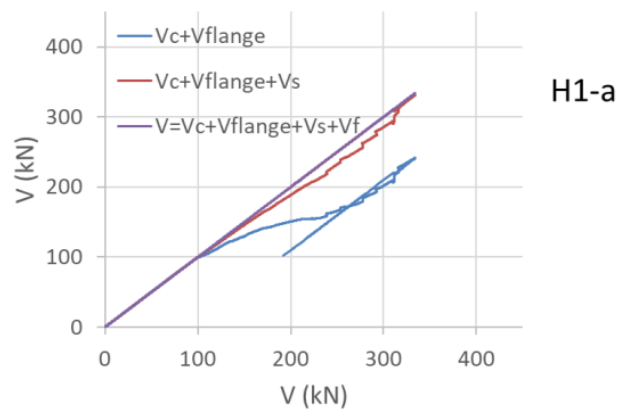

b)

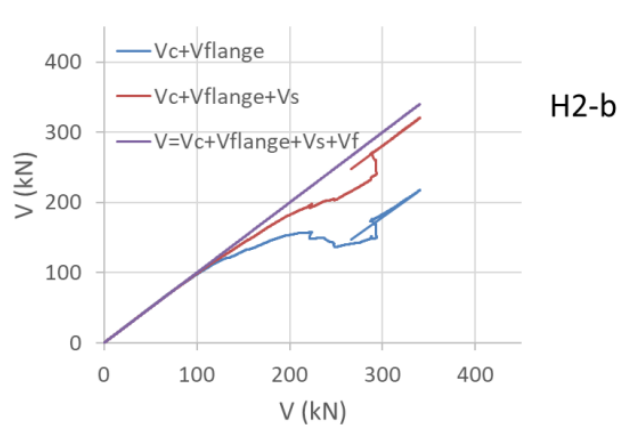

d) 


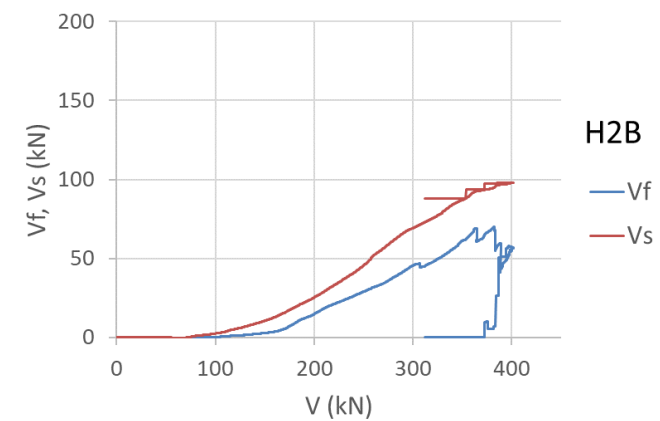

e)

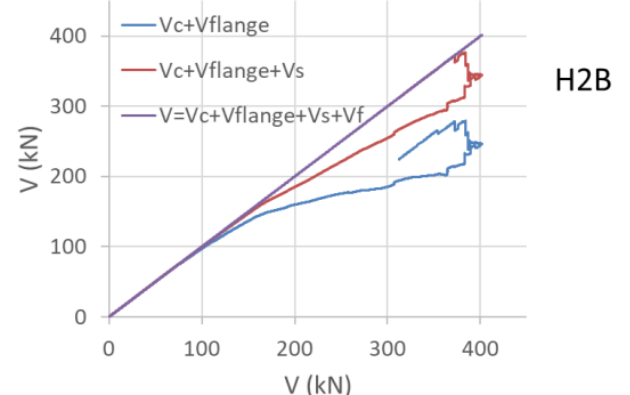

f)

Fig. 18 Shear strength components for beams H1-a, H2-b and H2B. 

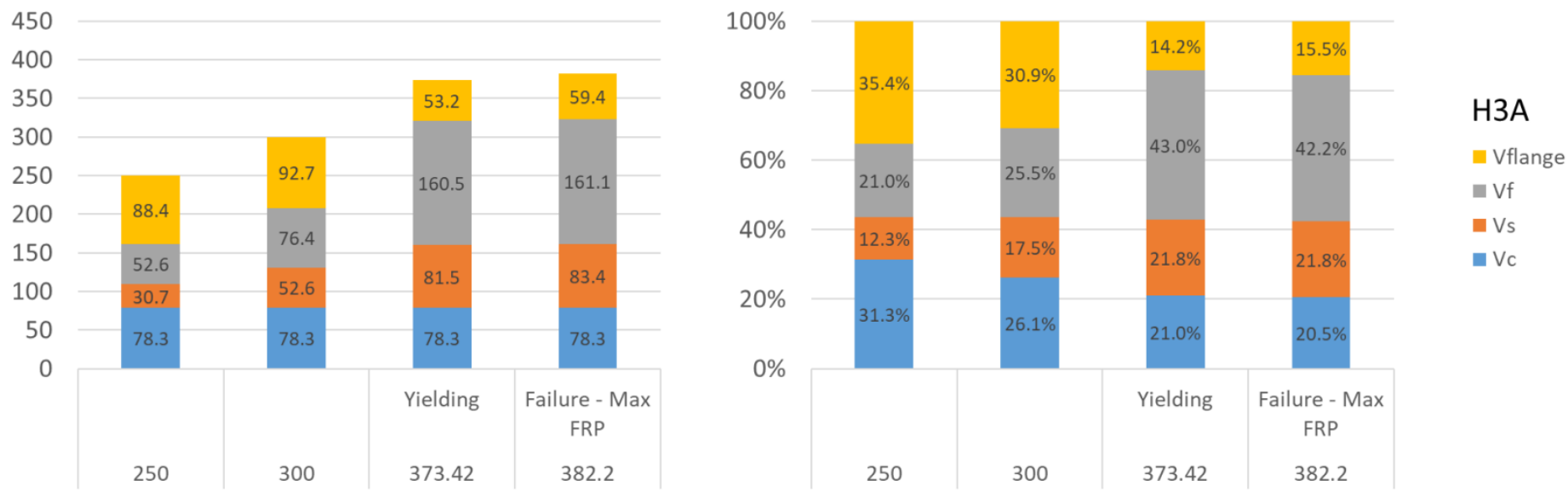

a)
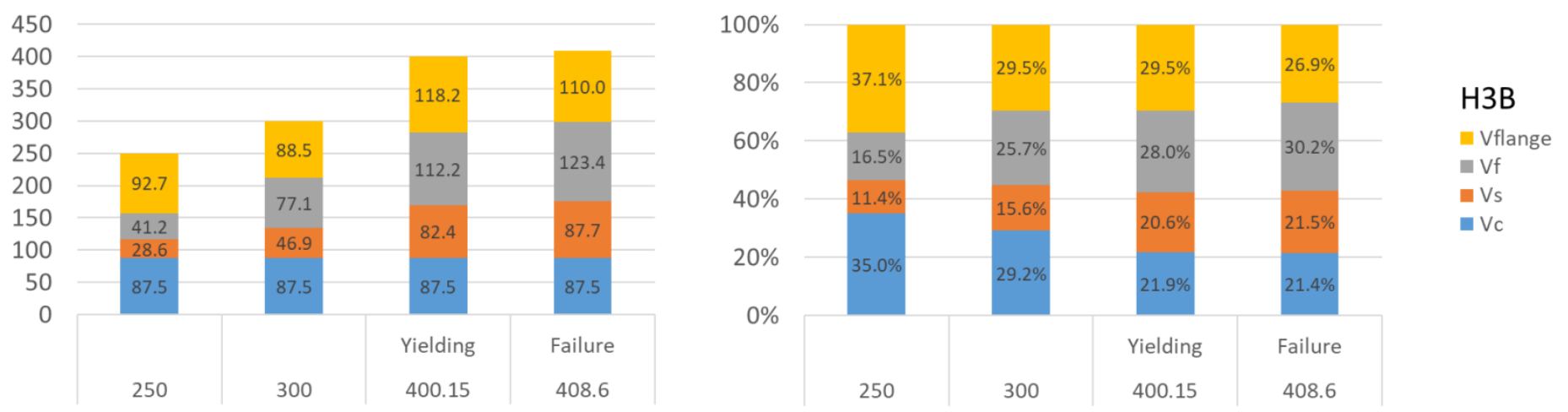

b) 


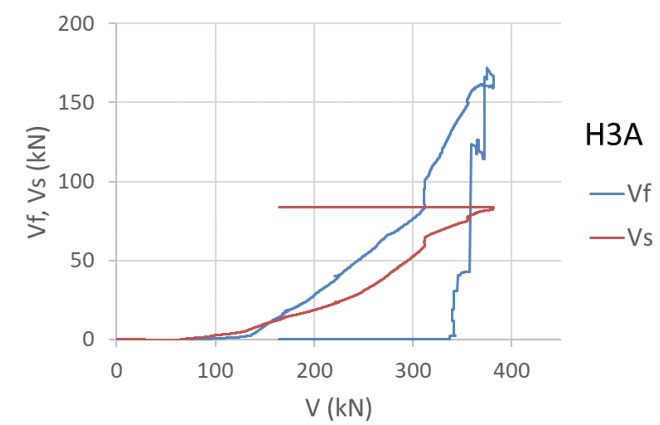

c)

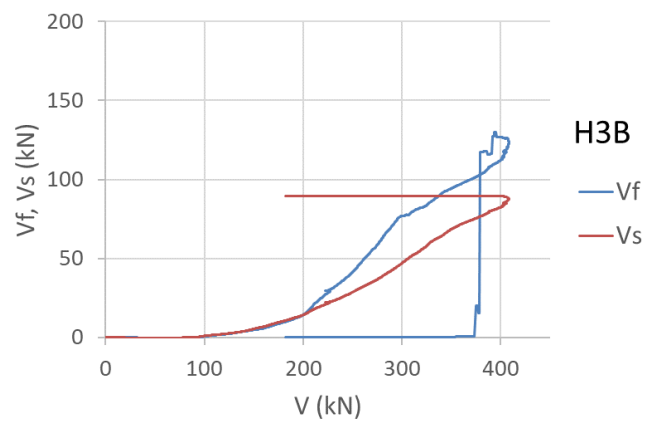

d)

582 Fig. 19 Shear strength components for beams H3A and H3B for different load levels. 


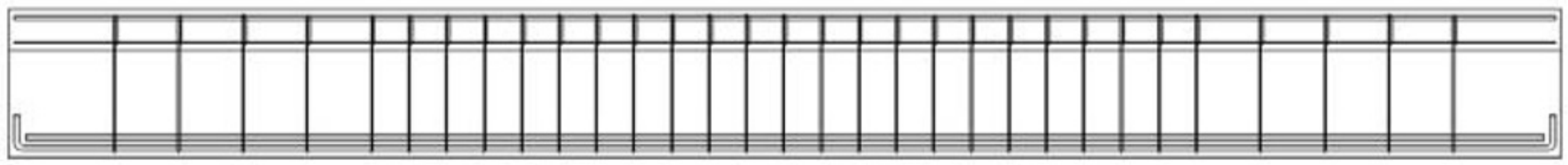

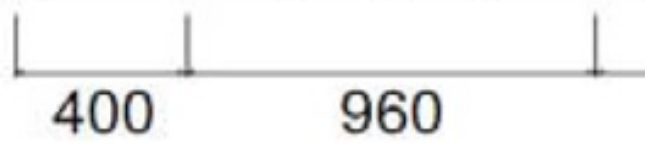

$1 \varnothing 6$ c $240 \mathrm{~mm}$
3080

$1 \varnothing 6$ c $140 \mathrm{~mm}$

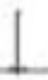

960 400

$1 \varnothing 6$ c $240 \mathrm{~mm}$ 

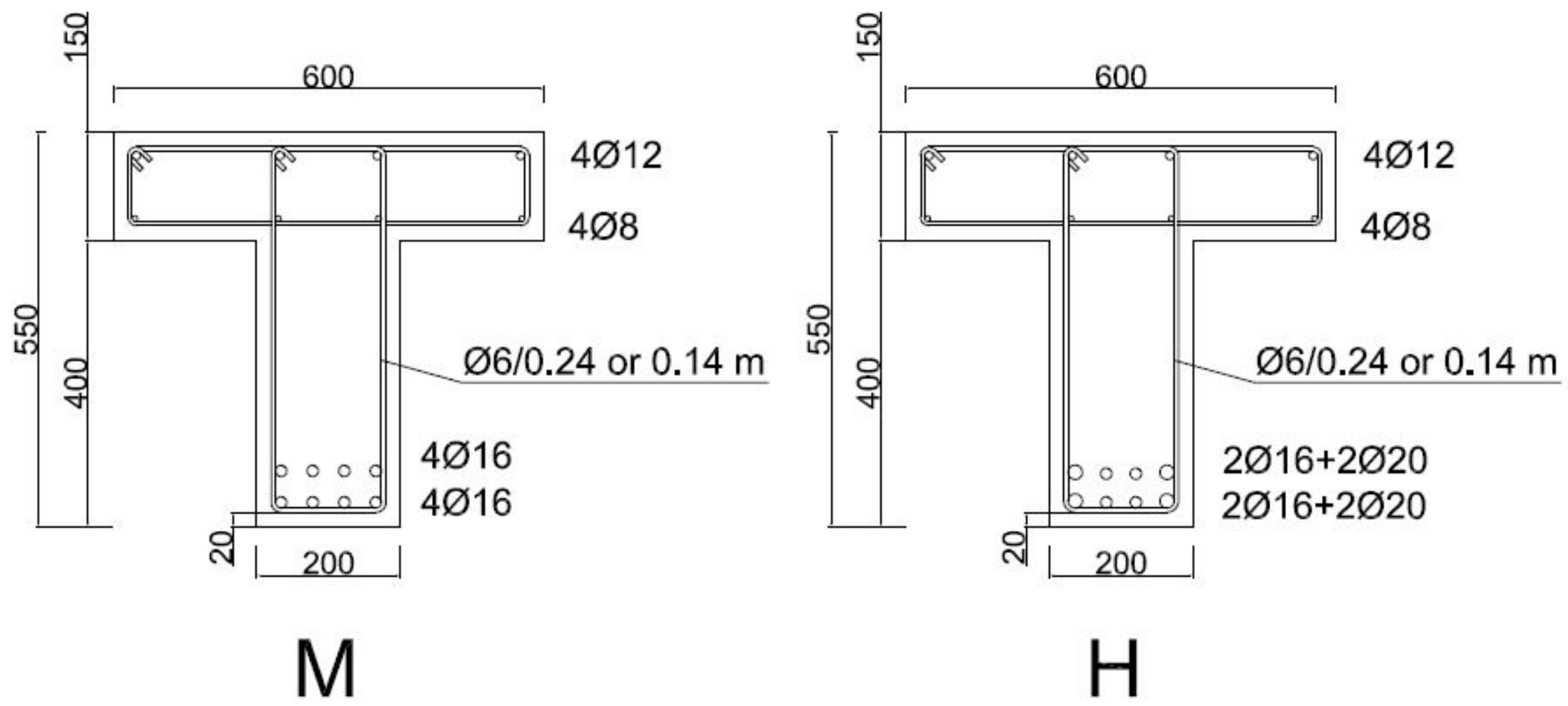


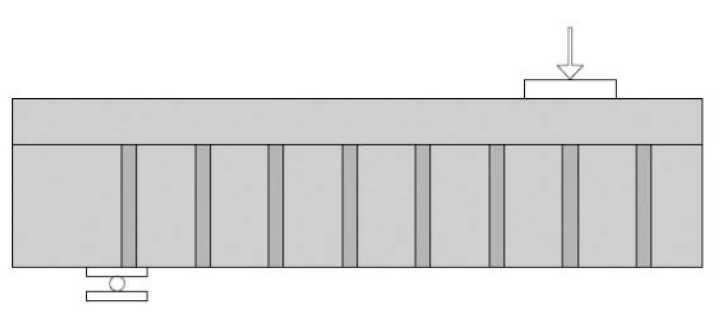

Type 1: 50 mm width@240 mm

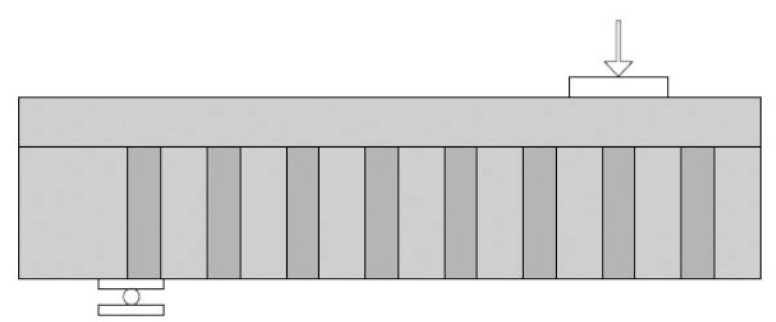

Type 2: 100 mm width @240 mm

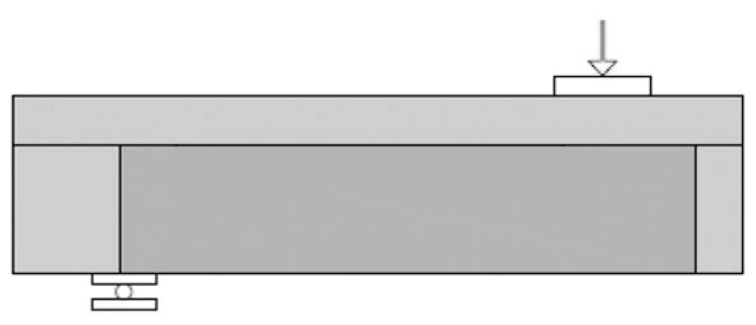

Type 3: Continuous 
Anchorage Type A
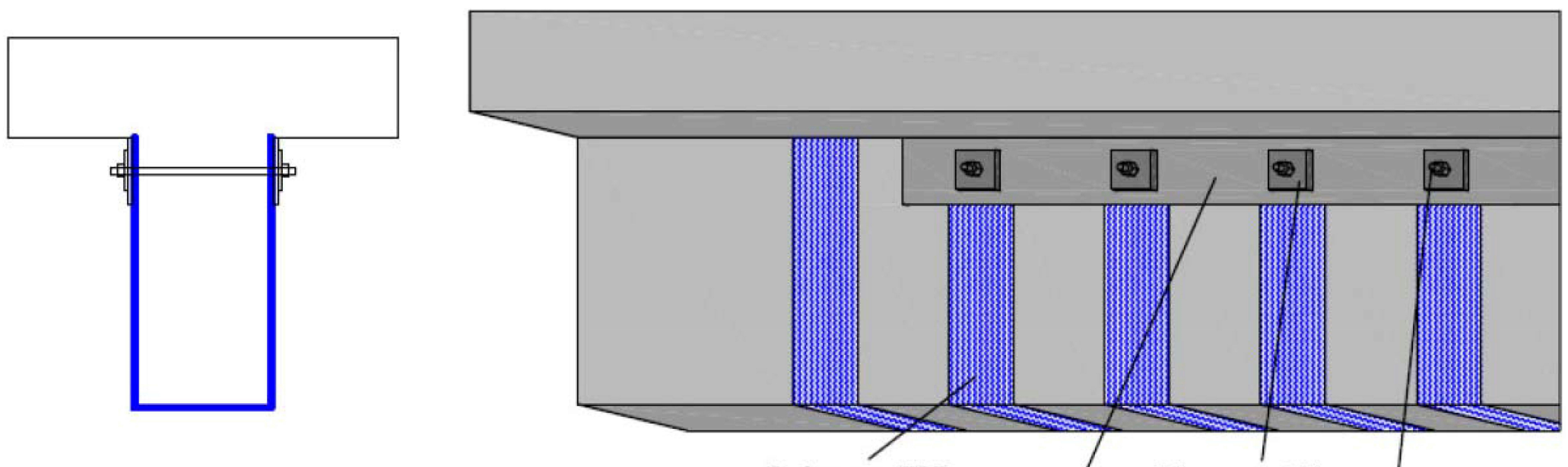

CFRP Mutidirectional Plates Bolts sheets laminate 
Anchorage Type B
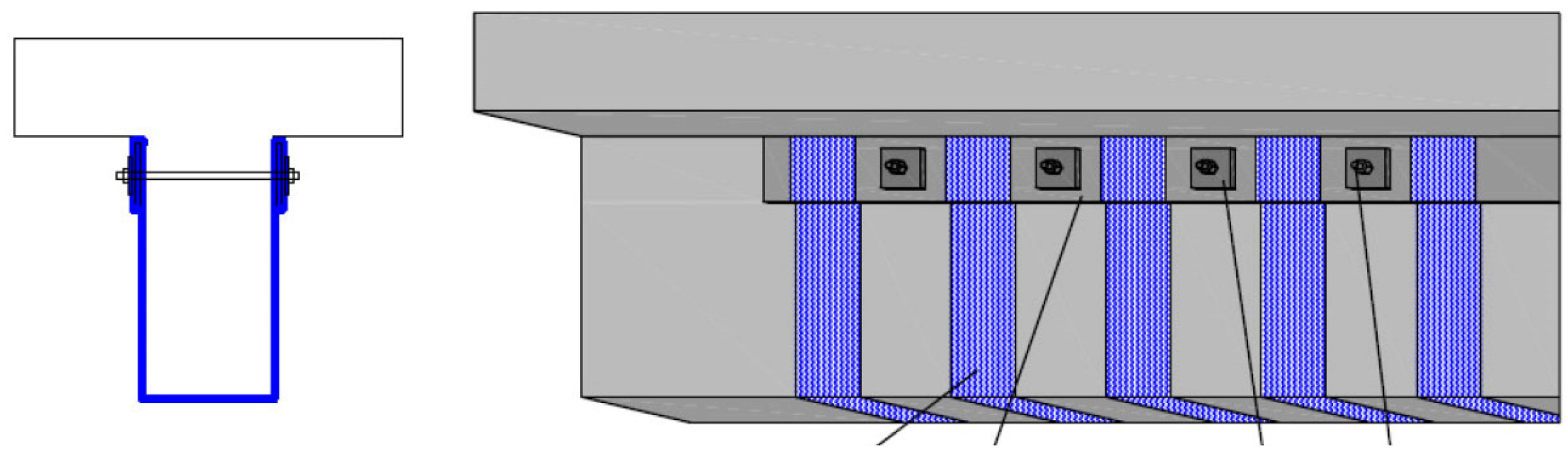

CFRP Steel plate Plates Bolts sheets 
1820

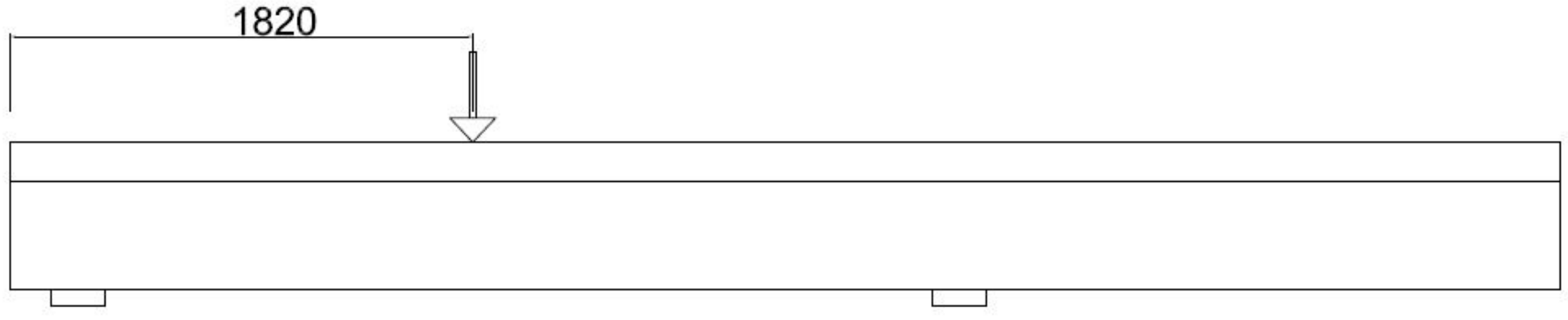

\begin{tabular}{|lll|}
340 & 3300 & 2160 \\
\hline
\end{tabular}

Test 1

1820

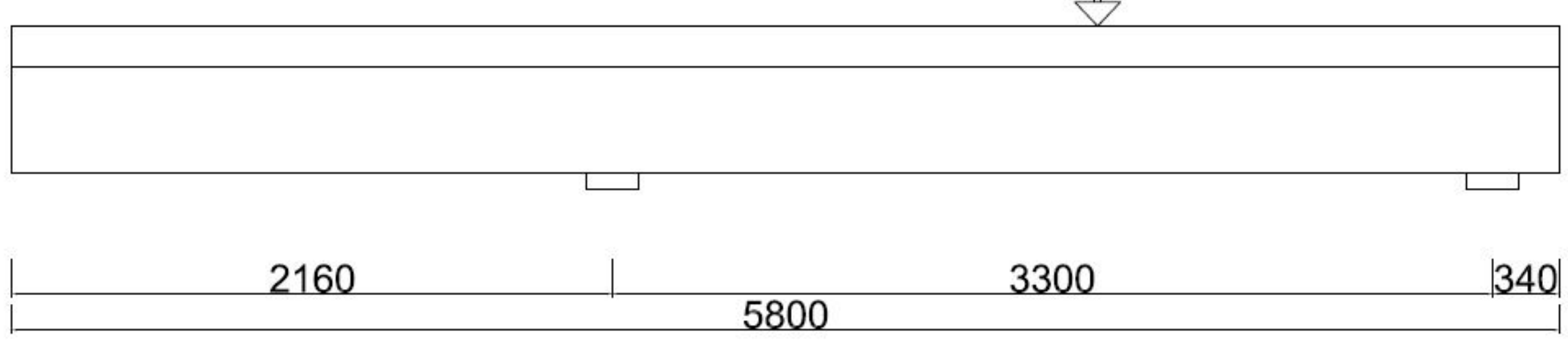

Test 2 


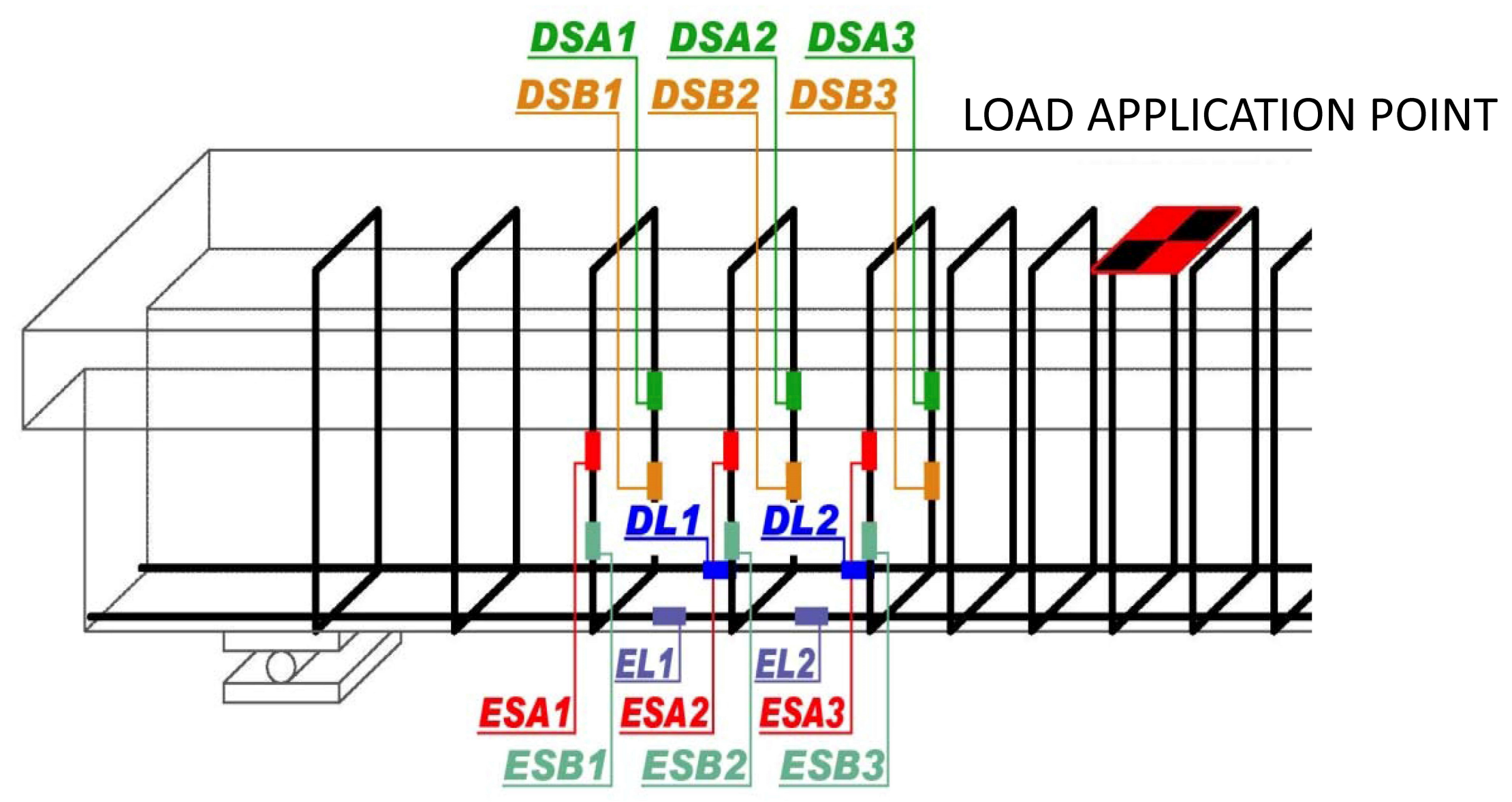




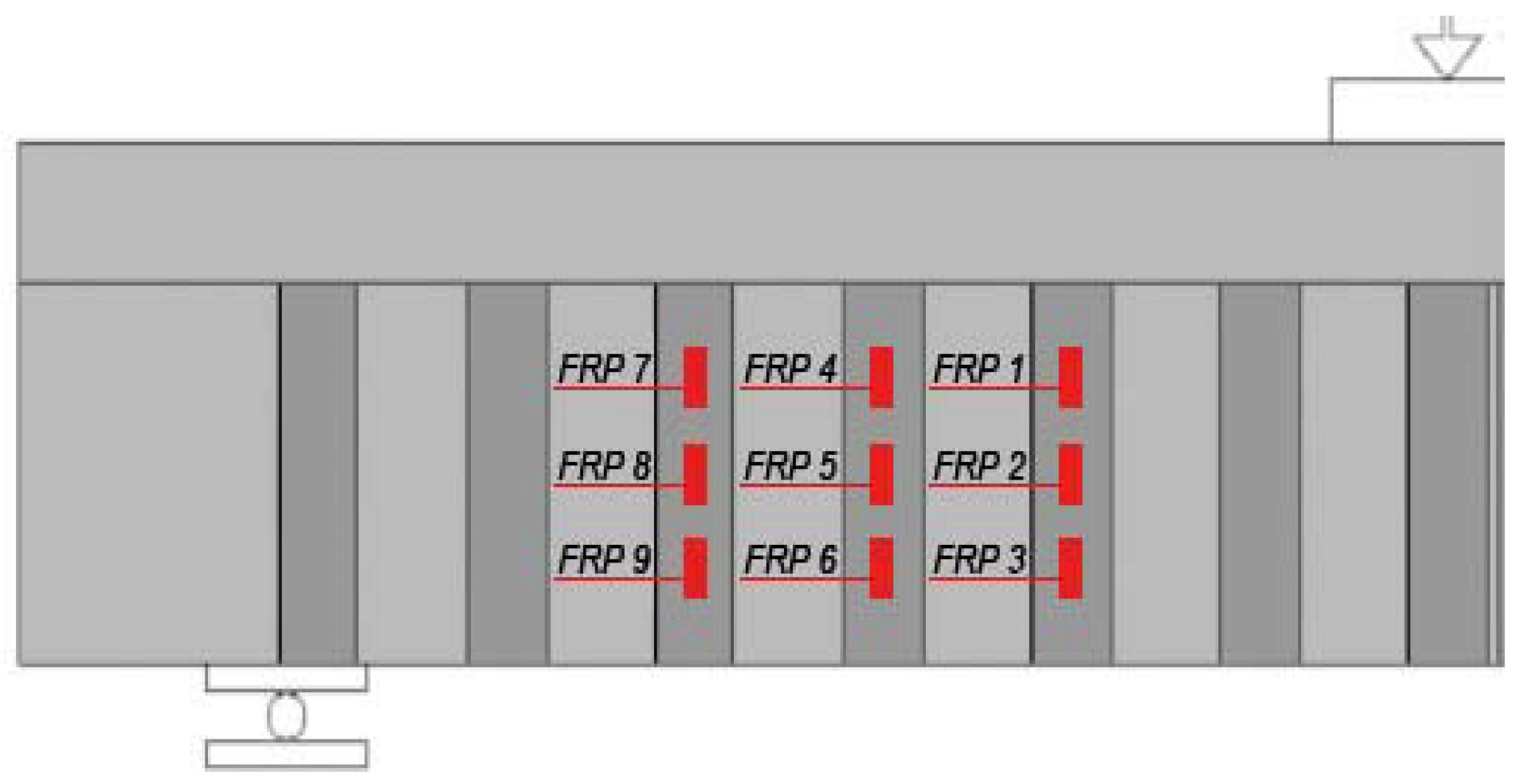




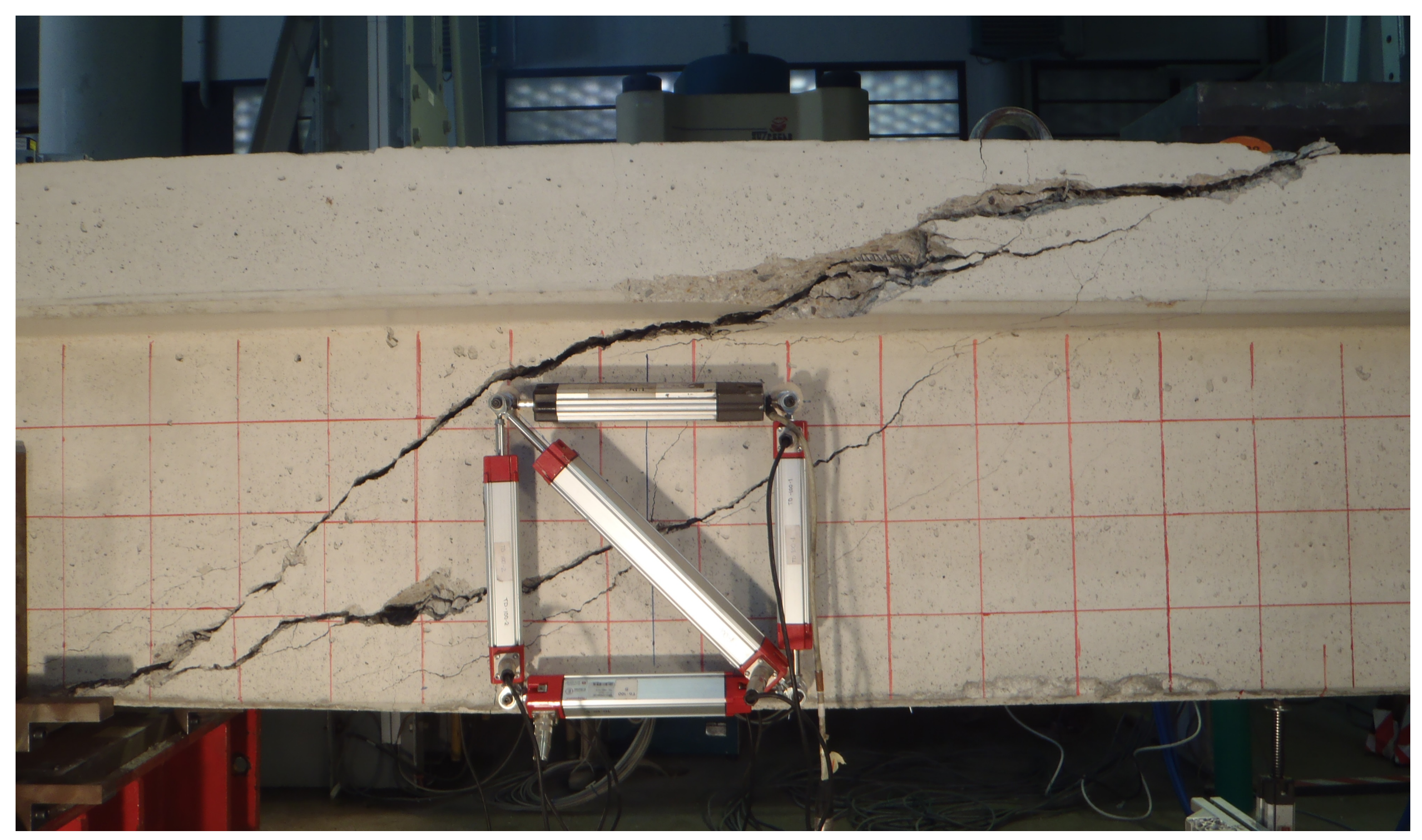




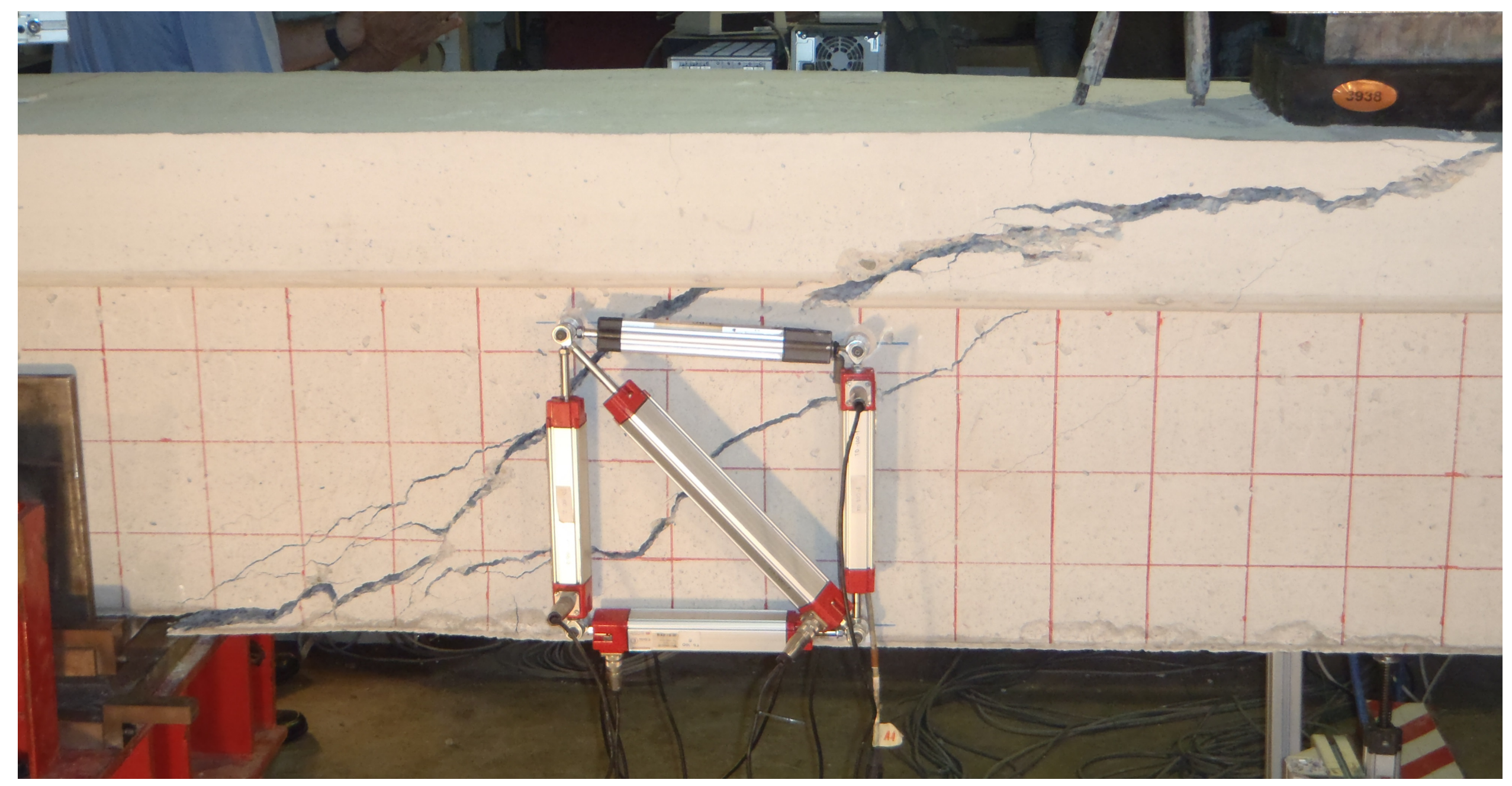




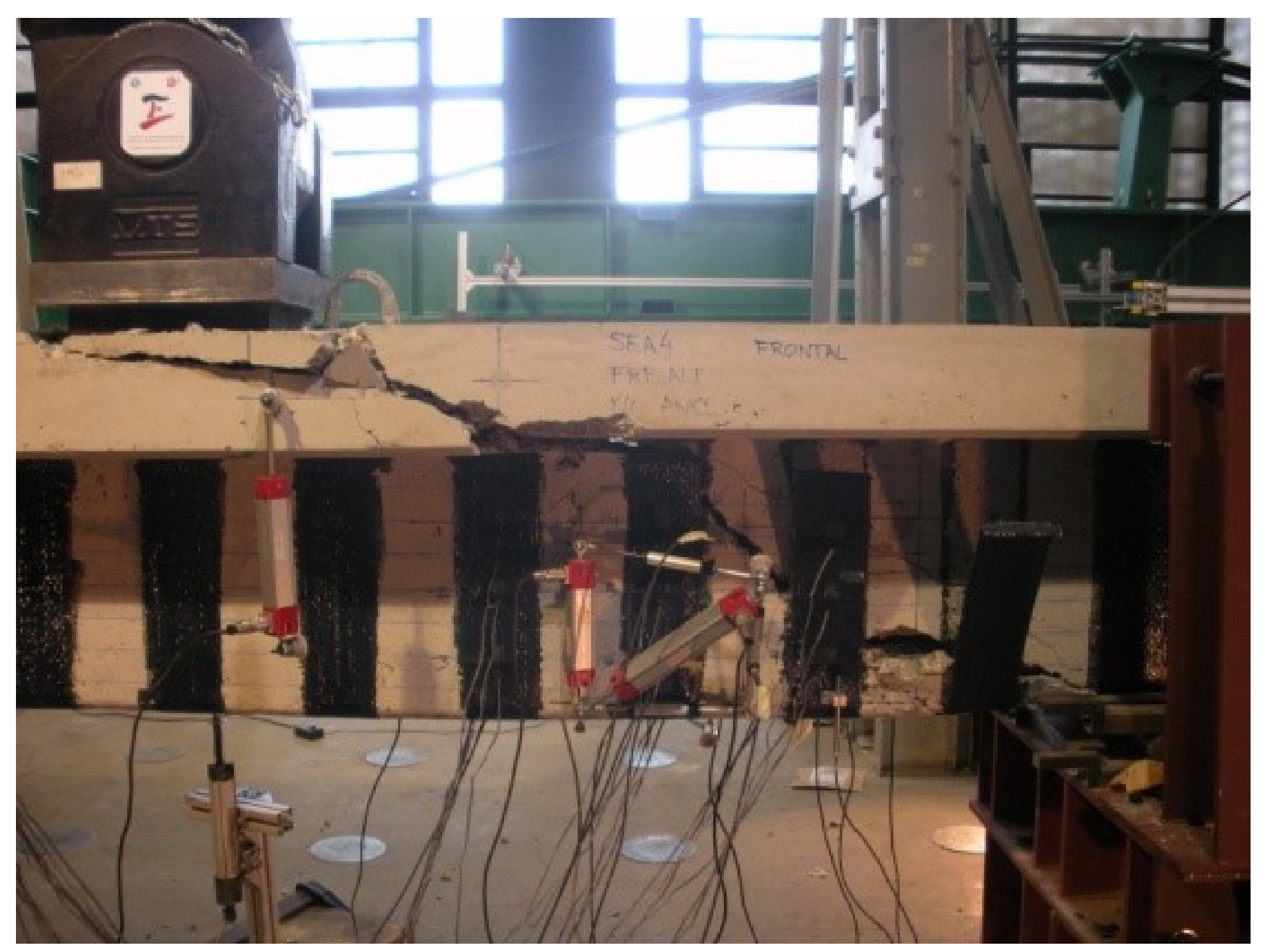




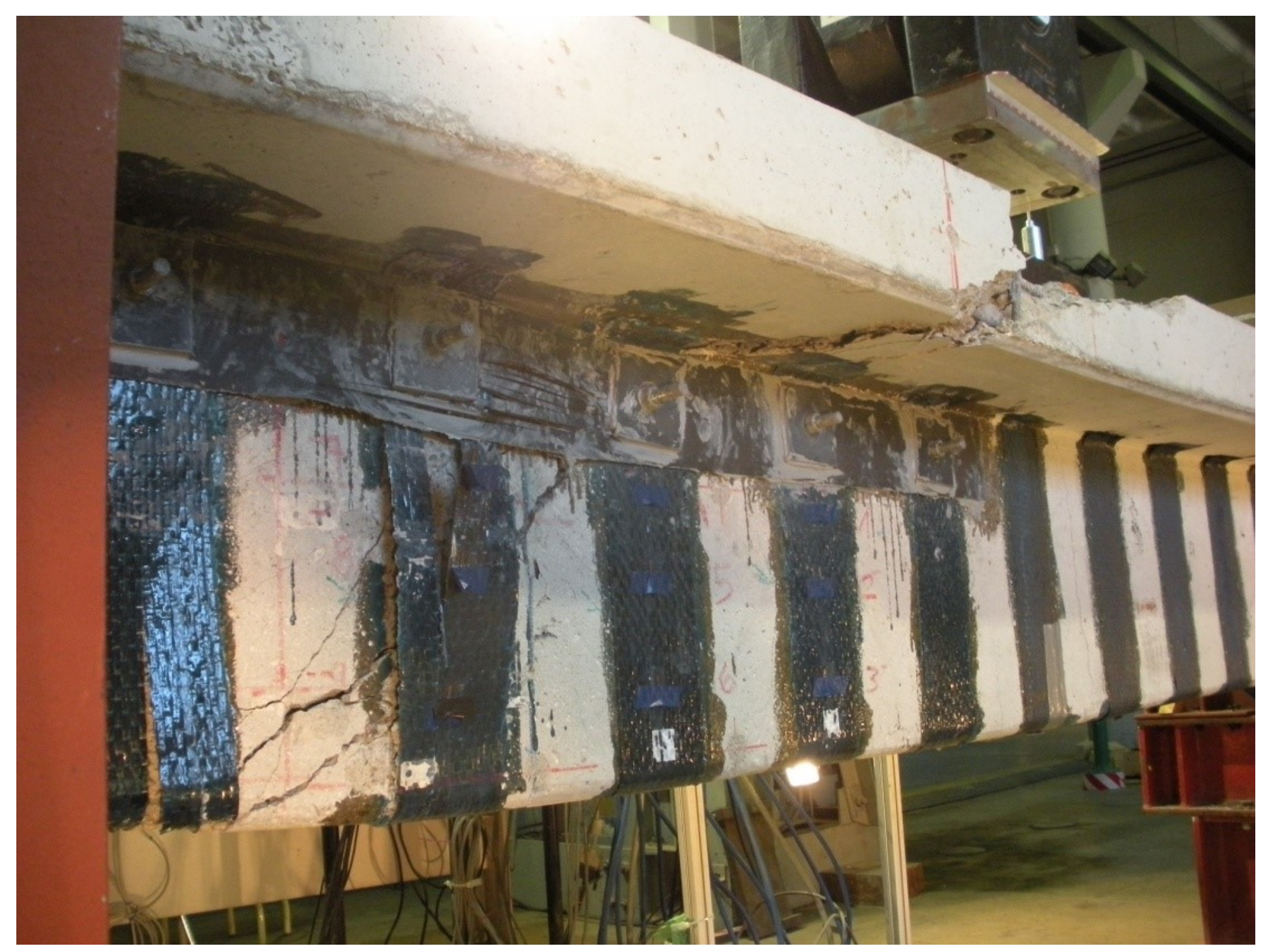




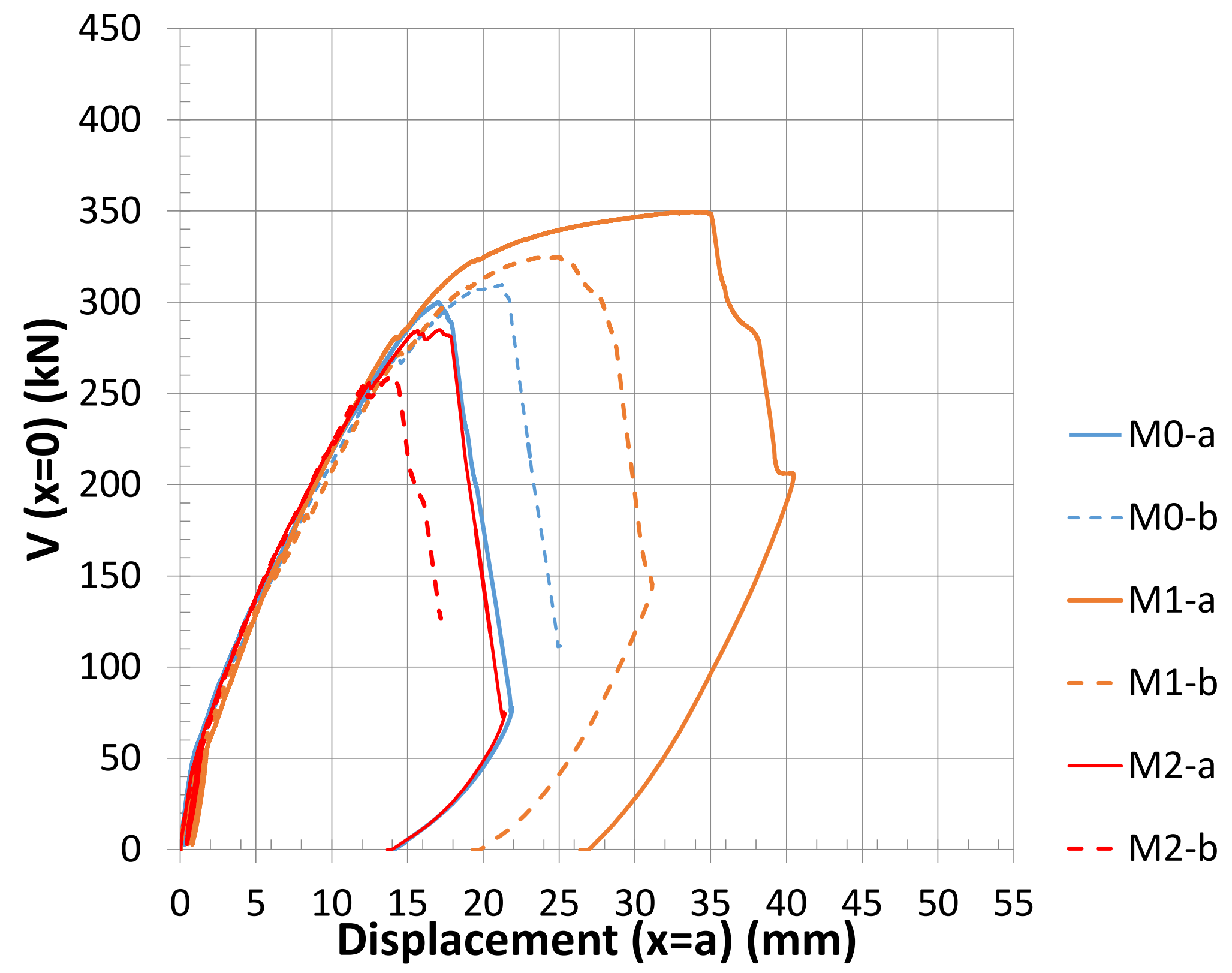




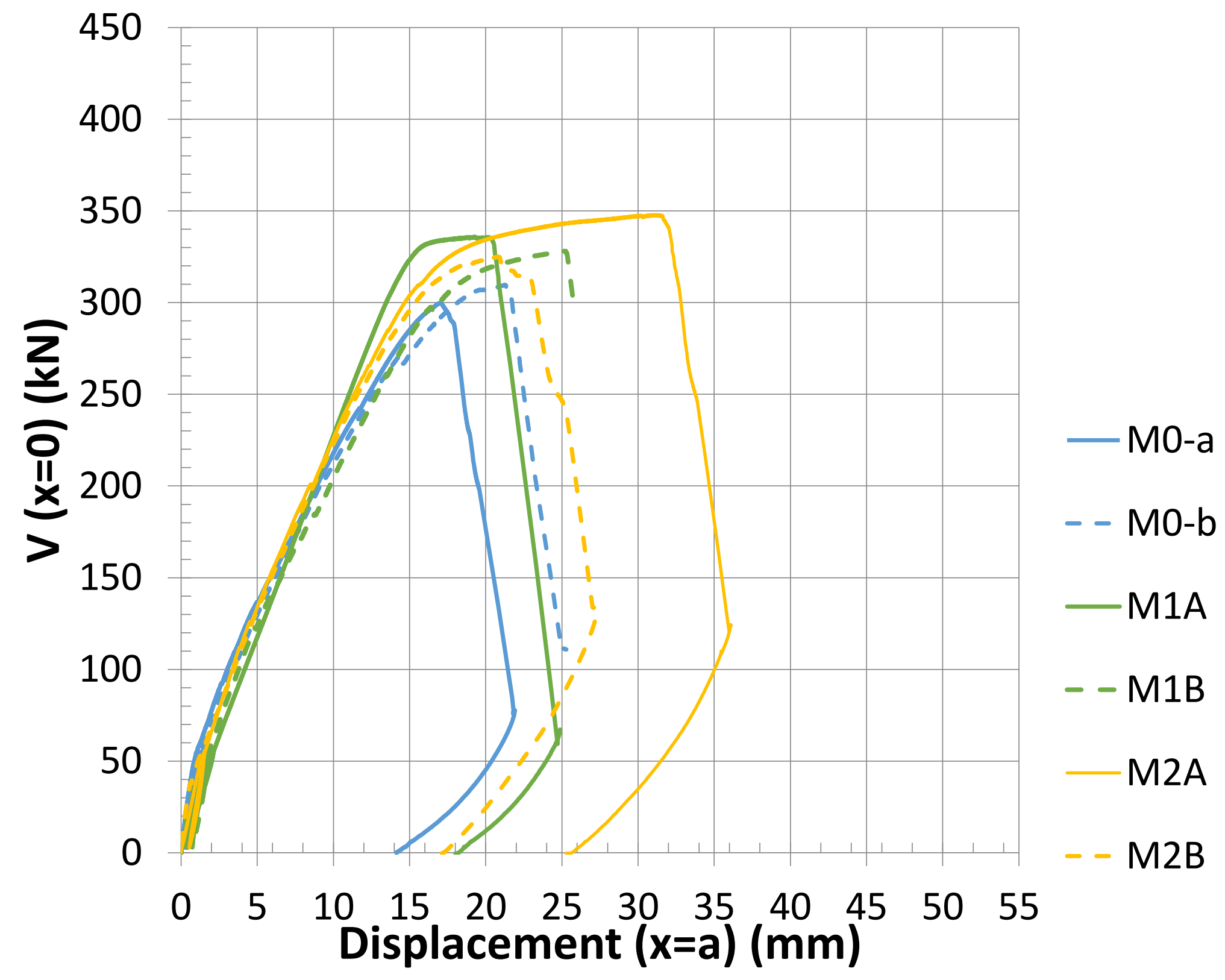




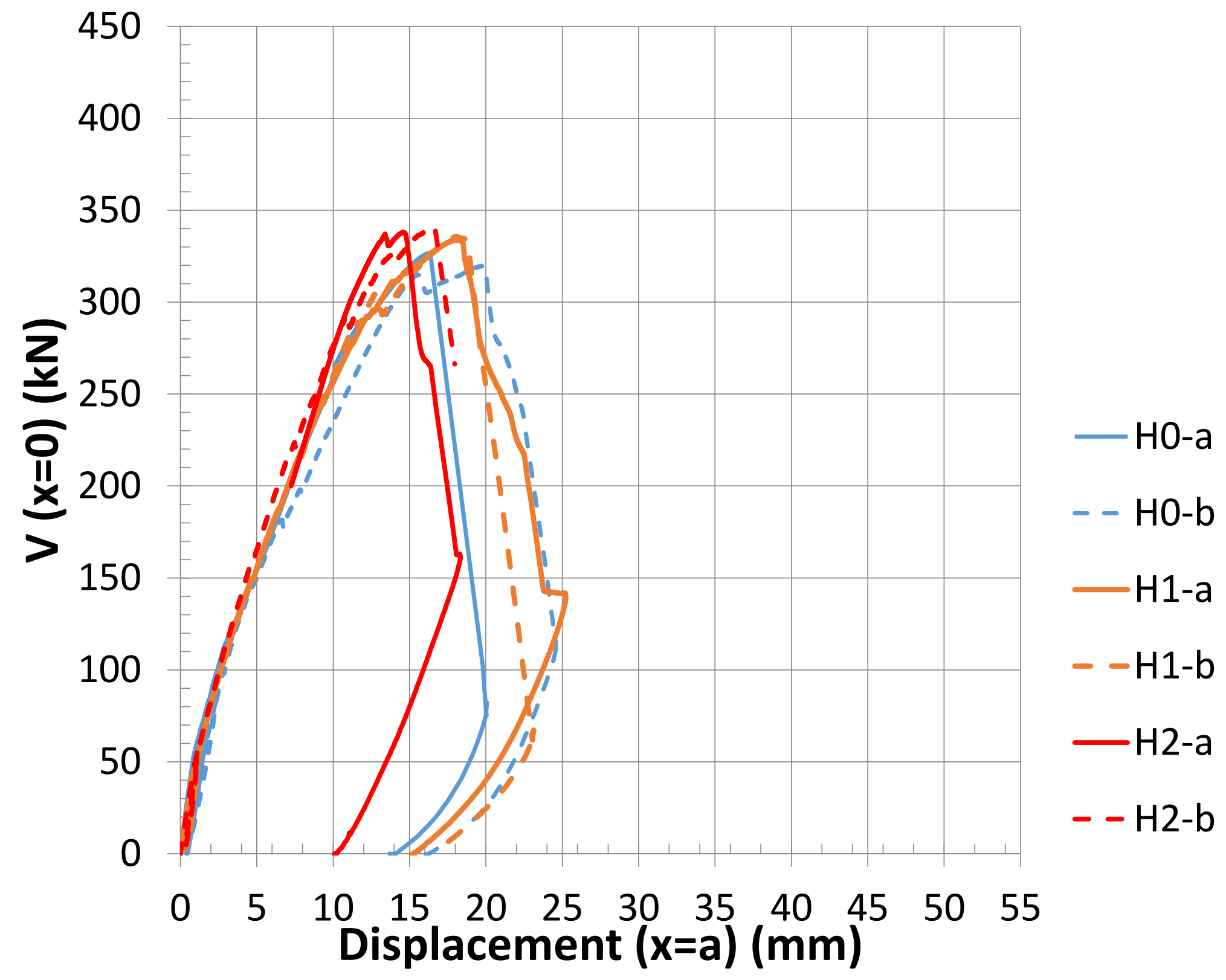




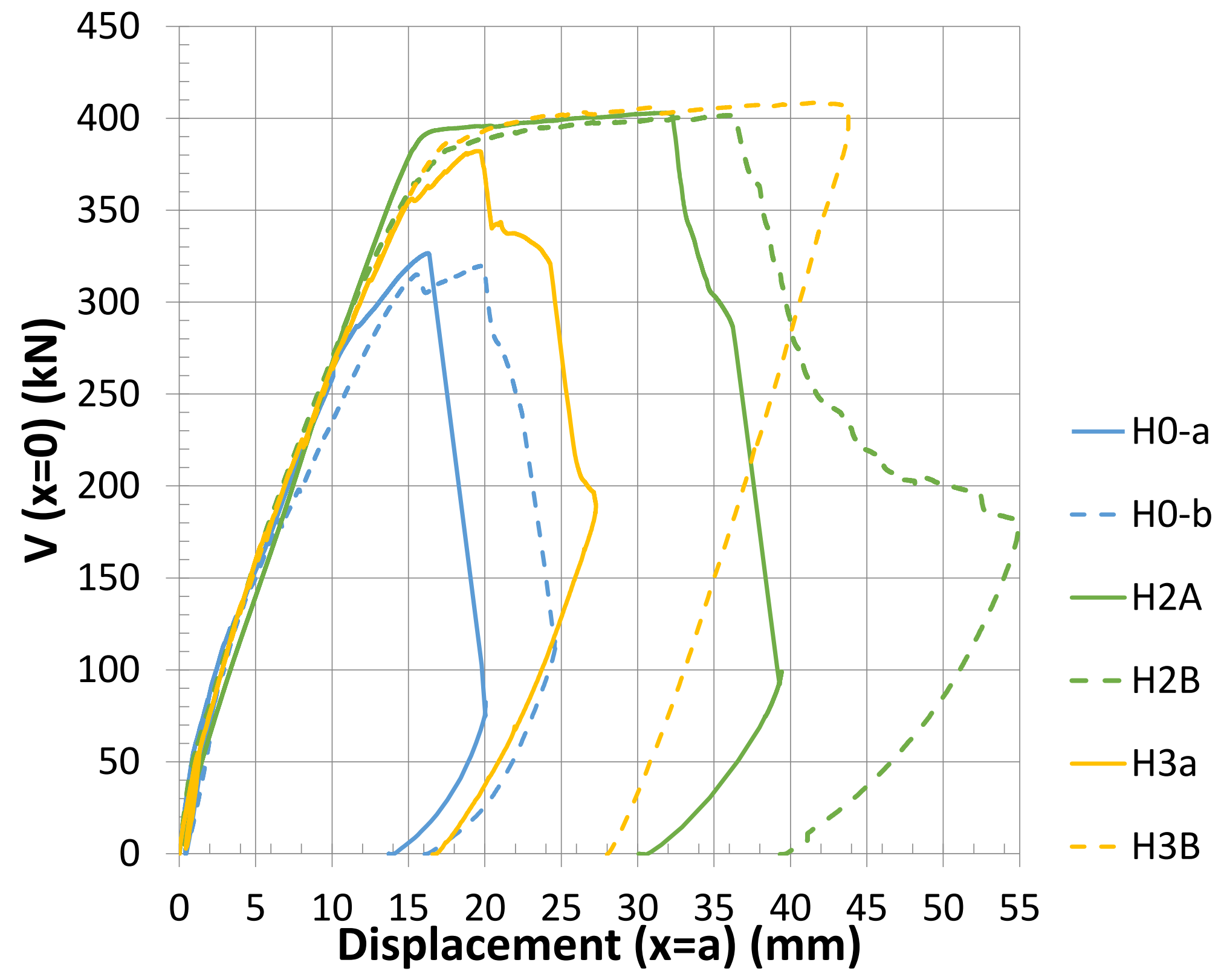



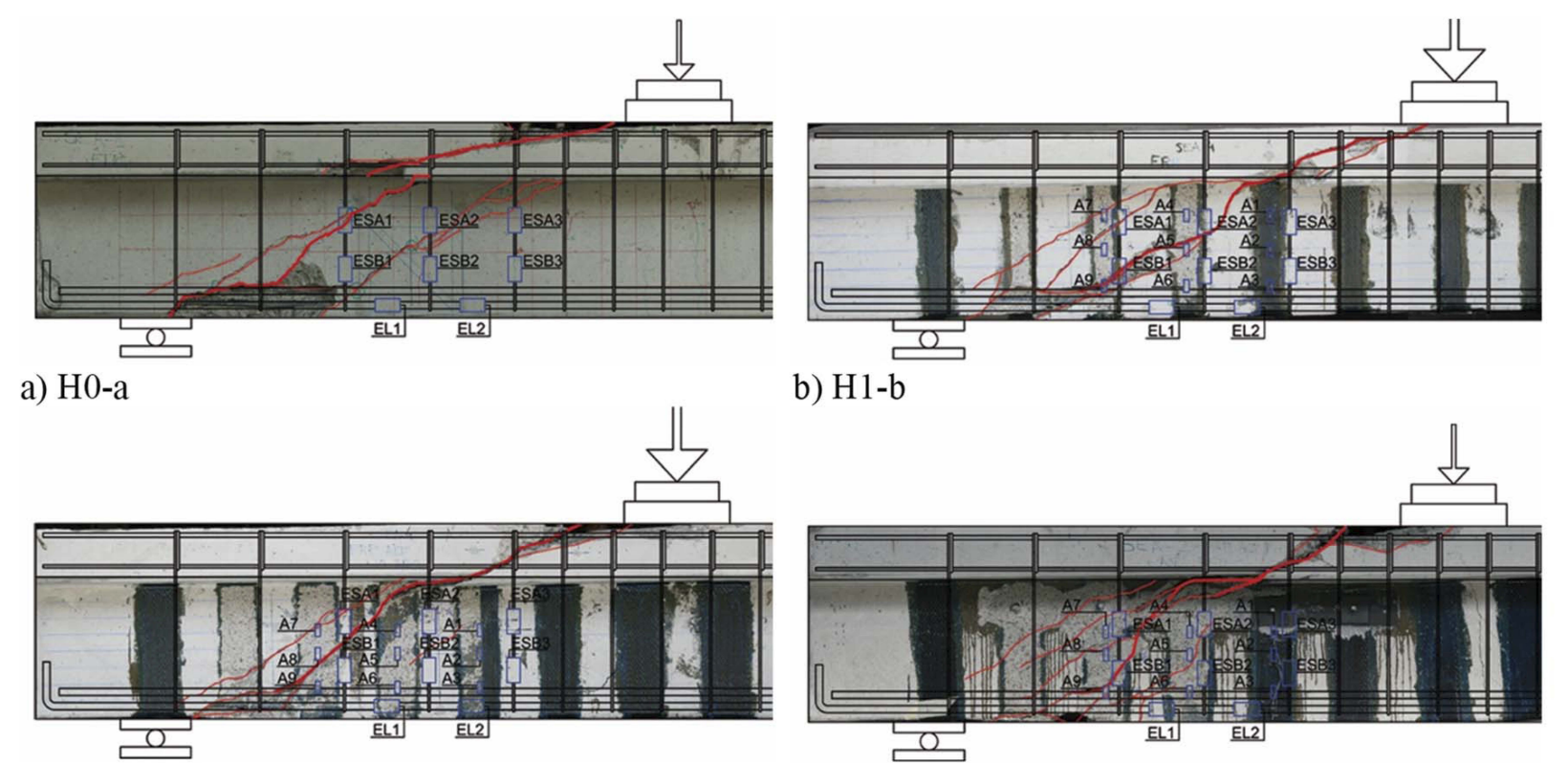

b) H1-b

c) $\mathrm{H} 2-\mathrm{b}$

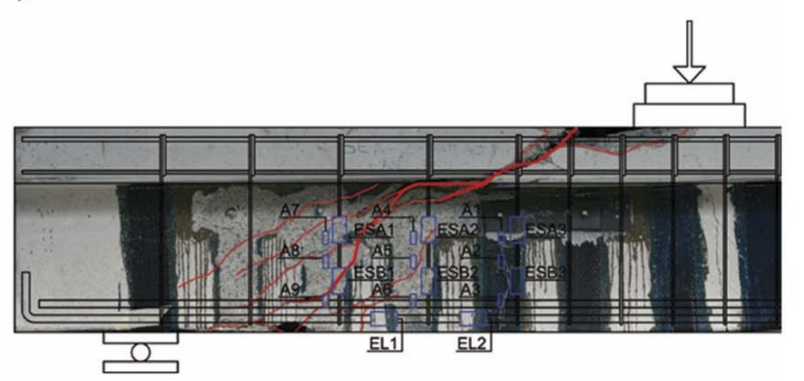

d) $\mathrm{H} 2 \mathrm{~A}$ 


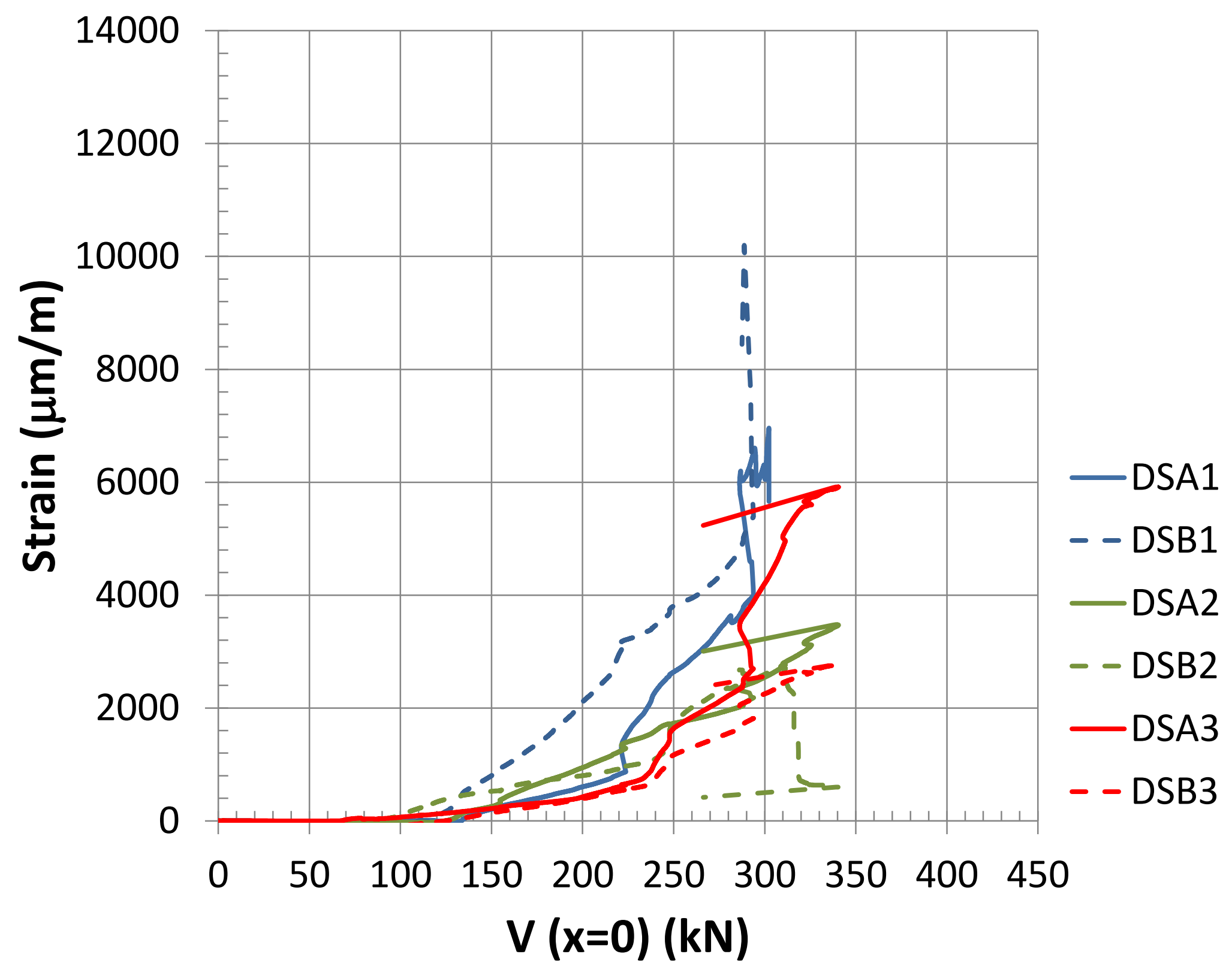




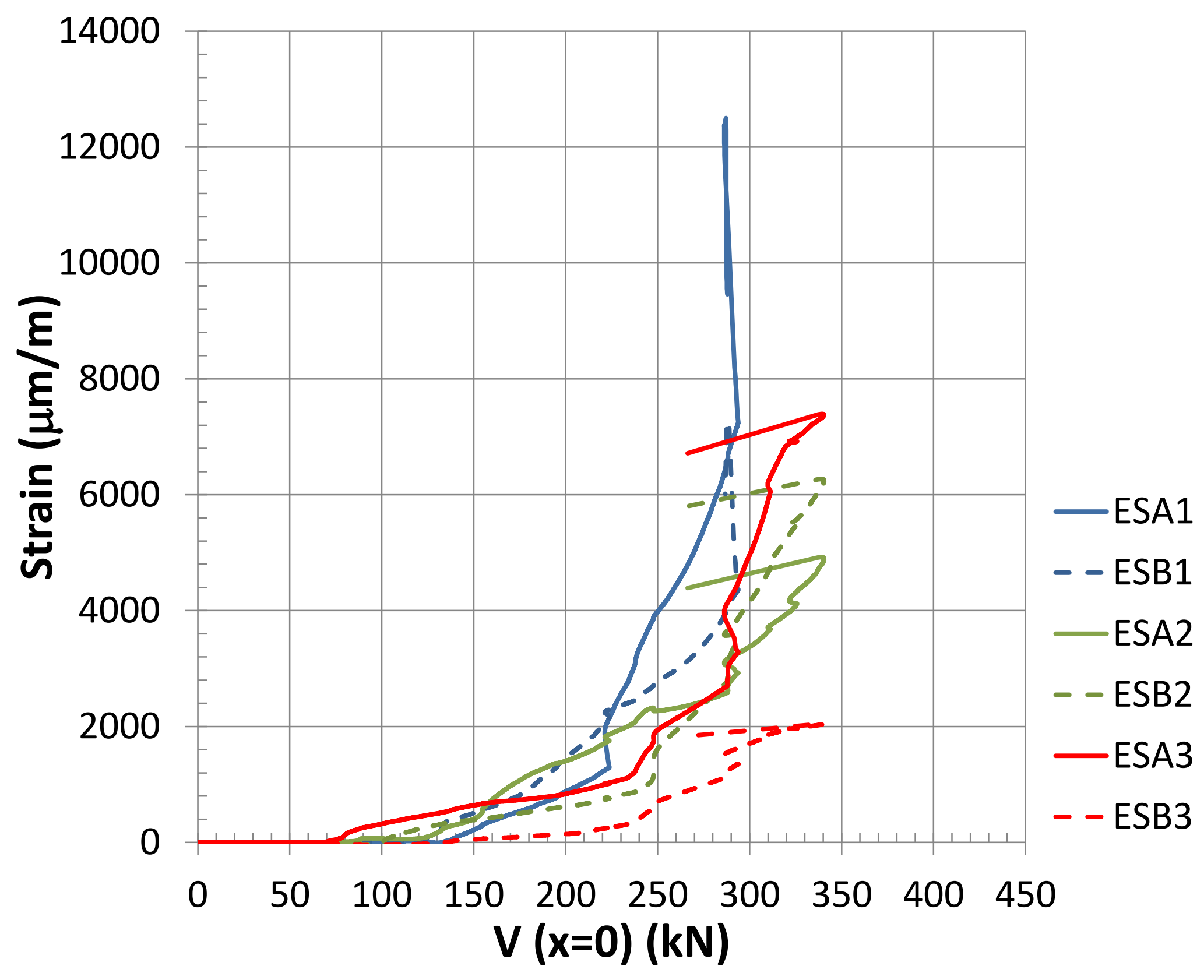




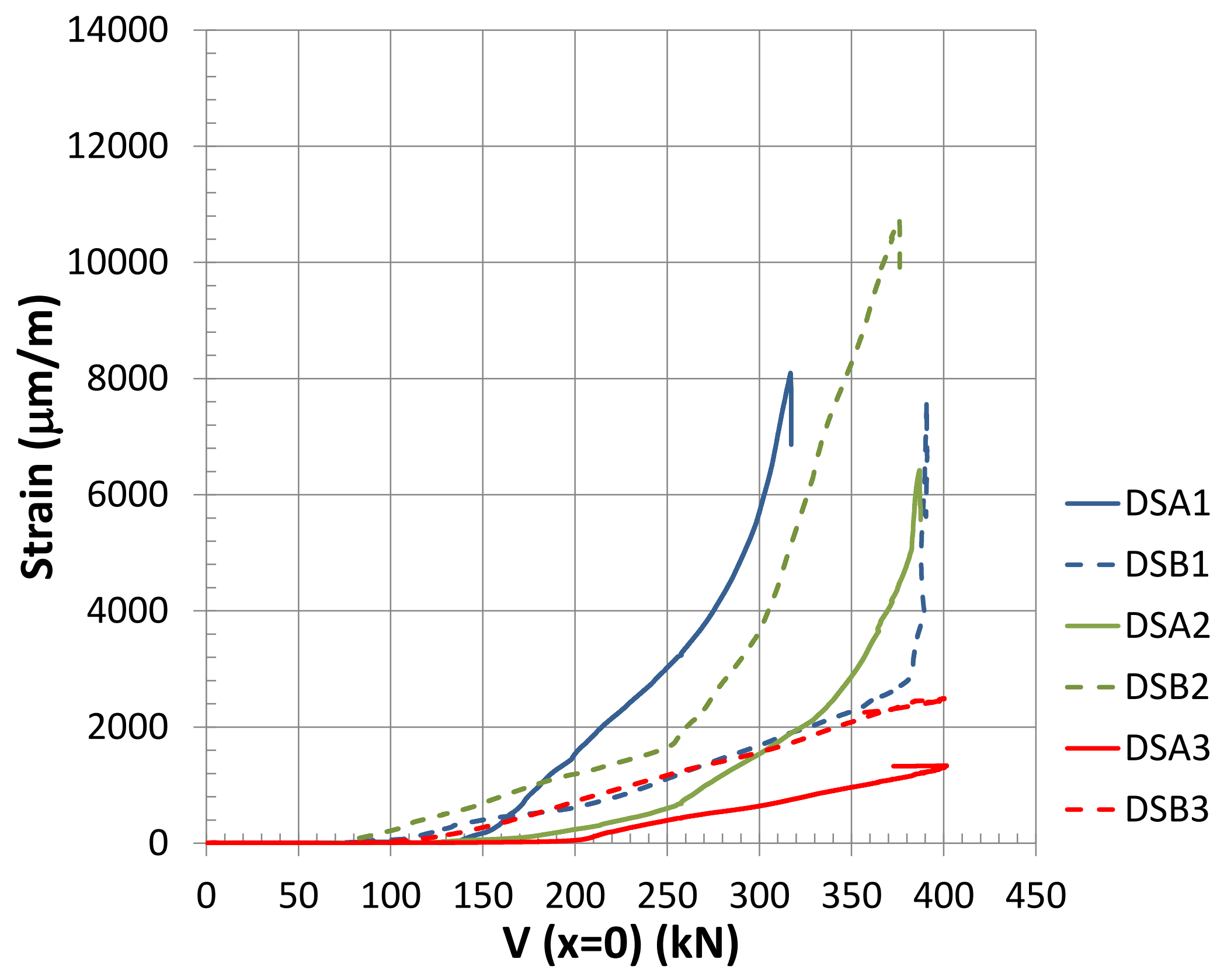




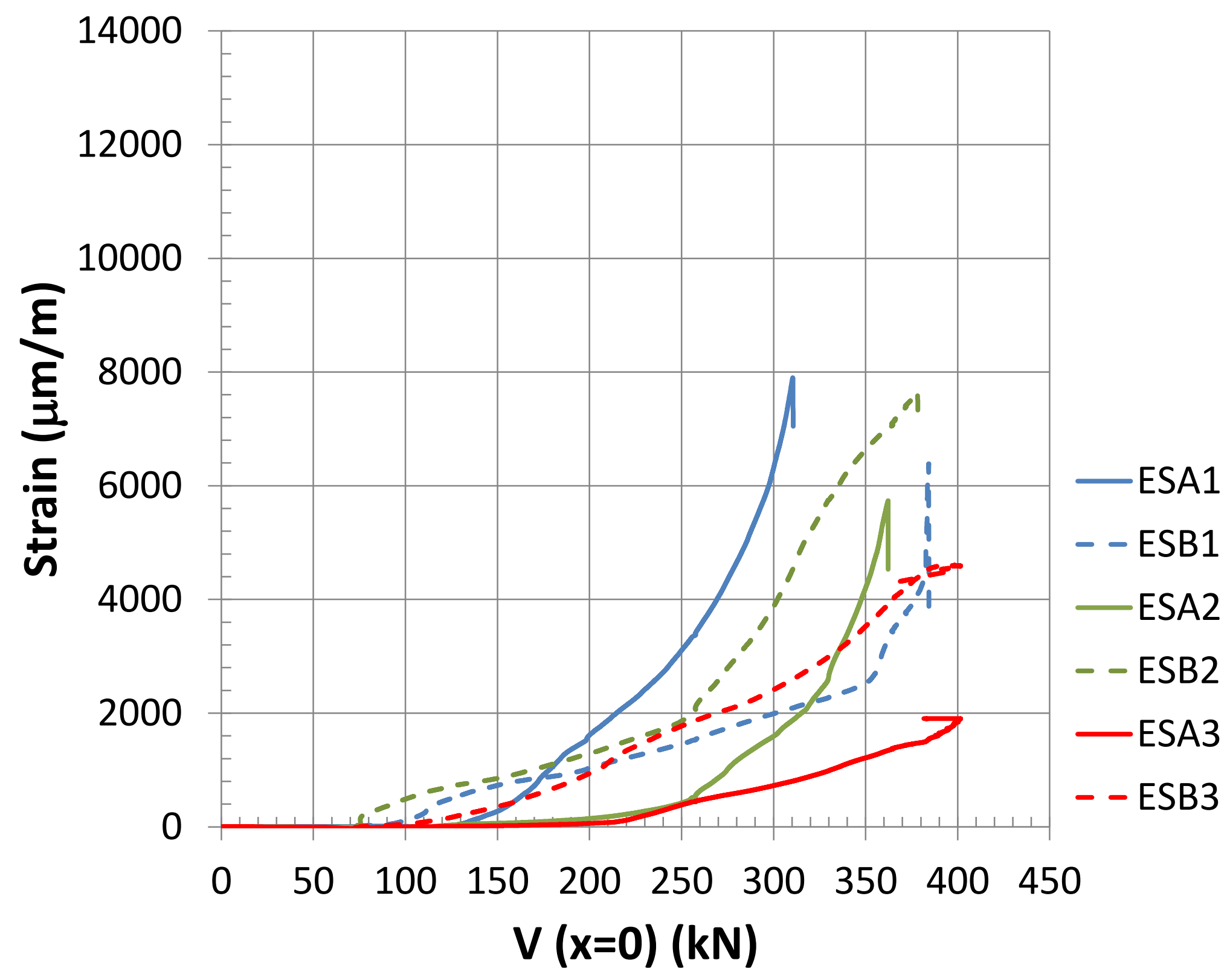




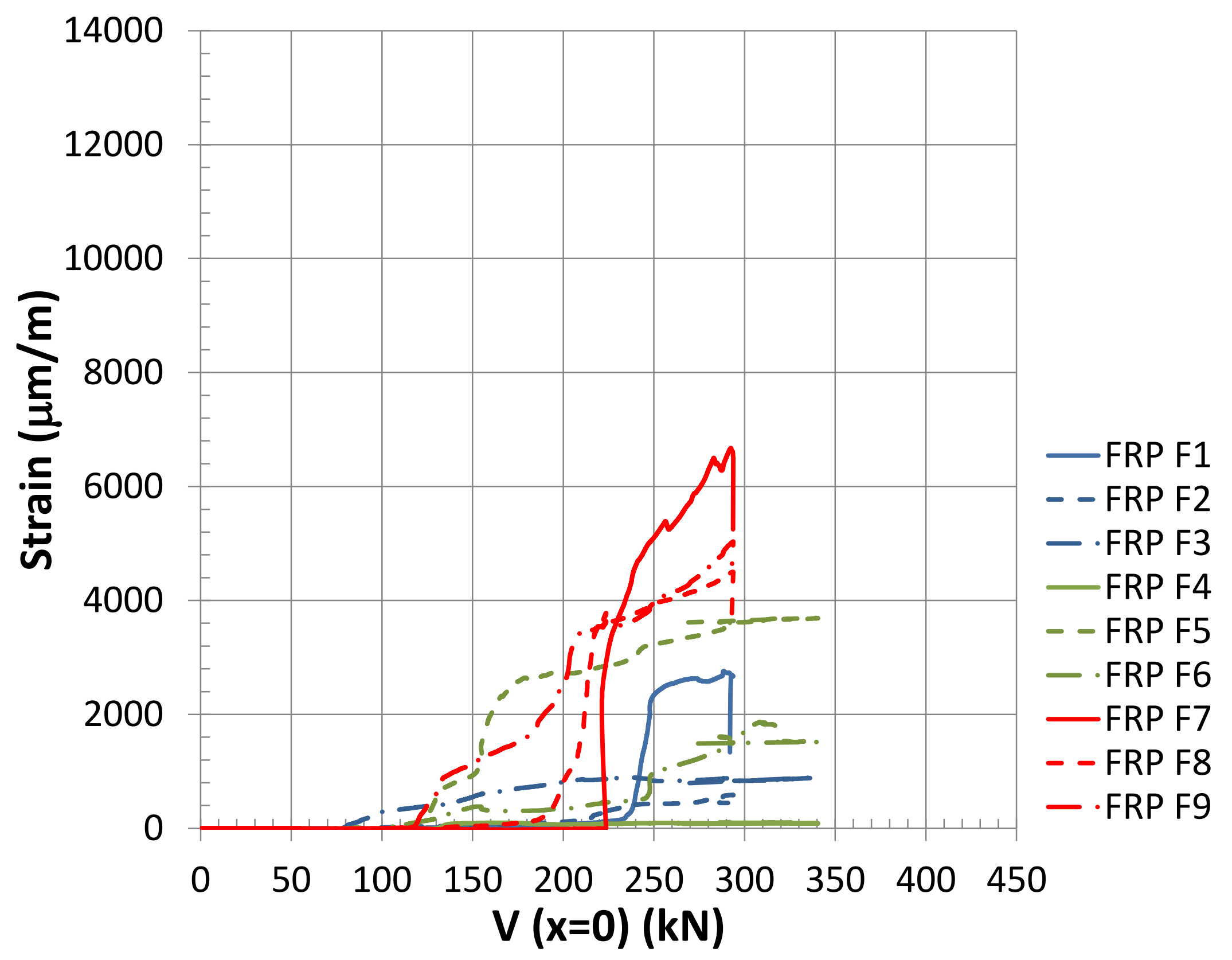




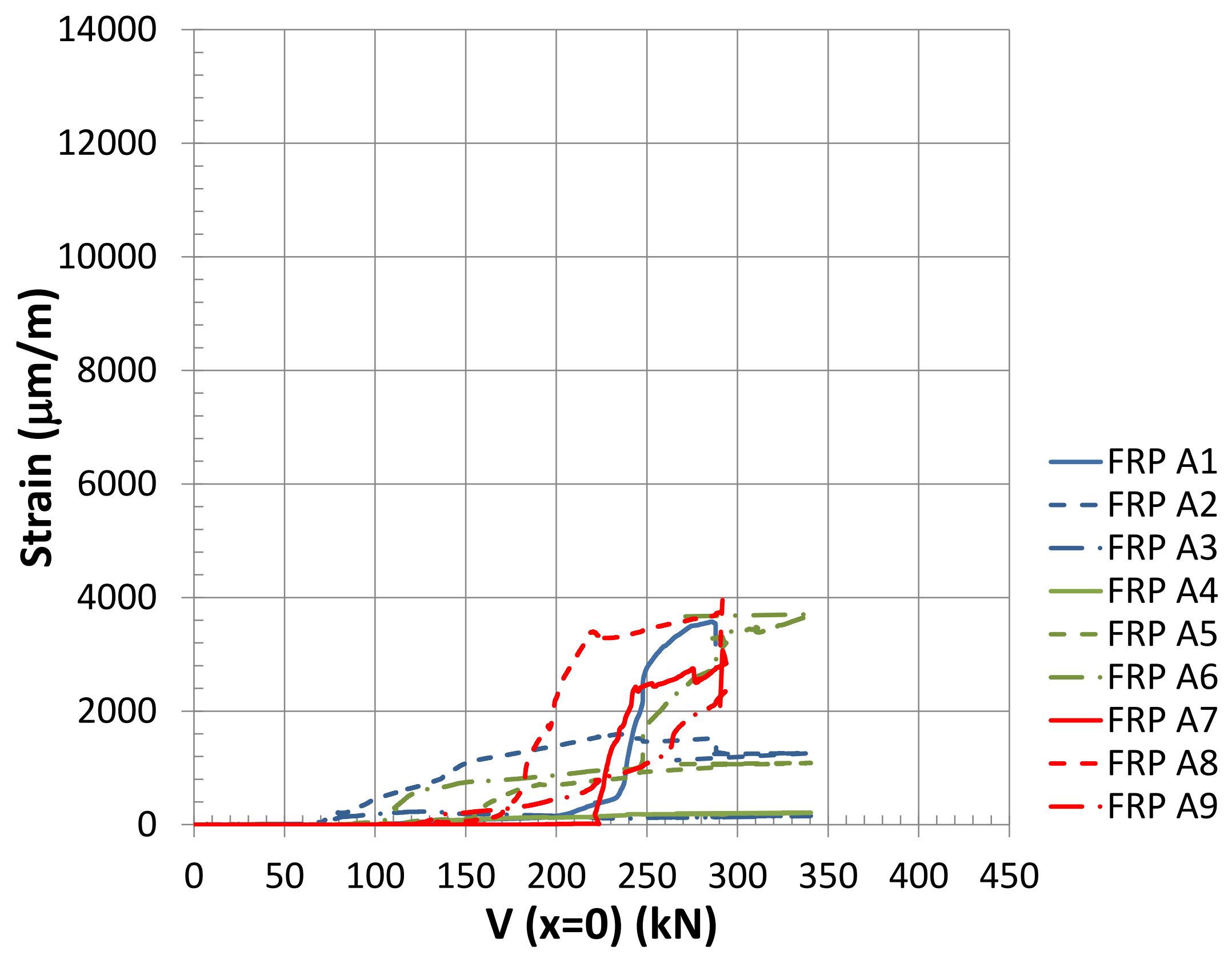




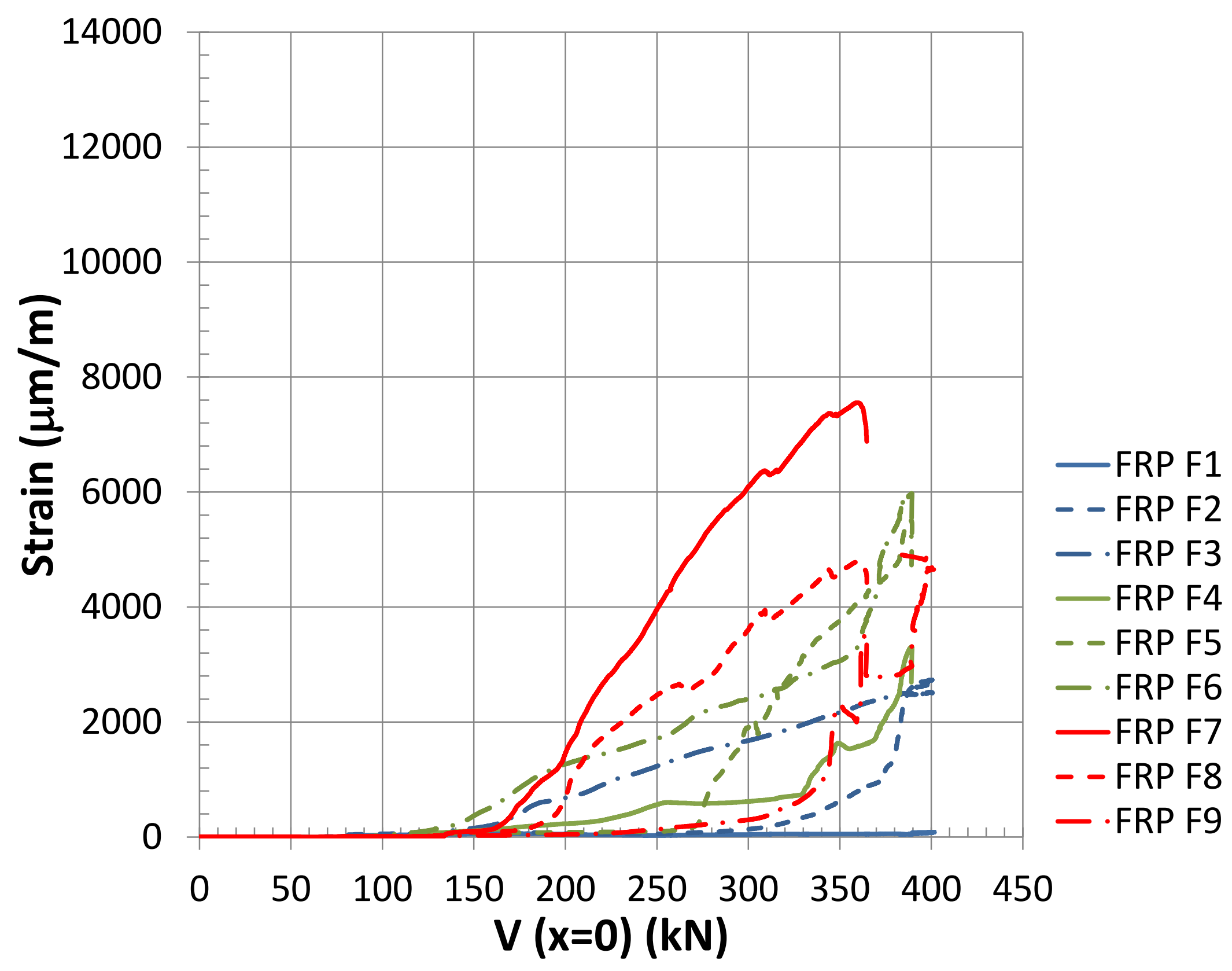




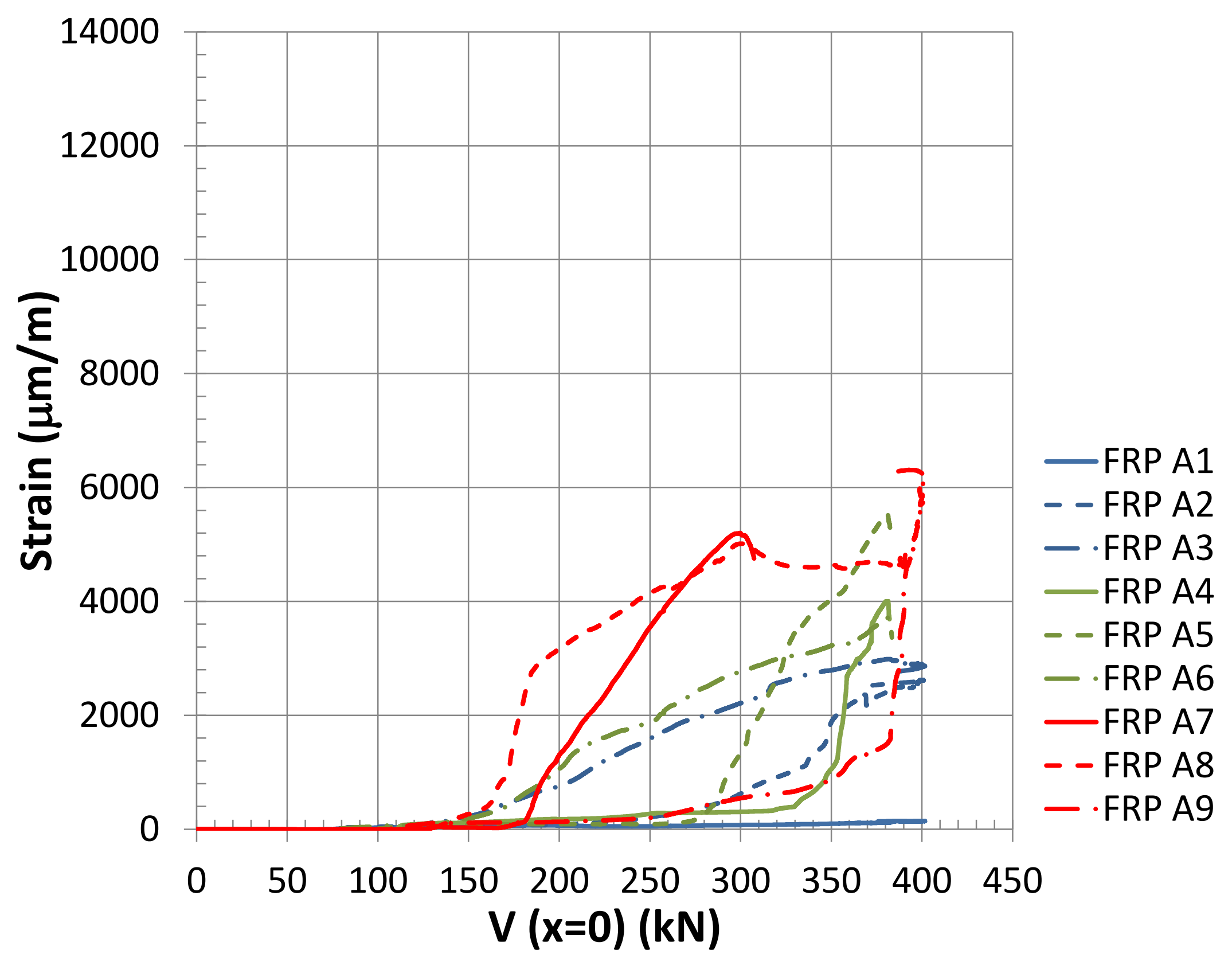




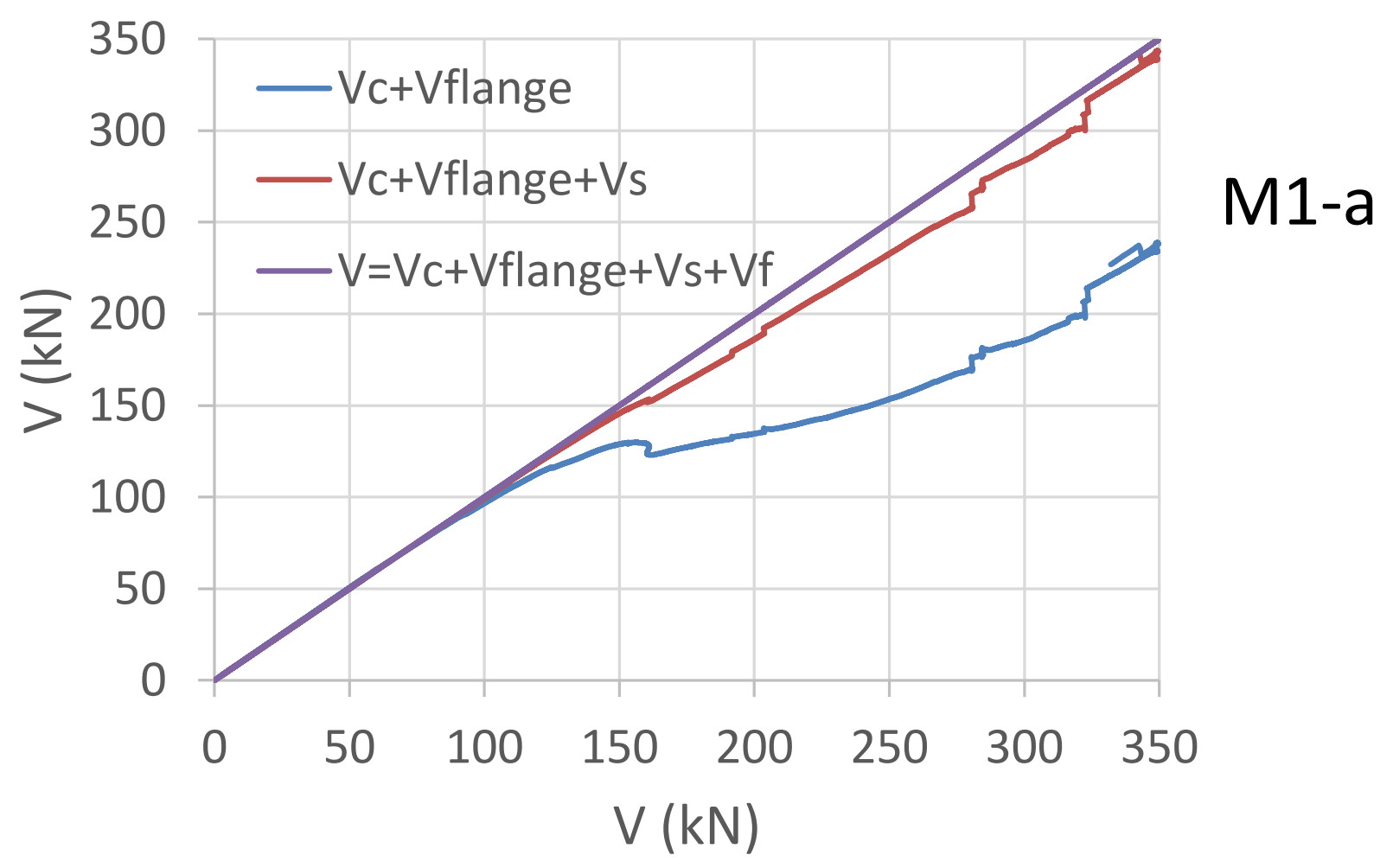




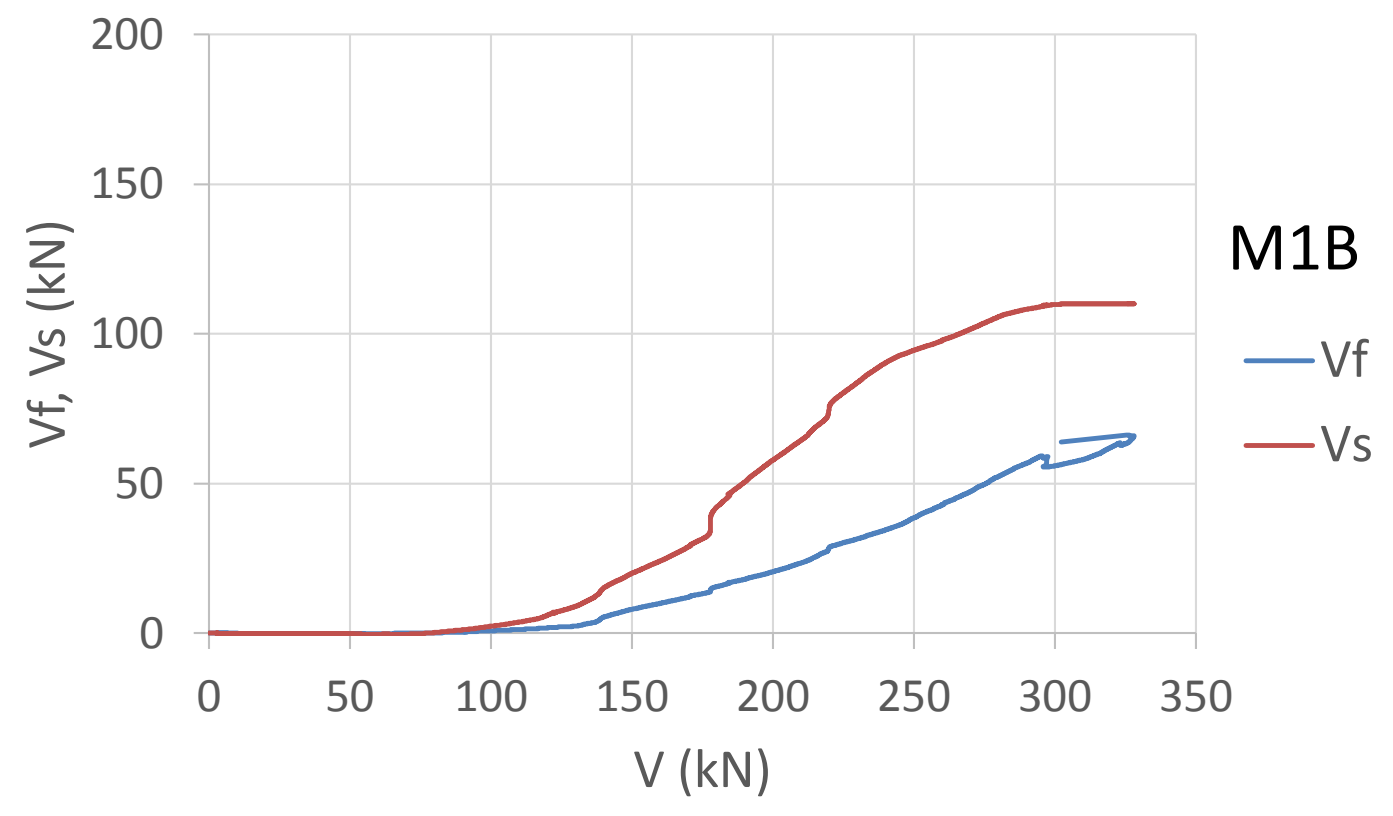




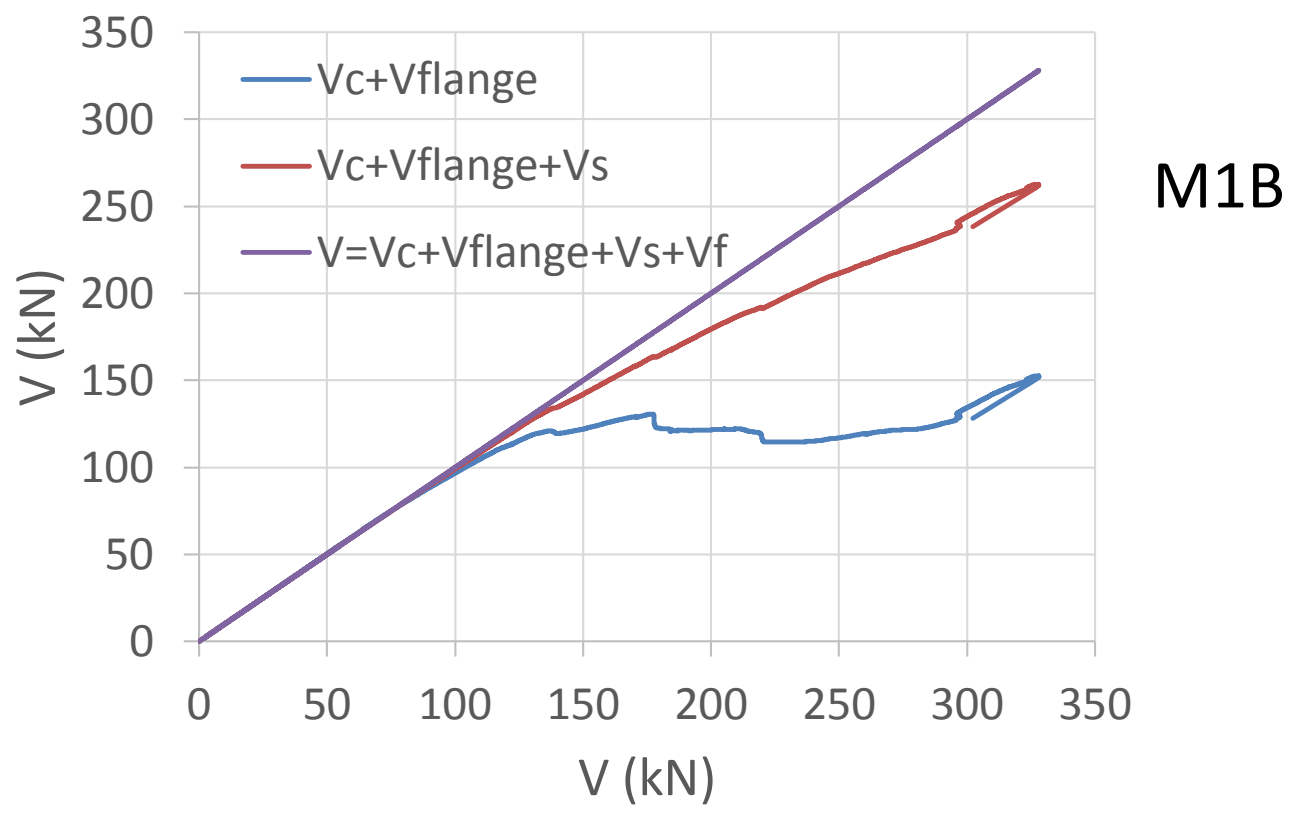



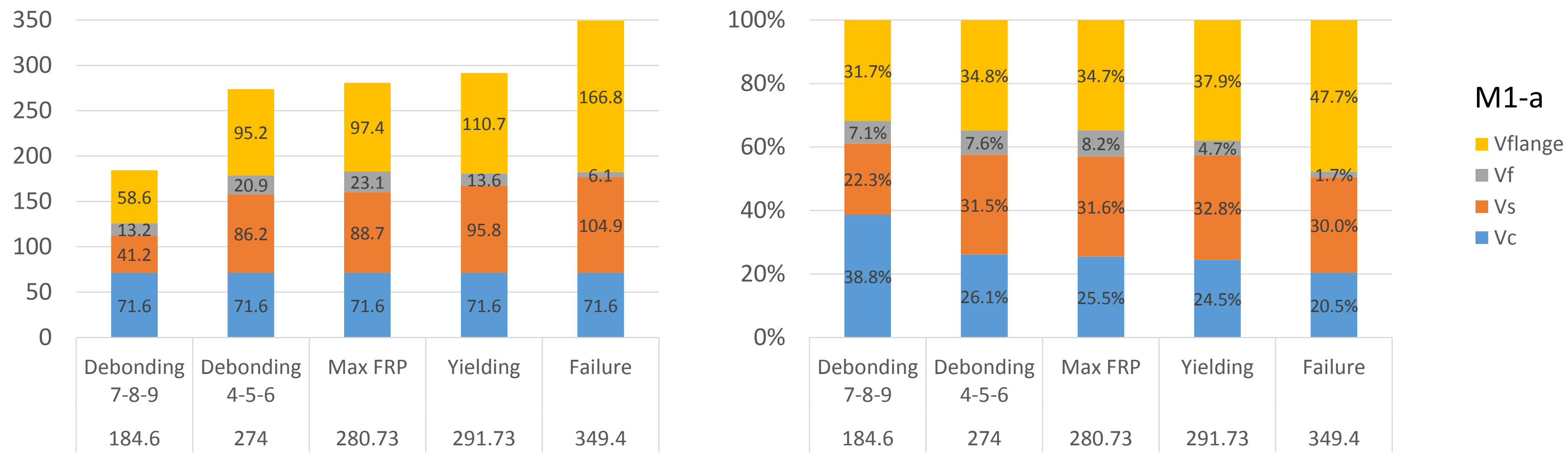

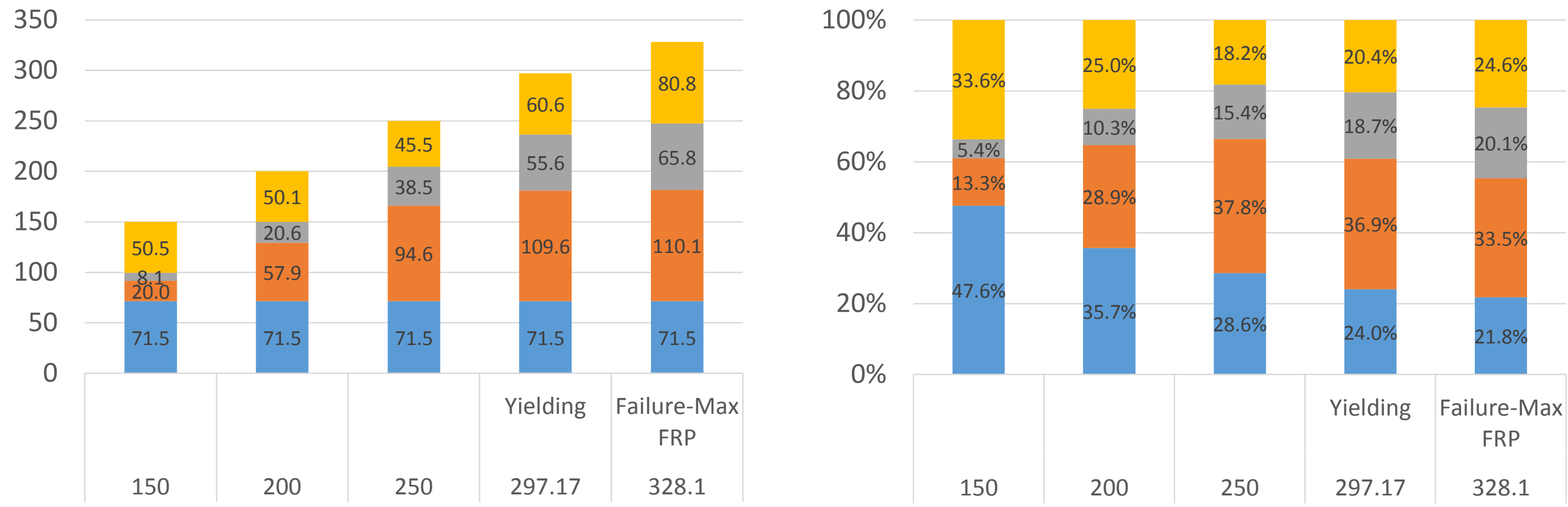

M1B

Vflange

vf

Vs

- Vc 


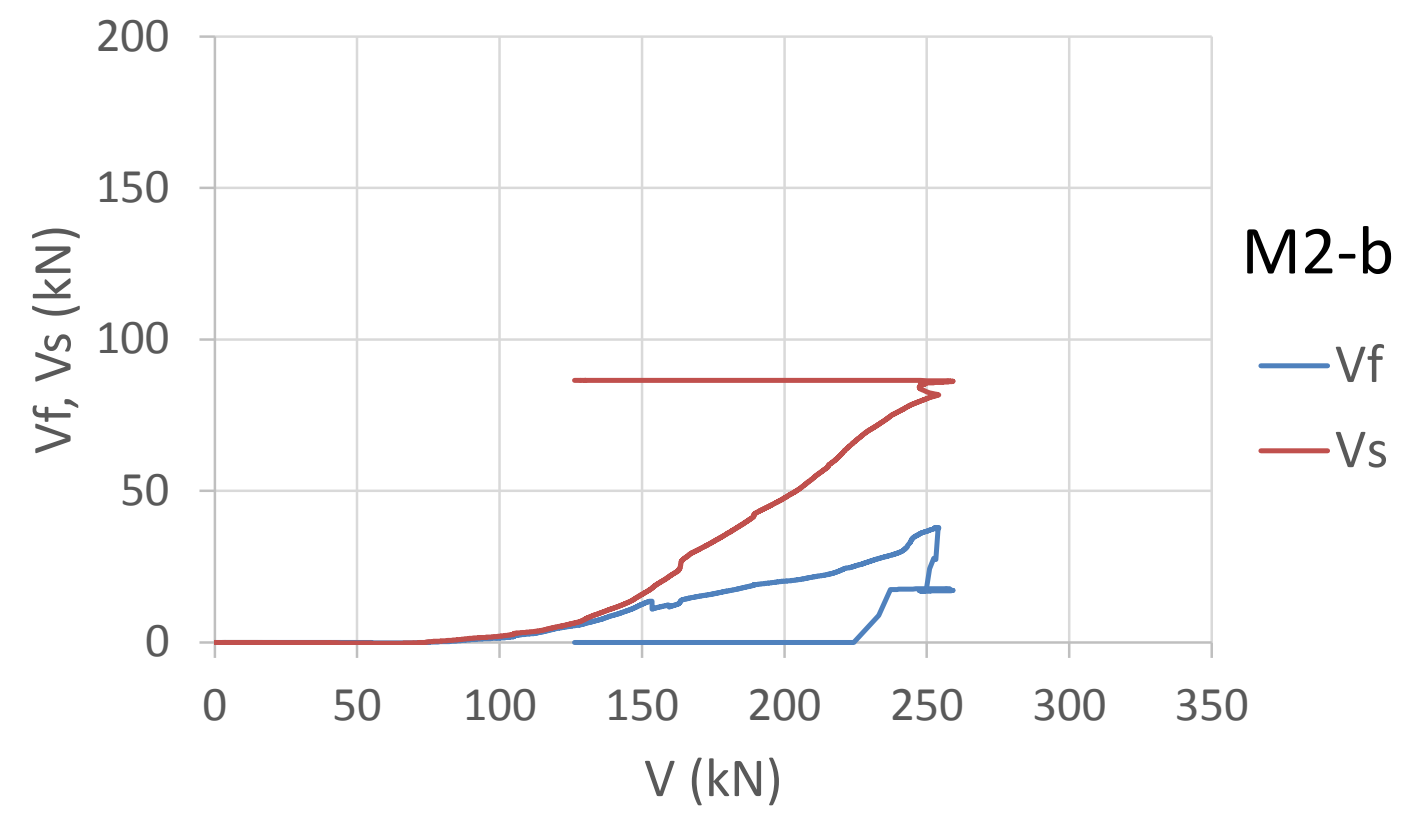




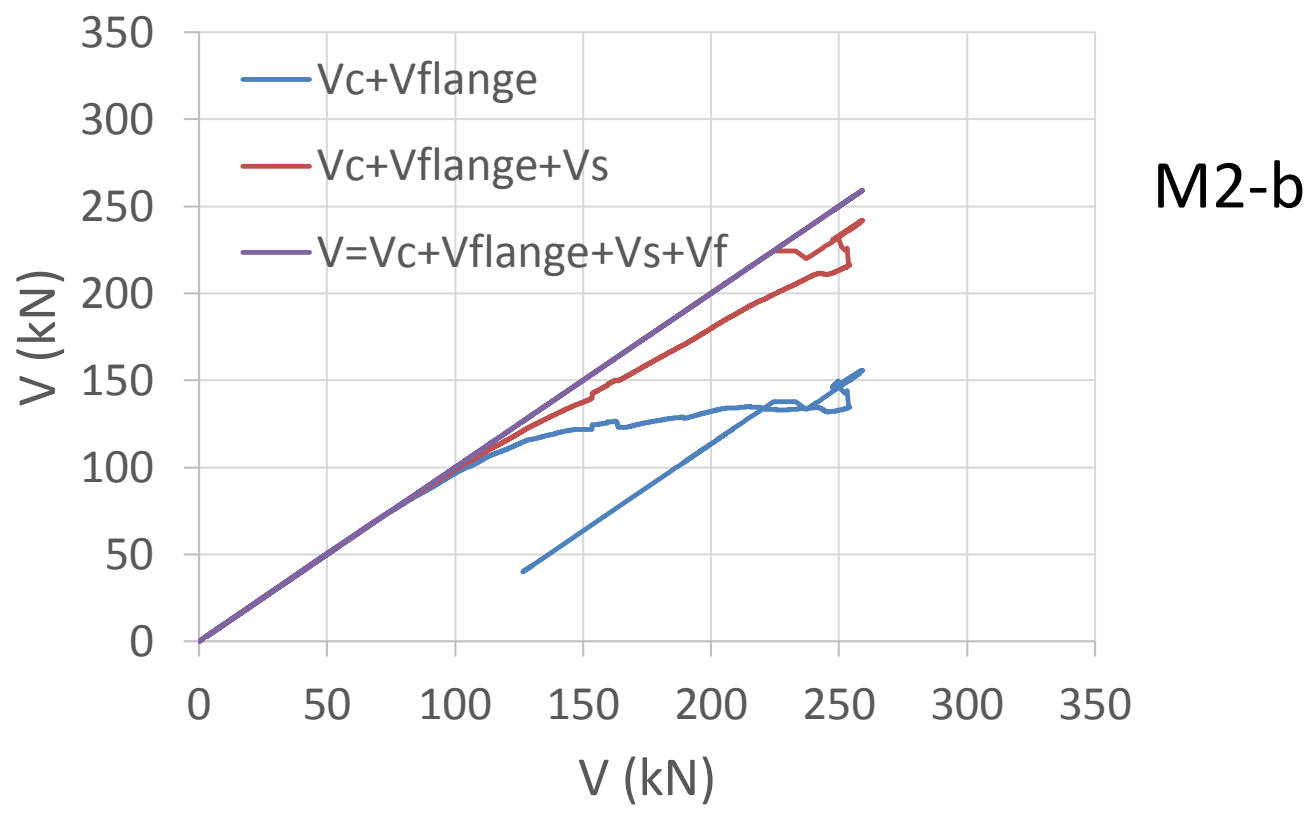




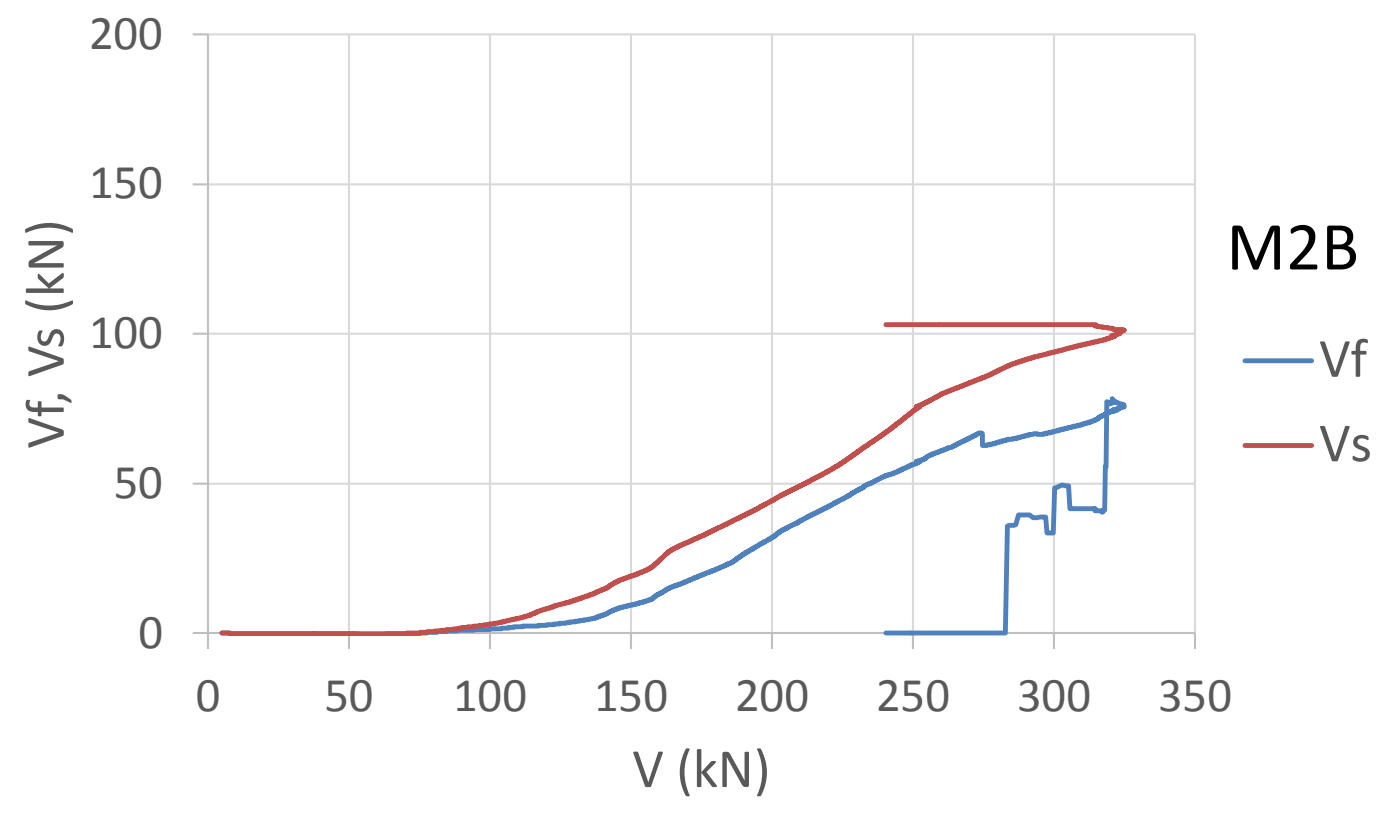




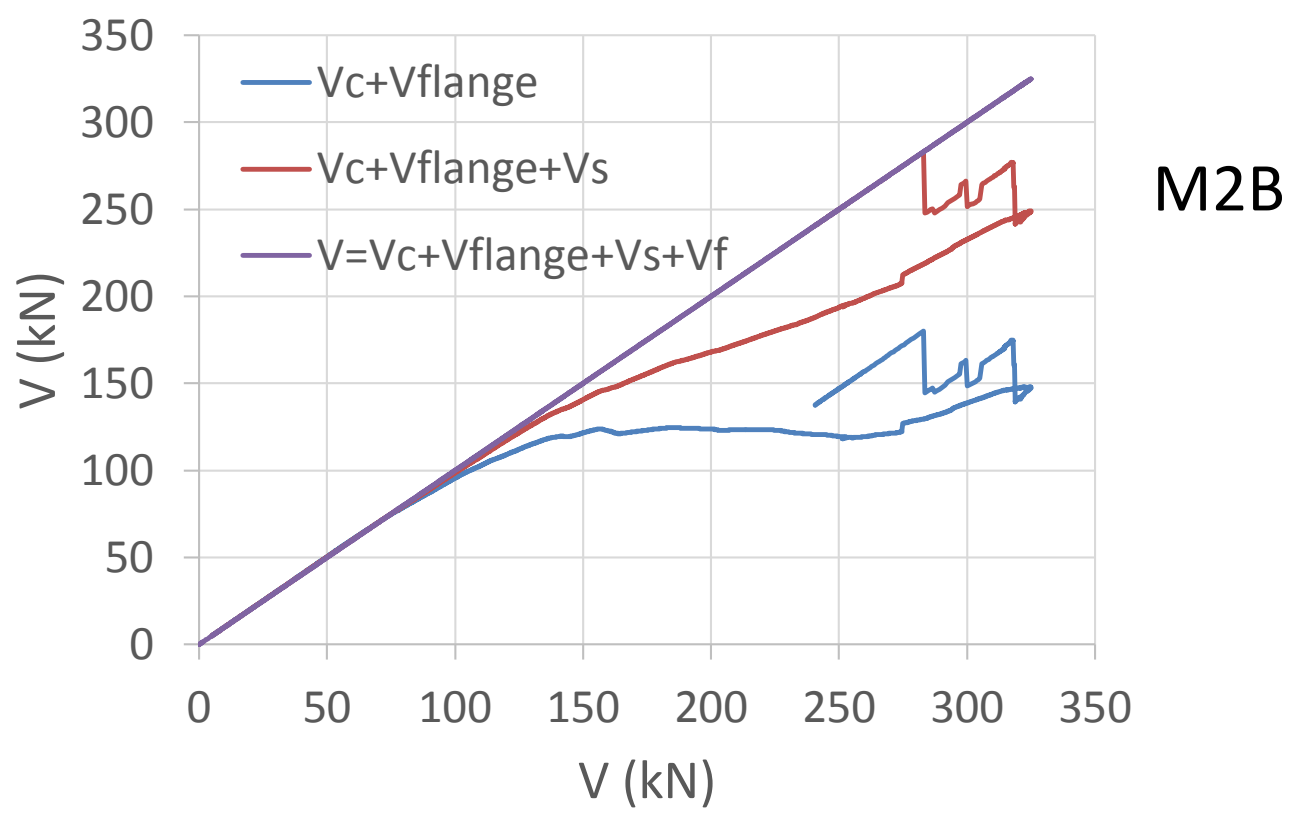



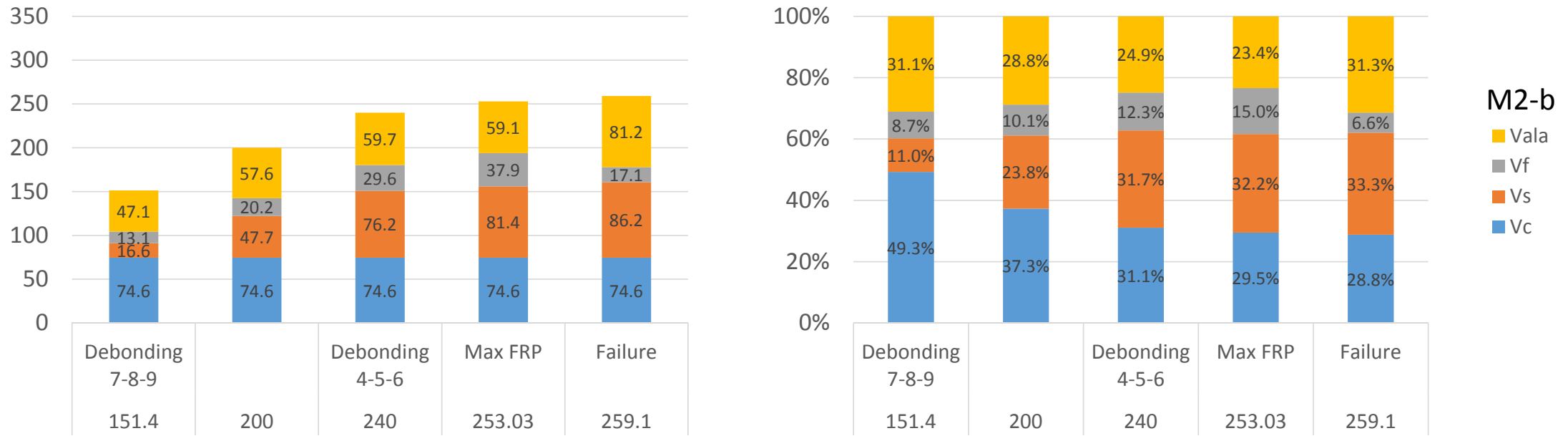

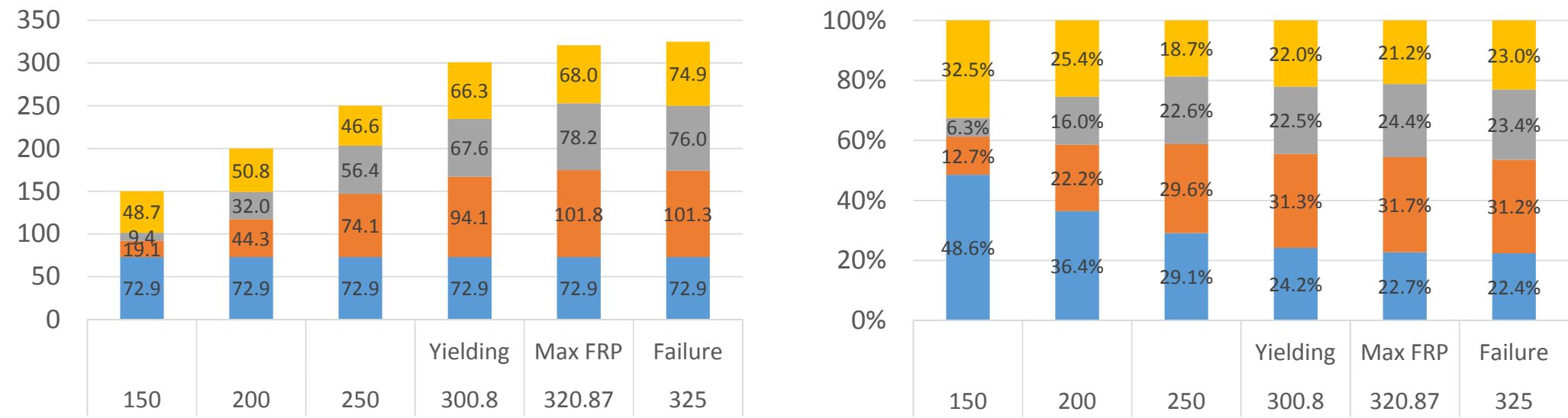

M2B

Vflange - Vf

Vs

Vc 

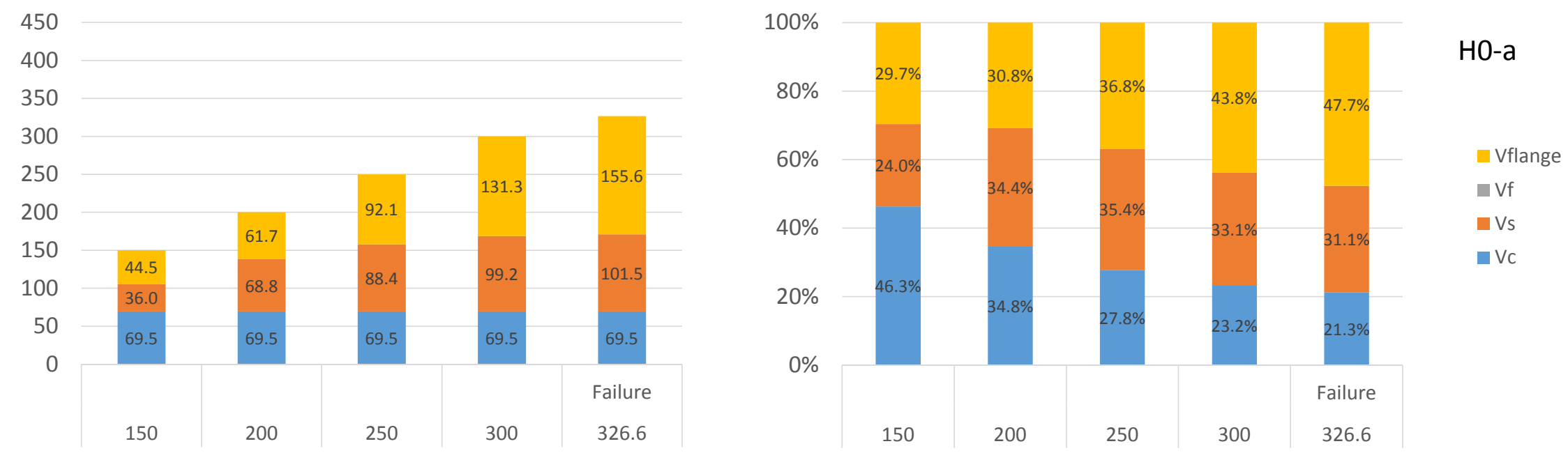


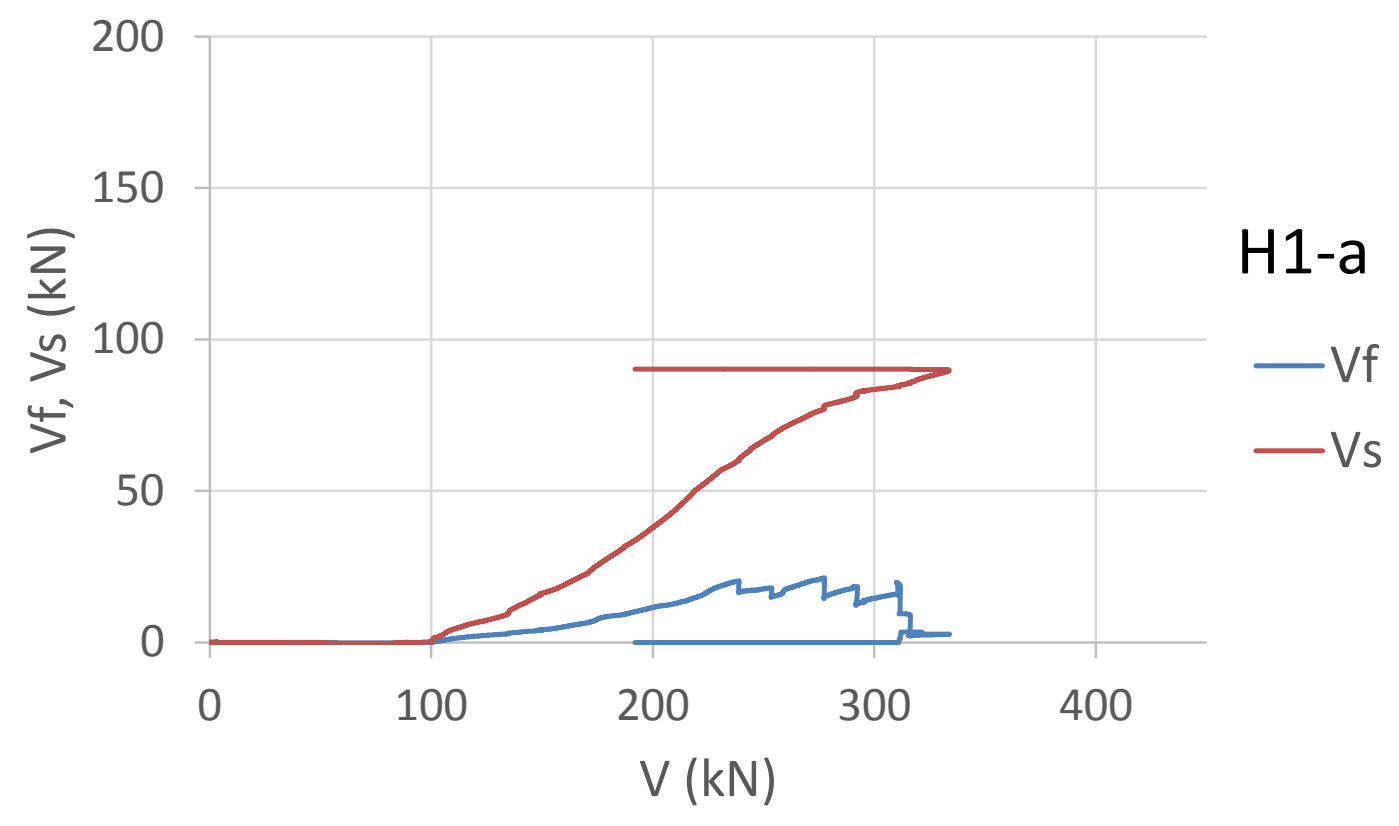




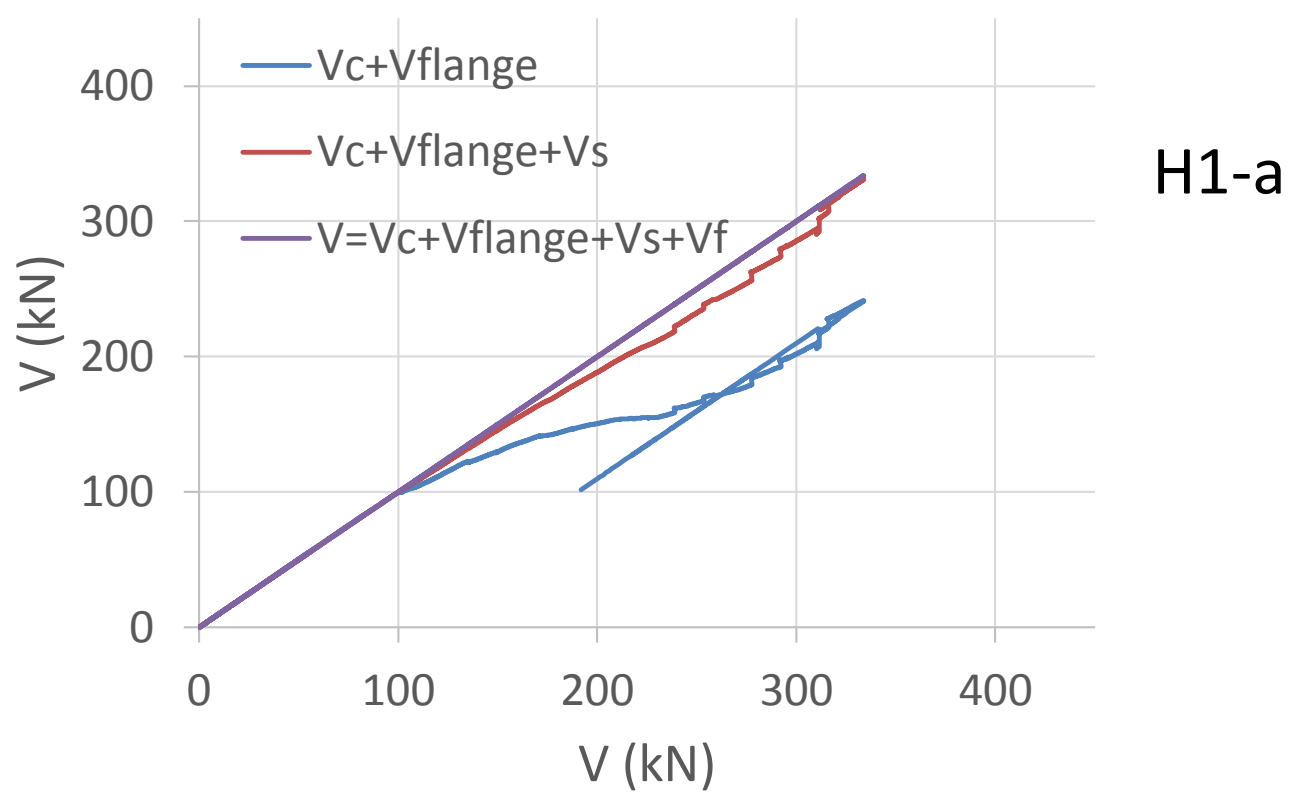




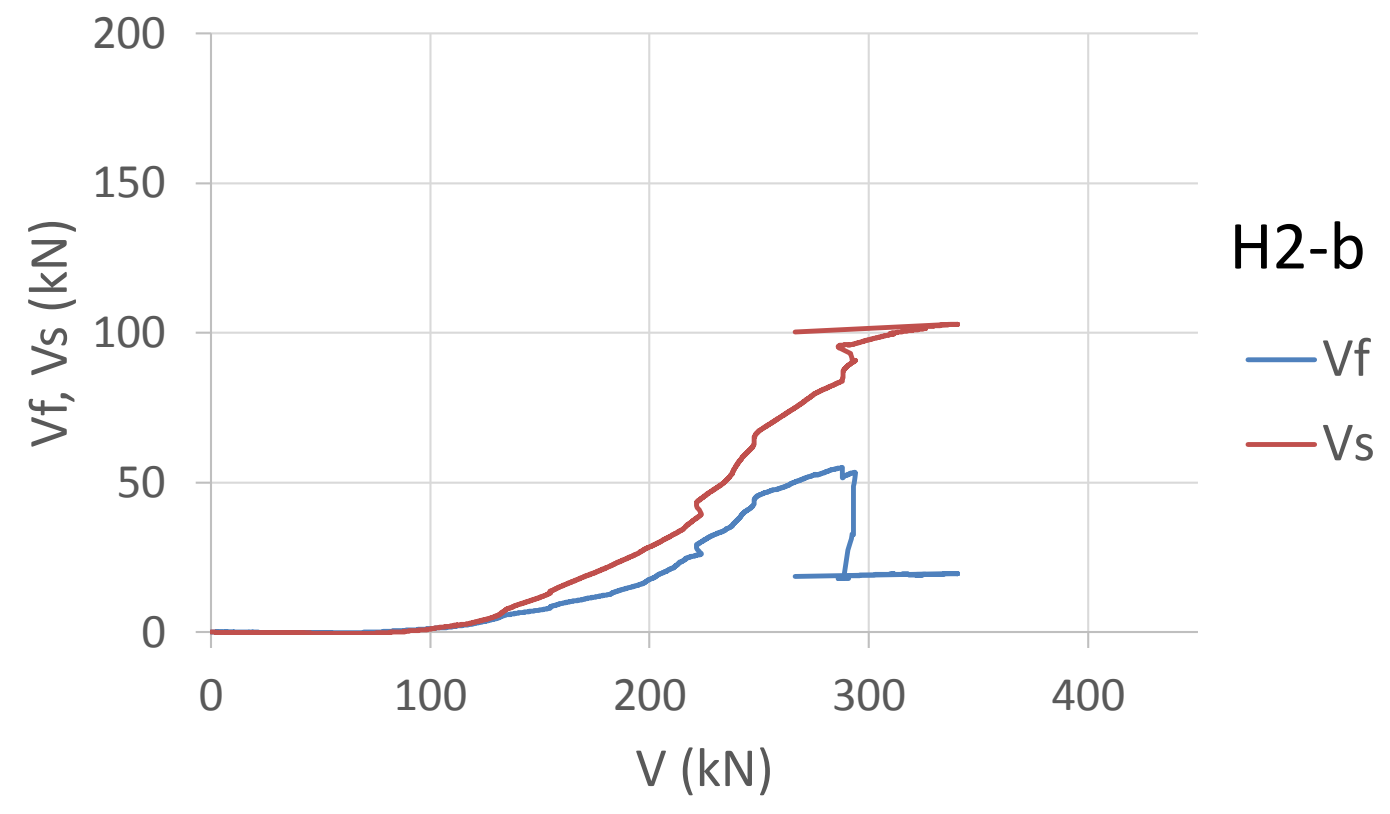




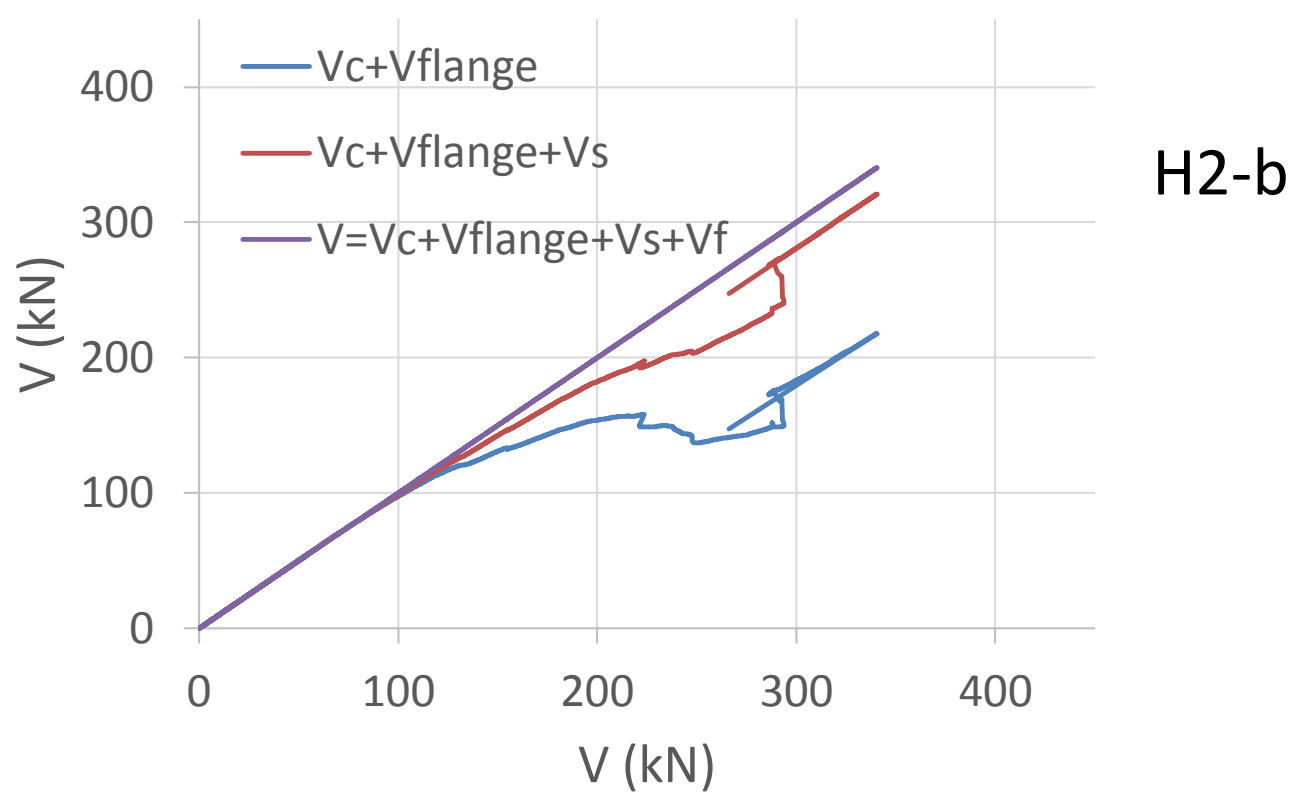




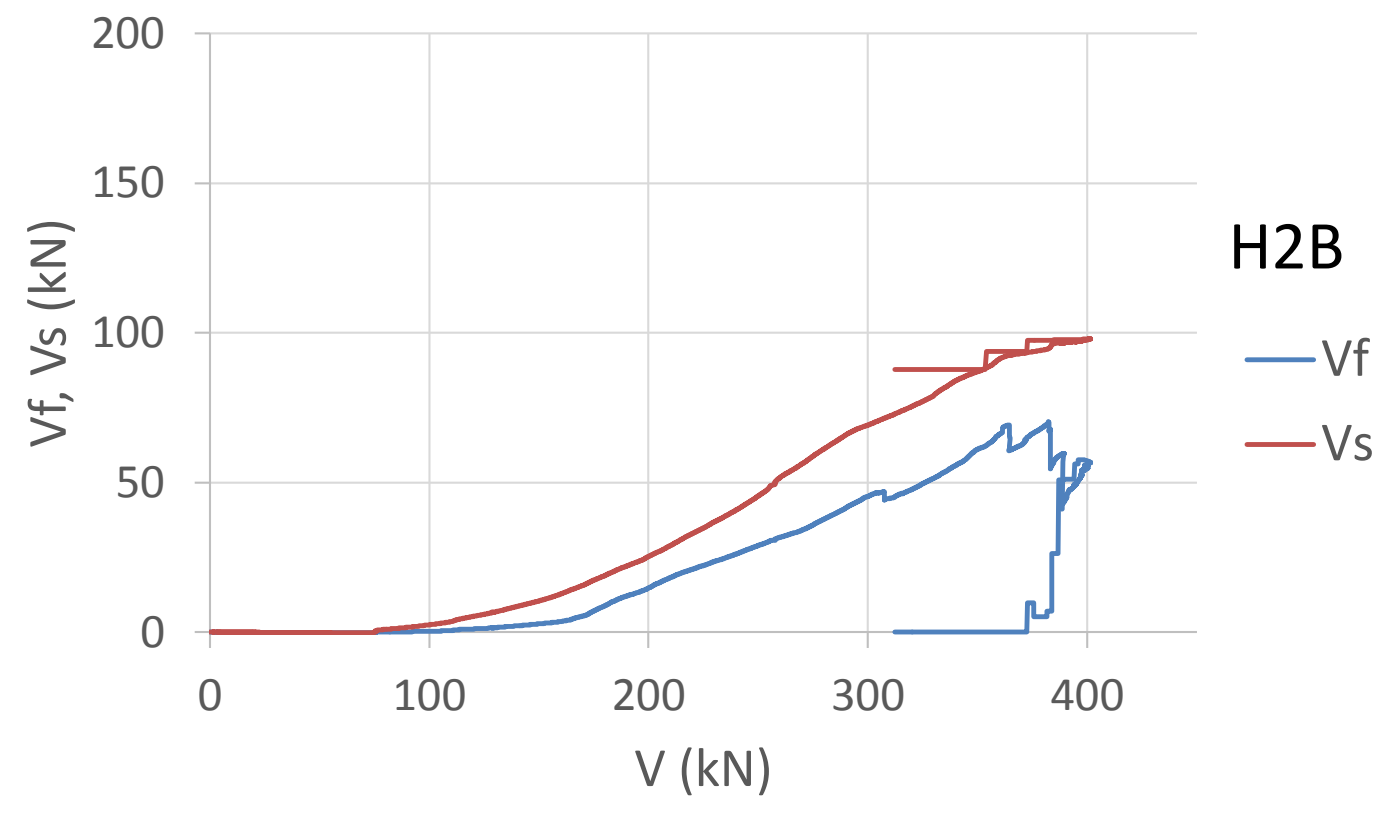




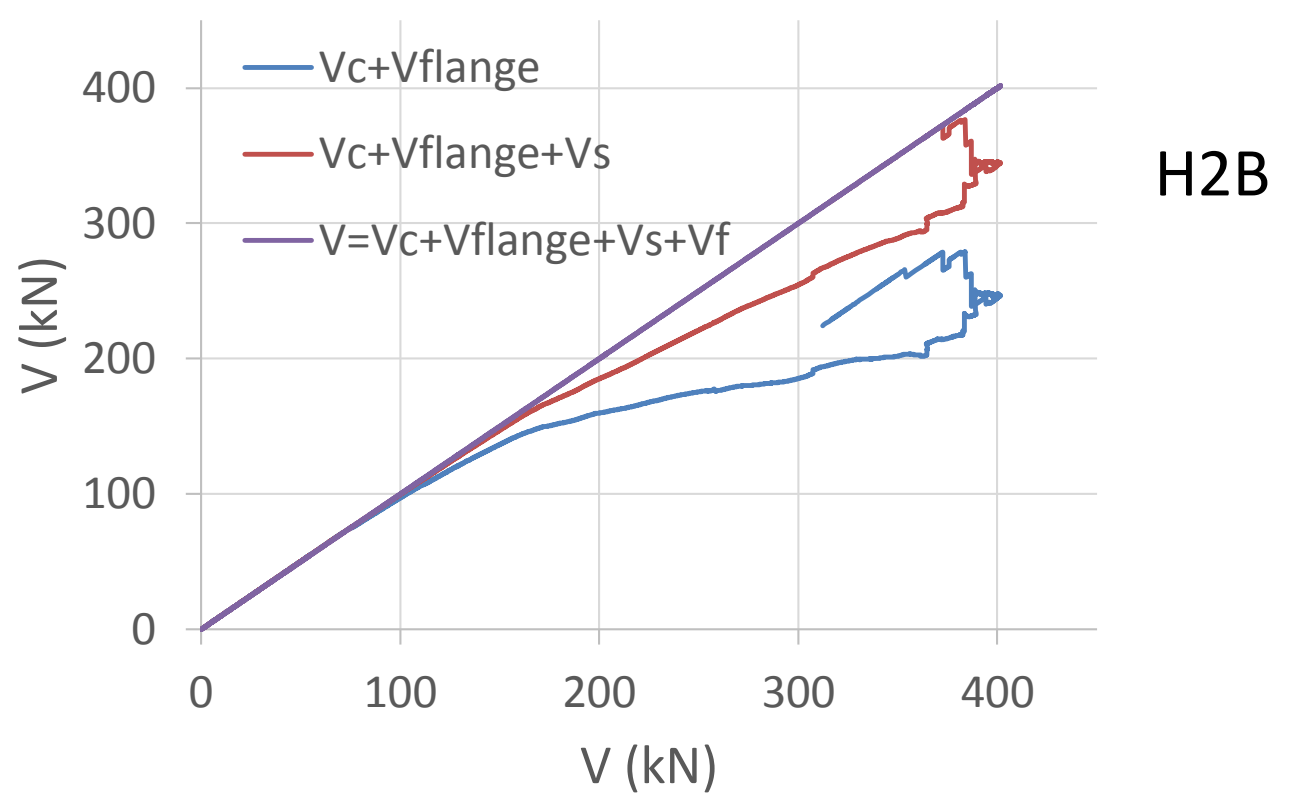



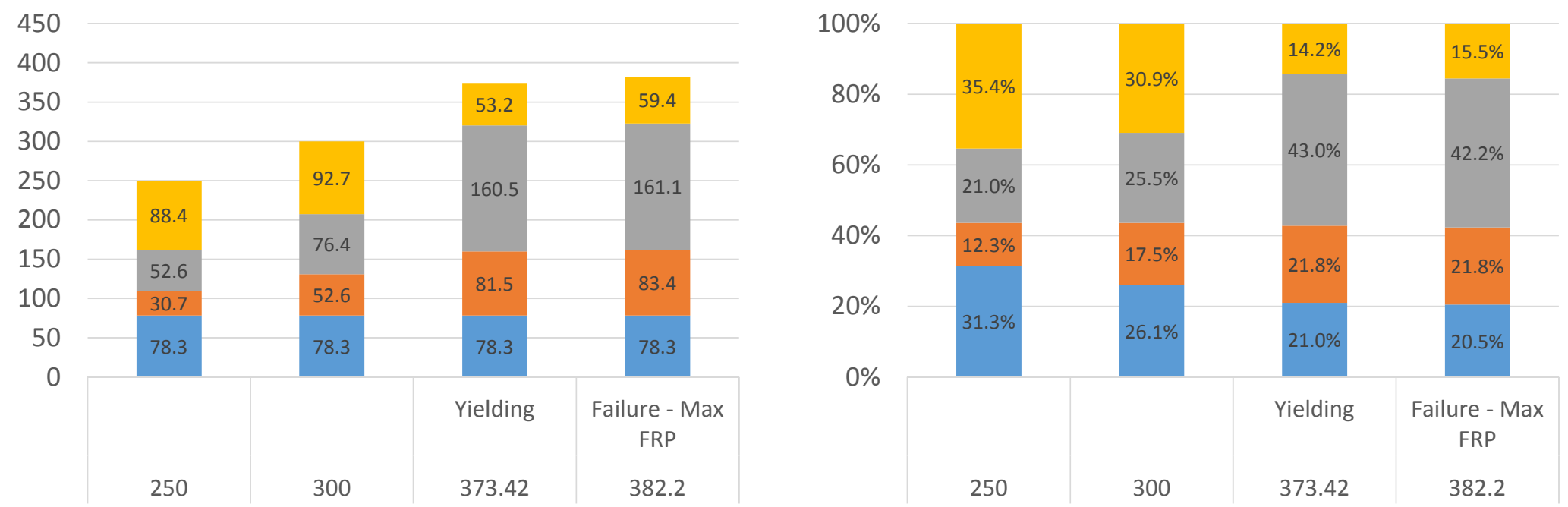

H3A

$\checkmark$ Vflange

Vf

- Vs

Vc 


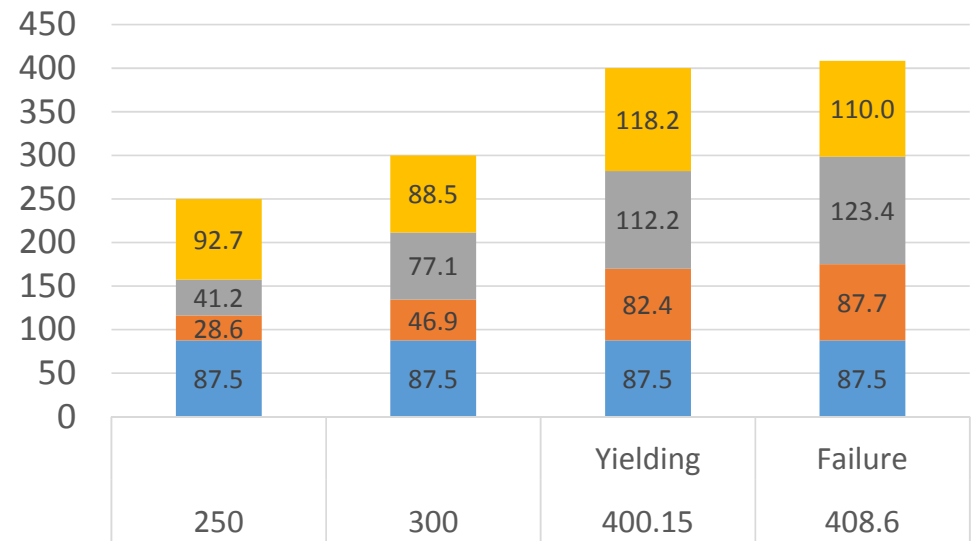

\begin{tabular}{|c|c|c|c|c|}
\hline $80 \%$ & $37.1 \%$ & $29.5 \%$ & $29.5 \%$ & $26.9 \%$ \\
\hline $60 \%$ & $16.5 \%$ & $25.7 \%$ & $28.0 \%$ & $30.2 \%$ \\
\hline $40 \%$ & $11.4 \%$ & $15.6 \%$ & & \\
\hline $0 \%$ & $35.0 \%$ & $29.2 \%$ & $21.9 \%$ & $21.4 \%$ \\
\hline & & & Yielding & Failure \\
\hline & 250 & 300 & 400.15 & 408.6 \\
\hline
\end{tabular}

H3B

Vflange

- Vf

Vs

Vc 


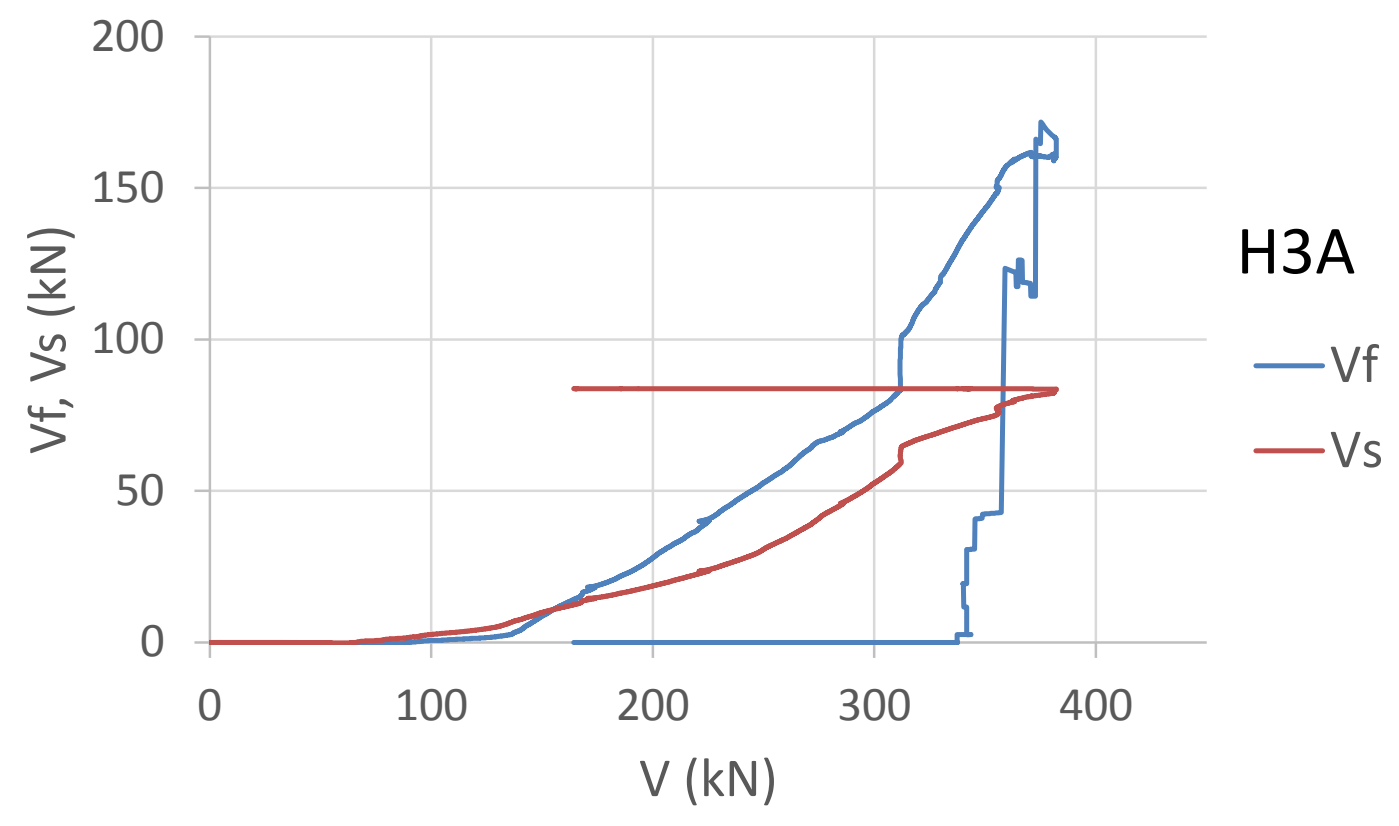




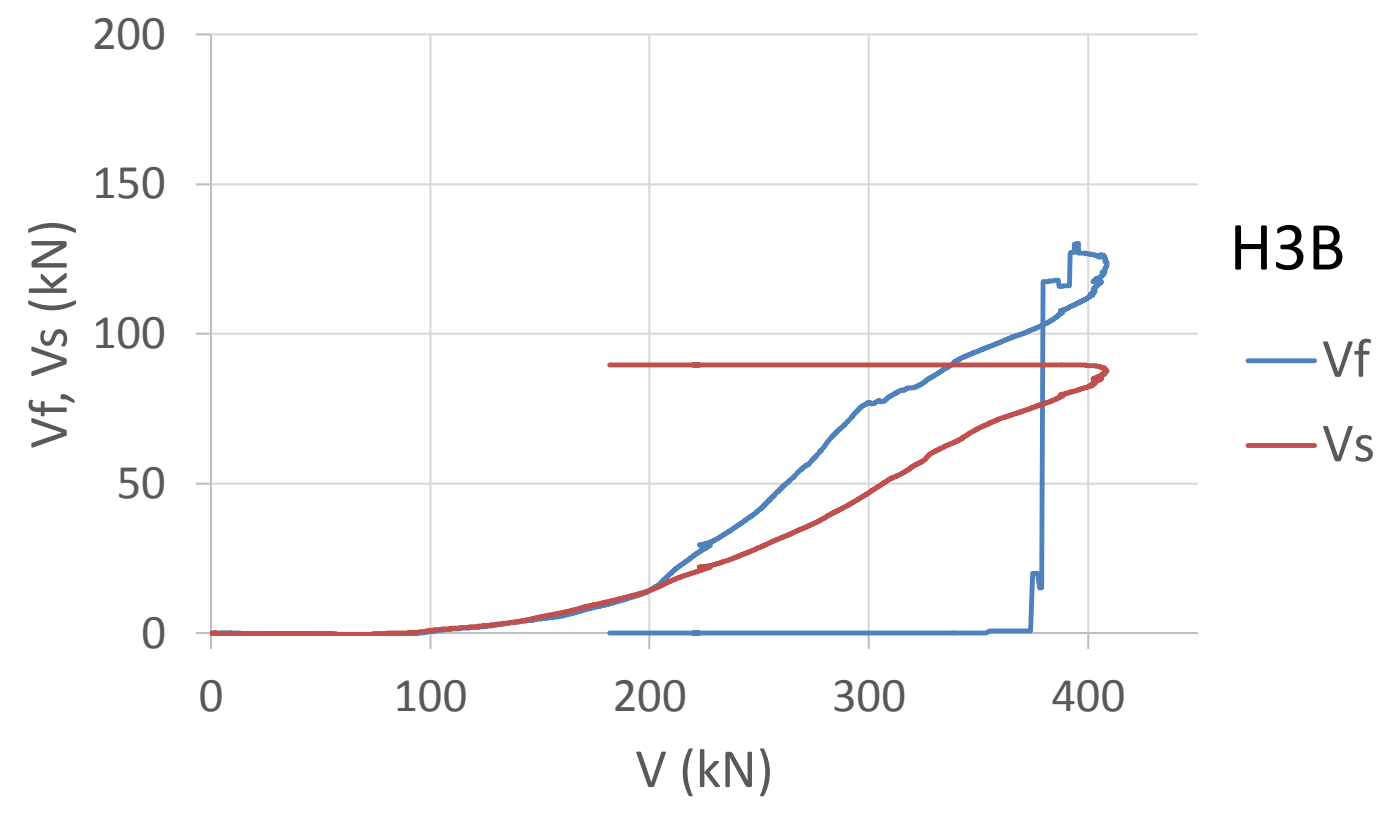


Table 1. Concrete properties of the specimens.

\begin{tabular}{ccccccc}
\hline Test & $\begin{array}{c}\text { Casting } \\
\text { Data }\end{array}$ & $\begin{array}{c}\text { Test } \\
\text { Data }\end{array}$ & $\begin{array}{c}\mathbf{f}_{\text {cm, 28d }} \\
\left(\mathbf{N} / \mathbf{m m}^{\mathbf{2}}\right)\end{array}$ & $\begin{array}{c}\mathbf{f}_{\text {cm,test }} \\
\left(\mathbf{N} / \mathbf{m m}^{\mathbf{2}}\right)\end{array}$ & $\begin{array}{c}\mathbf{f}_{\text {ctm,test }} \\
\left(\mathbf{N} / \mathbf{m m}^{\mathbf{2}}\right)\end{array}$ & $\begin{array}{c}\mathbf{E}_{\text {cm,test }} \\
\left(\mathbf{N} / \mathbf{m m}^{\mathbf{2}}\right)\end{array}$ \\
\hline M0-a & $11 / 06 / 28$ & $11 / 09 / 29$ & 32.9 & 40.2 & 3.7 & 31632 \\
M0-b & $11 / 06 / 28$ & $11 / 10 / 04$ & 32.9 & 40.2 & 3.7 & 31632 \\
M1-a & $11 / 06 / 30$ & $11 / 10 / 21$ & 37.4 & 42.8 & 3.6 & 33609 \\
M1-b & $11 / 06 / 30$ & $11 / 11 / 03$ & 37.4 & 42.8 & 3.6 & 33609 \\
M2-a & $11 / 06 / 29$ & $11 / 11 / 08$ & 33.2 & 39.8 & 3.3 & 30162 \\
M2-b & $11 / 06 / 29$ & $11 / 11 / 10$ & 33.2 & 39.8 & 3.3 & 30162 \\
M1A & $11 / 06 / 28$ & $11 / 04 / 26$ & 32.9 & 39.0 & 3.7 & 31632 \\
M1B & $11 / 06 / 29$ & $12 / 09 / 17$ & 33.2 & 38.5 & 3.3 & 30861 \\
M2A & $11 / 06 / 28$ & $12 / 05 / 07$ & 32.9 & 39.0 & 3.7 & 31632 \\
M2B & $11 / 06 / 29$ & $12 / 07 / 26$ & 33.2 & 38.5 & 3.3 & 30861 \\
\hline H0-a & $11 / 07 / 01$ & $11 / 09 / 20$ & 38.4 & 42.6 & 3.8 & 33060 \\
H0-b & $11 / 07 / 01$ & $11 / 09 / 27$ & 38.4 & 42.6 & 3.8 & 33060 \\
H1-a & $11 / 06 / 30$ & $12 / 01 / 27$ & 37.4 & 44.4 & 3.6 & 34857 \\
H1-b & $11 / 06 / 27$ & $12 / 05 / 18$ & 41.2 & 49.7 & 4.6 & 27004 \\
H2-a & $11 / 06 / 30$ & $12 / 01 / 23$ & 37.4 & 44.4 & 3.6 & 34857 \\
H2-b & $11 / 06 / 27$ & $12 / 05 / 30$ & 41.2 & 49.7 & 4.6 & 27004 \\
H2A & $11 / 07 / 01$ & $12 / 07 / 11$ & 38.4 & 44.7 & 3.8 & 33060 \\
H2B & $11 / 06 / 27$ & $12 / 09 / 21$ & 41.2 & 49.6 & 4.6 & 36913 \\
H3A & $11 / 07 / 01$ & $12 / 07 / 18$ & 38.4 & 44.7 & 3.8 & 33060 \\
H3B & $11 / 06 / 27$ & $12 / 09 / 27$ & 41.2 & 49.6 & 4.6 & 36913 \\
\hline
\end{tabular}


Table 2. Mechanical properties of the longitudinal and transverse steel reinforcement.

\begin{tabular}{cccccc}
\hline $\boldsymbol{\phi}$ & $\begin{array}{c}\mathbf{f}_{\mathbf{y m}} \\
\left(\mathbf{N} / \mathbf{m m}^{\mathbf{2}}\right)\end{array}$ & $\begin{array}{c}\mathbf{f}_{\mathbf{u m}} \\
\left(\mathbf{N} / \mathbf{m m}^{\mathbf{2}}\right)\end{array}$ & $\boldsymbol{\varepsilon}_{\mathbf{u}}$ & $\boldsymbol{\varepsilon}_{\mathbf{y}}$ & $\begin{array}{c}\mathbf{E}_{\mathbf{s}} \\
\left(\mathbf{N} / \mathbf{m m}^{\mathbf{2}} \mathbf{)}\right.\end{array}$ \\
\hline 6 & 645.73 & 767.91 & 0.1444 & 0.0034 & 189956 \\
8 & 642.26 & 765.65 & 0.1316 & 0.0069 & 204750 \\
12 & 590.40 & 690.45 & 0.1680 & 0.0043 & 219270 \\
16 & 572.24 & 685.27 & 0.1357 & 0.0029 & 196121 \\
20 & 603.65 & 652.48 & 0.1262 & 0.0034 & 175084
\end{tabular}

2 
1 Table 3. Concrete properties, initiation of debonding, ultimate shear force of the fictitious control and tested beams, and percentage of reinforcement

\begin{tabular}{|c|c|c|c|c|c|c|c|c|c|c|}
\hline Test & $\begin{array}{c}\mathbf{f}_{\mathrm{cm}, 28 \mathrm{~d}} \\
\left(\mathrm{~N} / \mathbf{m m}^{2}\right)\end{array}$ & $\begin{array}{c}\mathbf{f}_{\mathrm{cm}, \text { test }} \\
\left(\mathrm{N} / \mathbf{m m}^{2}\right)\end{array}$ & $\begin{array}{c}V_{\text {debonding }} \\
(\mathrm{kN})\end{array}$ & $\begin{array}{l}V_{\text {yield, Ast }} \\
(\mathrm{kN})\end{array}$ & $\begin{array}{c}V_{u, \text { unstrengthened }} \\
(\mathrm{kN})\end{array}$ & $\begin{array}{l}V_{u, \exp } \\
(k N)\end{array}$ & $\begin{array}{l}\Delta V \\
(\%)\end{array}$ & $\begin{array}{c}\theta_{\text {web }} \\
\left(^{o}\right)\end{array}$ & $\begin{array}{c}\theta_{\text {flange }} \\
\left(^{o}\right)\end{array}$ & $\begin{array}{c}\theta_{\text {mean }} \\
\left(^{\circ}\right)\end{array}$ \\
\hline M0-a & 32.9 & 40.2 & - & 177.5 & 299.9 & 299.9 & - & 27.5 & 9.0 & 24.5 \\
\hline M0-b & 32.9 & 40.2 & - & 172.1 & 309.6 & 309.6 & - & 37.5 & 10.5 & 28.0 \\
\hline M1-a & 37.4 & 42.8 & $(*)$ & 206.2 & 309.4 & 349.4 & $11.5 \%$ & 39.0 & 21.0 & 23.0 \\
\hline M1-b & 37.4 & 42.8 & 261.4 & 176.1 & 309.0 & 324.7 & $4.9 \%$ & 32.5 & 10.0 & 26.5 \\
\hline M2-a & 33.2 & 39.8 & 215.2 & 168.9 & 304.2 & 284.9 & $-6.8 \%$ & 28.0 & 9.5 & 23.5 \\
\hline M2-b & 33.2 & 39.8 & 154.0 & 198.4 & 304.2 & 259.1 & $-17.4 \%$ & 29.0 & 8.5 & 22.5 \\
\hline M1A & 32.9 & 39.0 & - & 318.1 & 302.3 & 335.8 & $10.0 \%$ & 47.5 & 9.0 & 27.0 \\
\hline M1B & 33.2 & 38.5 & - & 188.3 & 301.6 & 328.1 & $8.1 \%$ & 39.0 & 7.5 & 25.5 \\
\hline M2A & 32.9 & 39.0 & - & 206.3 & 302.6 & 348.0 & $13.1 \%$ & 38.0 & 8.0 & 26.5 \\
\hline $\mathrm{M} 2 \mathrm{~B}$ & 33.2 & 38.5 & - & 237.4 & 301.4 & 325.0 & $7.3 \%$ & 44.5 & 7.5 & 29.0 \\
\hline $\mathrm{HO}-\mathrm{a}$ & 38.4 & 42.6 & - & 177.1 & 326.6 & 326.6 & - & 29.0 & 7.0 & 23.5 \\
\hline $\mathrm{H} 0-\mathrm{b}$ & 38.4 & 42.6 & - & 193.6 & 319.7 & 319.7 & - & 28.0 & 9.5 & 23.5 \\
\hline $\mathrm{H} 1-\mathrm{a}$ & 37.4 & 44.4 & 238.3 & 211.1 & 325.7 & 333.8 & $2.4 \%$ & 26.0 & 8.0 & 22.5 \\
\hline $\mathrm{H} 1-\mathrm{b}$ & 41.2 & 49.7 & 286.8 & 204.6 & 334.7 & 335.8 & $0.3 \%$ & 33.0 & 8.5 & 25.5 \\
\hline $\mathrm{H} 2-\mathrm{a}$ & 37.4 & 44.4 & $(*)$ & 262.1 & 325.9 & 338.1 & $3.6 \%$ & 28.0 & 8.5 & 22.5 \\
\hline $\mathrm{H} 2-\mathrm{b}$ & 41.2 & 49.7 & 289.0 & 235.5 & 333.5 & 340.4 & $2.0 \%$ & 28.0 & 13.5 & 26.0 \\
\hline $\mathrm{H} 2 \mathrm{~A}$ & 38.4 & 44.7 & - & 292.2 & 327.1 & 402.9 & $18.8 \%$ & 30.5 & 12.5 & 30.5 \\
\hline $\mathrm{H} 2 \mathrm{~B}$ & 41.2 & 49.6 & - & 244.8 & 334.0 & 401.6 & $16.9 \%$ & 44.0 & 7.5 & 24.0 \\
\hline $\mathrm{H} 3 \mathrm{~A}$ & 38.4 & 44.7 & - & 292.2 & 327.1 & 382.2 & $16.8 \%$ & 39.5 & 15.5 & 29.0 \\
\hline H3B & 41.2 & 49.6 & - & 301.6 & 334.0 & 408.6 & $22.3 \%$ & - & - & - \\
\hline
\end{tabular}


1 Table 4. Contribution of the concrete web, flange, transverse steel and FRP to the ultimate shear force of 2

\begin{tabular}{cccccccccc}
\hline Test & $\begin{array}{c}\boldsymbol{V}_{\boldsymbol{c}} \\
(\boldsymbol{k} \boldsymbol{N})\end{array}$ & $\mathbf{( \% )}$ & $\begin{array}{c}\boldsymbol{V}_{\text {flange }} \\
(\boldsymbol{k} \boldsymbol{N})\end{array}$ & $\mathbf{( \% )}$ & $\begin{array}{c}\boldsymbol{V}_{\boldsymbol{s}} \\
(\boldsymbol{k} \boldsymbol{N})\end{array}$ & $\mathbf{( \% )}$ & $\begin{array}{c}\boldsymbol{V}_{\boldsymbol{f}} \\
(\boldsymbol{k} \boldsymbol{N})\end{array}$ & $\mathbf{( \% )}$ & $\begin{array}{c}\boldsymbol{V}_{\boldsymbol{u} \boldsymbol{u} \boldsymbol{e x p}} \\
(\boldsymbol{k} \boldsymbol{N})\end{array}$ \\
\hline M0-a & 53.9 & 18.0 & 146.6 & 48.9 & 99.4 & 33.1 & - & - & 299.9 \\
M0-b & 72.0 & 23.3 & 136.3 & 44.0 & 101.2 & 32.8 & - & - & 309.6 \\
M1-a & 71.6 & 20.5 & 166.8 & 47.7 & 104.9 & 30.0 & 6.1 & 1.7 & 349.4 \\
M1-b & 76.3 & 23.5 & 129.2 & 42.3 & 110.0 & 32.3 & 9.2 & 1.9 & 324.7 \\
M2-a & 70.3 & 24.7 & 104.3 & 36.6 & 96.2 & 33.8 & 14.1 & 4.9 & 284.9 \\
M2-b & 74.6 & 28.8 & 81.2 & 31.3 & 86.2 & 33.3 & 17.1 & 6.6 & 259.1 \\
M1A & 17.8 & 5.3 & 217.6 & 64.8 & 71.5 & 21.3 & 29.0 & 8.7 & 335.8 \\
M1B & 71.5 & 21.8 & 80.8 & 24.6 & 110.0 & 33.5 & 65.8 & 20.1 & 328.1 \\
M2A & 88.1 & 25.3 & 140.6 & 40.5 & 91.1 & 26.2 & 28.0 & 8.0 & 348.0 \\
M2B & 72.9 & 22.4 & 74.9 & 23.0 & 101.2 & 31.2 & 76.0 & 23.4 & 325.0 \\
\hline H0-a & 69.5 & 21.3 & 155.6 & 47.6 & 101.5 & 31.1 & - & - & 326.6 \\
H0-b & 53.3 & 16.7 & 167.1 & 52.3 & 110.1 & 34.4 & - & - & 319.7 \\
H1-a & 97.3 & 29.2 & 144.0 & 43.1 & 89.8 & 26.9 & 2.6 & 0.8 & 333.8 \\
H1-b & 87.1 & 25.9 & 148.3 & 44.2 & 94.8 & 28.2 & 5.6 & 1.7 & 335.8 \\
H2-a & 28.2 & 8.3 & 235.0 & 69.5 & 57.4 & 17.0 & 17.4 & 5.2 & 338.1 \\
H2-b & 75.9 & 22.3 & 142.0 & 41.7 & 102.9 & 30.2 & 19.6 & 5.8 & 340.4 \\
H2A & 18.2 & 4.5 & 226.7 & 56.3 & 80.4 & 20.0 & 77.5 & 19.2 & 402.9 \\
H2B & 75.3 & 18.8 & 171.7 & 42.7 & 98.0 & 24.4 & 56.7 & 14.1 & 401.6 \\
H3A & 78.3 & 20.5 & 59.4 & 15.5 & 83.4 & 21.8 & 161.1 & 42.2 & 382.2 \\
H3B & 87.5 & 22.1 & 110.0 & 22.3 & 87.7 & 22.6 & 123.4 & 32.9 & 408.6 \\
\hline
\end{tabular}


Table 5. Comparison of the experimental to the analytical predictions

\begin{tabular}{|c|c|c|c|c|c|c|c|c|}
\hline Test & $\begin{array}{c}V_{f, \text { exp }} \\
(\boldsymbol{k N}) \\
\text { at } \\
\text { failure }\end{array}$ & $\begin{array}{l}V_{f, \max } \\
(\mathrm{kN})\end{array}$ & $\begin{array}{c}V_{f, \text { exp }} \\
(k N)= \\
V_{u^{-}} \\
V_{u, u n s t r}\end{array}$ & $\begin{array}{c}V_{f} \\
(k N) \\
\text { fib14 }\end{array}$ & $\begin{array}{c}V_{f} \\
(k N) \\
A C I- \\
440.2 R- \\
08\end{array}$ & $\begin{array}{c}V_{f} \\
(k N) \\
C N R- \\
D T 200 / \\
2004\end{array}$ & $\begin{array}{c}V_{f} \\
(k N) \\
T R-55\end{array}$ & $\begin{array}{cc}V_{f}(k N) \\
\text { DafStB }\end{array}$ \\
\hline (1) & (2) & (3) & (4) & (5) & $\begin{array}{l}\text { (6) } \\
\end{array}$ & $(7)$ & $(8)$ & (9) \\
\hline M1-a & 6.1 & 23.1 & 40.0 & $\begin{array}{l}151.9 \\
(0.15)\end{array}$ & $\begin{array}{c}22.7 \\
(1.02)\end{array}$ & $\begin{array}{c}65.2 \\
(0.35)\end{array}$ & $\begin{array}{c}22.7 \\
(1.02)\end{array}$ & $\begin{array}{c}40.0 \\
(0.58)\end{array}$ \\
\hline M1-b & 9.2 & 31.3 & 15.8 & $\begin{array}{l}145.1 \\
(0.22)\end{array}$ & $\begin{array}{c}22.7 \\
(1.38)\end{array}$ & $\begin{array}{l}60.57 \\
(0.52)\end{array}$ & $\begin{array}{c}22.7 \\
(1.38)\end{array}$ & $\begin{array}{c}15.8 \\
(1.98)\end{array}$ \\
\hline M2-a & 14.1 & 30.2 & -20.4 & $\begin{array}{l}219.6 \\
(0.14)\end{array}$ & $\begin{array}{c}45.4 \\
(0.67)\end{array}$ & $\begin{array}{l}128.27 \\
(0.24)\end{array}$ & $\begin{array}{c}45.4 \\
(0.67)\end{array}$ & $\begin{array}{l}110.4 \\
(0.27)\end{array}$ \\
\hline M2-b & 17.1 & 37.9 & -46.1 & $\begin{array}{l}230.6 \\
(0.16)\end{array}$ & $\begin{array}{c}45.4 \\
(0.83)\end{array}$ & $\begin{array}{l}134.65 \\
(0.28)\end{array}$ & $\begin{array}{c}45.4 \\
(0.83)\end{array}$ & $\begin{array}{l}115.9 \\
(0.33)\end{array}$ \\
\hline M1A & 29.0 & 29.0 & 33.5 & $\begin{array}{l}124.2 \\
(0.23)\end{array}$ & $\begin{array}{c}22.7 \\
(1.28)\end{array}$ & $\begin{array}{l}54.93 \\
(0.53)\end{array}$ & $\begin{array}{c}22.7 \\
(1.28)\end{array}$ & $\begin{array}{c}33.5 \\
(0.87)\end{array}$ \\
\hline M1B & 65.8 & 65.8 & 26.5 & $\begin{array}{l}128.4 \\
(0.51)\end{array}$ & $\begin{array}{l}22.7 \\
(2.90)\end{array}$ & $\begin{array}{c}55.0 \\
(1.20)\end{array}$ & $\begin{array}{c}22.7 \\
(2.90)\end{array}$ & $\begin{array}{c}25.6 \\
(2.57)\end{array}$ \\
\hline M2A & 28.0 & 60.9 & 45.4 & $\begin{array}{l}206.2 \\
(0.30)\end{array}$ & $\begin{array}{c}45.4 \\
(1.34)\end{array}$ & $\begin{array}{l}107.9 \\
(0.56)\end{array}$ & $\begin{array}{c}45.4 \\
(1.34)\end{array}$ & $\begin{array}{c}45.4 \\
(1.34)\end{array}$ \\
\hline M2B & 76.0 & 78.2 & 23.6 & $\begin{array}{l}179.6 \\
(0.44)\end{array}$ & $\begin{array}{c}45.4 \\
(1.72)\end{array}$ & $\begin{array}{c}92.6 \\
(0.84)\end{array}$ & $\begin{array}{c}45.4 \\
(1.72)\end{array}$ & $\begin{array}{c}23.6 \\
(3.31)\end{array}$ \\
\hline $\mathrm{H} 1-\mathrm{a}$ & 2.6 & 21.3 & 8.0 & $\begin{array}{l}175.6 \\
(0.12)\end{array}$ & $\begin{array}{c}22.4 \\
(0.95)\end{array}$ & $\begin{array}{c}73.0 \\
(0.29)\end{array}$ & $\begin{array}{c}22.4 \\
(0.95)\end{array}$ & $\begin{array}{c}60.0 \\
(0.36)\end{array}$ \\
\hline $\mathrm{H} 1-\mathrm{b}$ & 5.6 & 39.4 & 7.9 & $\begin{array}{l}206.9 \\
(0.19)\end{array}$ & $\begin{array}{c}22.4 \\
(1.76)\end{array}$ & $\begin{array}{l}121.9 \\
(0.32)\end{array}$ & $\begin{array}{c}22.4 \\
(1.76)\end{array}$ & $\begin{array}{l}104.2 \\
(0.38)\end{array}$ \\
\hline $\mathrm{H} 2-\mathrm{a}$ & 17.4 & 17.4 & 3.4 & $\begin{array}{l}181.1 \\
(0.10)\end{array}$ & $\begin{array}{c}44.8 \\
(0.39)\end{array}$ & $\begin{array}{c}80.2 \\
(0.22)\end{array}$ & $\begin{array}{c}44.8 \\
(0.39)\end{array}$ & $\begin{array}{c}65.5 \\
(0.27)\end{array}$ \\
\hline $\mathrm{H} 2-\mathrm{b}$ & 19.6 & 55.0 & 7.0 & $\begin{array}{l}181.4 \\
(0.30)\end{array}$ & $\begin{array}{c}44.8 \\
(1.23)\end{array}$ & $\begin{array}{l}114.4 \\
(0.48)\end{array}$ & $\begin{array}{c}44.8 \\
(1.23)\end{array}$ & $\begin{array}{c}96.8 \\
(0.57)\end{array}$ \\
\hline $\mathrm{H} 2 \mathrm{~A}$ & 77.5 & 77.7 & 75.8 & $\begin{array}{l}177.9 \\
(0.44)\end{array}$ & $\begin{array}{c}44.8 \\
(1.73)\end{array}$ & $\begin{array}{c}94.6 \\
(0.82)\end{array}$ & $\begin{array}{c}44.8 \\
(1.73)\end{array}$ & $\begin{array}{c}40.9 \\
(1.90)\end{array}$ \\
\hline $\mathrm{H} 2 \mathrm{~B}$ & 56.7 & 70.3 & 67.6 & $\begin{array}{l}240.4 \\
(0.29)\end{array}$ & $\begin{array}{c}44.8 \\
(1.57)\end{array}$ & $\begin{array}{l}134.4 \\
(0.52)\end{array}$ & $\begin{array}{c}44.8 \\
(1.57)\end{array}$ & $\begin{array}{c}54.1 \\
(1.30)\end{array}$ \\
\hline $\mathrm{H} 3 \mathrm{~A}$ & 161.1 & 161.1 & 55.1 & $\begin{array}{l}348.9 \\
(0.46)\end{array}$ & $\begin{array}{l}107.6 \\
(1.50)\end{array}$ & $\begin{array}{l}227.5 \\
(0.71)\end{array}$ & $\begin{array}{l}107.6 \\
(1.50)\end{array}$ & $\begin{array}{l}104.4 \\
(1.54)\end{array}$ \\
\hline H3B & 123.4 & 123.4 & 74.7 & $\begin{array}{l}356.4 \\
(0.35)\end{array}$ & $\begin{array}{l}107.6 \\
(1.15)\end{array}$ & $\begin{array}{l}244.2 \\
(0.51)\end{array}$ & $\begin{array}{l}107.6 \\
(1.15)\end{array}$ & $\begin{array}{l}104.4 \\
(1.18)\end{array}$ \\
\hline
\end{tabular}

